\title{
The effects of recreational cannabis access on labor markets: evidence from Colorado
}

\begin{abstract}
Recreational cannabis markets possibly increase labor demand through investments in facilities for growing, processing, and retail sales of cannabis, as well as through other industries such as manufacturing, leisure, and hospitality. However, this increase in labor demand may vary substantially across counties within a state as most states with legal recreational cannabis allow individual counties to ban commercial cannabis sales. Meanwhile, labor supply may change through positive and negative effects from cannabis use. Using county-level Colorado data from 2011 to 2018 and exploiting variation across counties in the existence and timing of the start of dispensary sales, we test for changes in the unemployment rate, employment, and wages, overall and by industry subsector. Consistent with an increase in labor demand, we estimate that the sale of recreational cannabis through dispensaries is associated with a 0.7 percentage point decrease in the unemployment rate with no effect on the size of the labor force. We also find a $4.5 \%$ increase in the number of employees, with the strongest effects found in manufacturing. We find no effect on wages. Given the lack of a reduction in labor force participation or wages, negative effects on labor supply are likely limited, in line with the existing literature. The decrease in unemployment, coupled with an increase in the number of employees, indicates that labor demand effects likely dominate effects on labor supply. Our results suggest that policymakers considering recreational access to cannabis should anticipate a possible increase in employment.
\end{abstract}

$\begin{array}{ll}\text { Current version: } & \text { April 26, 2021 } \\ \text { Keywords: } & \text { cannabis, marijuana, labor demand, manufacturing } \\ \text { JEL codes: } & \text { J21, R11, J3, K00 } \\ \text { Corresponding author: } & \text { Sarah Stith } \\ & \text { ssstith@unm.edu }\end{array}$

1 Department of Economics, University of New Mexico, 1915 Roma Ave. NE, Albuquerque, NM 87131. email: achakraborty@unm.edu

2 Department of Economics, Orfalea College of Business, California Polytechnic State University, 1 Grand Ave., San Luis Obispo, CA. email: jdoremus@calpoly.edu

3 Department of Economics, University of New Mexico, 1915 Roma Ave. NE, Albuquerque, NM 87131. email: ssstith@unm.edu 


\section{Introduction}

In 2014, the first recreational cannabis dispensaries opened in Colorado. Today, recreational cannabis dispensaries outnumber Starbucks and McDonald's locations combined (Colorado Department of Revenue [CDOR], 2019). As the number of recreational dispensaries grew between 2014 and 2019, so did the value of their sales, dwarfing those of the existing medical cannabis market. When comparing recreational and medical cannabis sales during this time period (Figure 1A), medical cannabis sales stayed around $\$ 35$ million, while recreational cannabis sales increased 10 -fold, from $\$ 10$ million to $\$ 110$ million. ${ }^{1}$

As in most other legal recreational cannabis markets, legalization in Colorado occurred at the state level, but individual counties and municipalities can choose to ban cannabis businesses, from growing facilities through retail dispensaries. Of the 64 counties in our sample, only 37 experienced entry of dispensaries between 2014 and the end of our sampling period in 2018. Many local areas continue to ban cannabis, including El Paso County, in which Colorado Springs, the second largest city in the state, is located. ${ }^{2}$

This paper is the first to analyze the effects of recreational dispensary access on labor market outcomes beyond workers' compensation benefits, to use a county-level approach to explore the effect, and to identify demand-side effects, rather than supply-side effects. Using monthly data from the Local Area Unemployment Statistics (LAUS) and quarterly data from the Quarterly Census of Employment and Wages (QWEC) for the period 2011-2018, we test for changes in the unemployment rate, the number of people unemployed, the total labor force, the number of employees (overall and by major industry), and wages (overall and by major industry) in Colorado counties in response to the entry of recreational cannabis dispensaries. We investigate the effects on labor market outcomes by exploiting quasi-random variation in the timing of the

Figure 1 Cannabis sales in Colorado counties, by year.

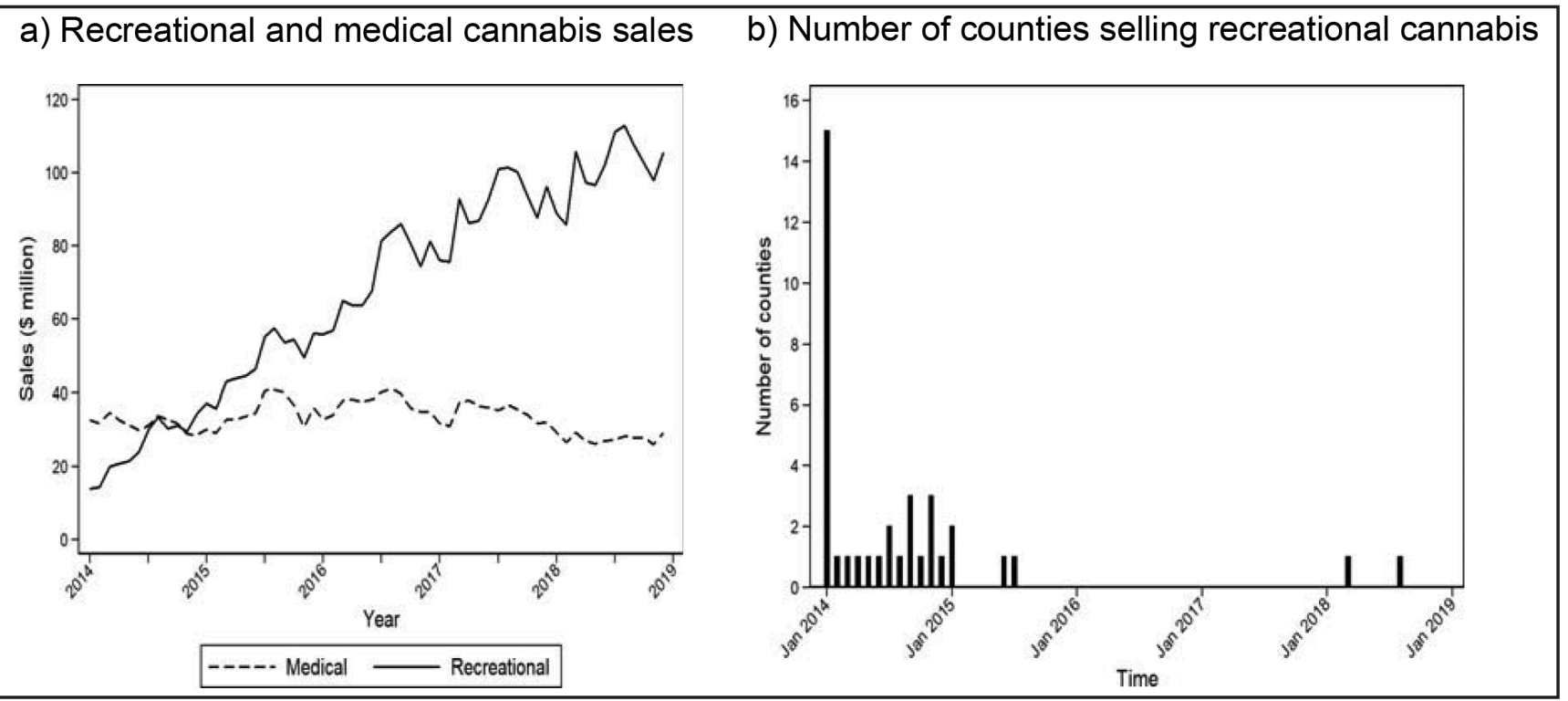

Notes: (A) Sales of medical and recreational cannabis. Data were obtained from the Colorado Department of Revenue and are in U.S. dollars. (B) The number of new counties selling cannabis, based on sales data obtained from the Colorado Department of Revenue.

1 These are retail (recreational) and medical cannabis sales, as reported to the Colorado Department of Revenue.

2 https://www.visitcos.com/travel-tools/local-services-information/recreational-marijuana/. Accessed 07/16/21. 
entry of recreational cannabis dispensaries at the county level. With a difference-in-differences (DID) research design, we compare labor market outcomes within and across counties and across industries, before and after counties began selling recreational cannabis, controlling for the county, month, and year fixed effects and the number of medical cannabis patients.

We find that the opening of recreational cannabis dispensaries is associated with a decrease in the number of unemployed people and the unemployment rate, with no significant effect on the total labor force. We further find an increase in the total number of employees overall, with effects being the strongest in the manufacturing sector. For wages, we find no significant effect on average weekly wages overall or by industry. Our results suggest that labor demand effects dominate any impact on labor supply. Because of potential spillovers across counties within a state and possible endogeneity in dispensary entry, we corroborate the robustness of our results in multiple ways, including capitalizing on institutional factors limiting entry, attempting to predict pretreatment using pre-trends, assessing the existence and magnitude of county-level spillovers using a nearest-neighbor, distance-based approach, and using the generalized synthetic control (GSC) method presented by Xu (2017).

That the creation of a newly legal industry affects local labor markets, either directly or indirectly, is supported by the broader literature on new industry entry. Benefits associated with the arrival of new casinos to local areas include doubling of earnings in the local gambling industry and indirect spillover effect on employment growth in closely related local industries (Cotti, 2008; Humphreys and Marchand, 2013). With respect to abrupt increases in the size of legal industries, a study found that the opening of an ethanol plant in a county increases employment opportunities, labor earnings, and demand for land and housing, with spillover effects on other industries (Low and Isserman, 2009), while Black et al. (2005) found that spillover effects from coal booms increase employment but not wages in the construction and services sectors. The empirical evidence from these two industries supports that positive benefits also arise in the cannabis industry, with a direct increase in labor demand within the cannabis industry and spillovers across other industrial sectors.

The fact that demand-side effects seem to dominate labor supply-side effects matches a literature that finds ambiguous and limited effects on health and productivity. Older studies using survey data have typically identified negative associations between cannabis use and health-and-productivity-related outcomes (Van Ours, 2007; Hanson et al., 2010; Van Ours et al., 2013; Volkow et al., 2014; Williams and Van Ours, 2020; Winward et al., 2014; Kaestner, 1994; Register and Williams, 1992; Irons et al., 2014), or no association (MacDonald and Pudney, 2000). More recent studies of medical cannabis legalization indicate potential positive health and productivity effects, often through substitution away from more harmful substances (Ullman, 2017; Nicholas and Maclean, 2019; Bonn-Miller et al., 2007; Vigil et al., 2017; Doremus et al., 2019; Bradford et al., 2018; Bradford and Bradford, 2018; Anderson et al., 2018, 2014; Chu, 2015; Baggio et al., 2018; Anderson et al., 2013; Choi et al., 2019).

The limited literature on how medical marijuana laws (MMLs) affect labor supply shows mixed results as well. On the one hand, medical cannabis dispensaries' entry may have potential positive employment and earnings effects, at least in older populations (Nicholas and Maclean, 2019), and for more extreme outcomes, such as workplace deaths (Anderson et al., 2014), workers' compensation claims (Ghimire and Maclean, 2020), and job absences (Ullman, 2017). On the other hand, Sabia and Nguyen (2018) find a small decrease in wages among males aged 
20-39 years. Older studies, using survey data on cannabis use rather than the introduction of legal medical cannabis, found that cannabis use reduced wages (Van Ours, 2007). These effects were the strongest among men (Kaestner, 1994) and, within men, among younger men (Register and Williams, 1992), although Kaestner (1994) found some evidence of positive effects for women. How much these studies relate to our study depends on the extent to which medical and recreational uses are similar. Medical legalization and associated dispensary access affect a significantly smaller, but potentially sicker, population than does recreational access. Medical legalization limits use to those with severely debilitating symptoms, typically for a limited range of conditions. Recreational access facilitates use not just for recreational purposes, but for medical use as well among those with conditions not previously approved for medical cannabis authorization, whose conditions were insufficiently severe to qualify, or with severe approved conditions but who were unwilling to join a registry.

The literature on the effects of recreational legalization on labor-related outcomes is even more nascent. The possibility that cannabis legalization may improve labor supply is supported by recent work finding reductions in disability claims (Maclean et al., 2021) and workers' compensation benefits (Abouk et al., 2021) following recreational cannabis legalization. This reduction in worker injuries and injury severity could translate into positive effects on labor market outcomes more generally, but our results suggest that such effects are not large enough to translate into measurable changes in employment or wages. A recent working paper focuses on the demand-side effects in agriculture and retail sectors following recreational legalization in Washington and Colorado and, similar to this study, generally finds increased employment with limited wage effects (Jiang and Miller, 2021).

In summation, this paper explores the effect of entry of recreational cannabis dispensaries on local labor markets, using Colorado county-level data on employment and wages. We begin by providing a brief summary of cannabis legalization and detailing the potential effects of cannabis on labor supply and labor demand. The paper then proceeds to present our empirical analysis before discussing our results and concluding.

\section{Background}

\subsection{Cannabis legalization}

Cannabis is classified as a Schedule I substance ${ }^{3}$ and federal law continues to prohibit the cultivation, possession, and consumption of cannabis and related products. However, most of states have either decriminalized cannabis possession or have begun to legalize cannabis through a regulated market. As of December 2018, the end of our sample period, 33 states and the District of Columbia allowed for medical cannabis in some form, and this number has been increasing ever since. In 2012, Colorado and Washington became the first states to legalize commercial cultivation and sales of recreational cannabis to adults 21 years or older. Since then, other states have followed, and by December 2018, recreational cannabis was legal in 11 states and the District of Colombia (Figure A1). Significant heterogeneity exists across states in how recreational

3 The federal government defines a Schedule I drug as having no medical use, significant potential for abuse, and a high probability of dependence. Cannabis containing $>0.3 \%$ tetrahydrocannabinol (THC) is considered Schedule I under federal law. For comparison, cannabis popular in legal recreational cannabis dispensaries often contains THC exceeding 20\% (Stith and Vigil, 2016). 
cannabis has been legalized, from differences in taxes and limits on purchase quantity to the legality of home cultivation.

Colorado legalized recreational cannabis in 2012, with the law going into effect in December 2012. Home cultivation became legal in 2013, with the first indoor harvest cycle likely ending around May 2013. ${ }^{4}$ Dispensary sales began in January 2014, allowing anyone 21 years and older to purchase, possess, or consume commercially cultivated cannabis. The law permits cannabis consumption anywhere other than in public places, with a buying limit of 0.03 kilograms ( 1 ounce) of cannabis at a time. Counties and municipalities are allowed to restrict commercial cultivation and sales, including banning these activities altogether. Initially, licenses were restricted to previously licensed medical cannabis businesses, with most jurisdictions opening up retail licenses to other applicants by the end of 2014. Over the past several years, access to recreational cannabis across counties has increased, but with heterogeneity in the timing of commencement of sale. Figure $1 \mathrm{~B}$ plots the number of counties with dispensaries selling recreational cannabis by month from 2014 through 2018, while Figure A2 in the Appendix uses maps to depict the geographic variation in the number of counties with dispensaries in January 2014 through December 2018. Many counties with dispensaries first entered in January 2014, and by the end of January 2014, out of a total of 64 counties in Colorado, 15 counties were selling recreational cannabis (Figure A2a in the Appendix). Dispensaries continued to enter counties with no preexisting dispensaries throughout 2014 regularly. Entry into new counties thereafter is more limited. By the December 2018, 37 counties had recreational dispensaries (Figure A2b). Except for four counties, all counties with recreational dispensary access also have medical dispensary access (Figure A2c).

\subsection{Cannabis and labor supply}

Cannabis access increases cannabis use, ${ }^{5}$ which may affect labor supply. Increased cannabis consumption has varied effects on individuals, depending on the intensity, amount of use, and even individual-specific characteristics. Suppose the effects of cannabis on health are negative. In that case, increased use should manifest in worse labor market outcomes, including decreased labor force participation, a higher likelihood of being unemployed, and lower wages resulting from lower productivity. Suppose, instead, that the effects of cannabis on health are positive, either through direct effects or indirectly, such as through substitution away from more harmful substances. In that case, an increase in labor market participation, likelihood of employment, and wages should be expected. We first summarize the literature on the health and wage effects of cannabis use and then describe in greater detail results from the literature on the effect of MMLs on labor supply.

When investigating the effect of cannabis use on health, earlier studies tended to find negative effects from consumption, generally in contexts in which cannabis is not legal and based on retrospective survey data. These studies found that cannabis use may lead to increased suicidal

4 Residents are allowed to grow up to six cannabis plants for personal use.

5 A recent study on the effect of recreational legalization on cannabis use found increased use among adults over the age of 25 years, although use among adults 18-25 years old did not change (Cerd'a et al., 2020). Wen et al. (2015) found that MMLs are associated with an increase in cannabis use of $15 \%-25 \%$, with some increase in the incidence of cannabis dependence as well. Choi et al. (2019) found a 2-3 percentage point increase in cannabis consumption among adults. Chu (2014) showed that MMLs increase arrests for cannabis possession by $10 \%-20 \%$. 
ideation for males (Van Ours et al., 2013), adverse mental and physical health (Van Ours and Williams, 2011, 2012), and a decrease in cognitive functioning (Volkow et al., 2014; Winward et al., 2014). With respect to labor market outcomes, earlier studies documented that recent cannabis use is associated with a wage penalty among men (Kaestner, 1994), especially young men (Register and Williams, 1992). However, perhaps foreshadowing the more positive effects found in recent papers on medical marijuana, Kaestner (1994) and Register and Williams (1992) found some evidence of positive effects on wages, specifically among women reporting recent use and in overall population estimates, respectively. Studies suggest that the timing of the start of cannabis use may be important, with an earlier start to cannabis use associated with a larger negative wage impact (Van Ours, 2007), reduced likelihood of returning to education following entry into the workforce (Williams and Van Ours, 2020), lower acquisition of human capital (Chatterji, 2006; Williams and Van Ours, 2020), a decrease in concentration and mental functioning (Hanson et al., 2010; Volkow et al., 2016), and an increase in laziness (Irons et al., 2014).

To date, we are aware of no published studies on the effects of recreational cannabis legalization and access on labor market outcomes beyond disability claims (Maclean et al., 2021), but studies on labor market-related effects of medical cannabis legalization and access do exist. These studies have found that legal medical use successfully treats adverse health conditions (Bonn-Miller et al., 2007), decreases pain (Li et al., 2019; Nicholas and Maclean, 2019), improves disease symptoms (Vigil et al., 2018; Stith et al., 2019), leads to better self-assessed health (Nicholas and Maclean, 2019), and encourages substitution away from opioids and other medications (Smith, 2020a; Vigil et al., 2017; Bradford et al., 2018; Doremus et al., 2019; Stith et al., 2019). ${ }^{6}$ Furthermore, studies have found that legal medical cannabis lowers rates of workplace fatalities for workers aged 25-44 years (Anderson et al., 2018), decreases job absences by $8.4 \%-8.7 \%$ among workers aged $15-65$ years (Ullman, 2017), and reduces suicide rates among young men aged 20-39 years (Anderson et al., 2014). These outcomes could be associated with increases in labor productivity, which, in competitive labor markets, should lead to higher wages. Whether the positive effects found by these prior studies on medical cannabis legalization and access are likely to arise from recreational cannabis legalization and access is an unanswered question.

Along with an increasing number of studies documenting the direct benefits from cannabis consumption (Stith et al., 2018), indirect benefits may also be significant and arise from individuals substituting away from other substances toward cannabis. For example, Chu (2015) found that with the legalization of medical cannabis, arrests for cocaine and heroin possession combined decreased by $0 \%-15 \%$, and admissions for heroin-related treatment decreased by $20 \%$ (Chu, 2015). Other studies have found that alcohol consumption decreases (Baggio et al., 2018), alcohol-related traffic fatalities decrease by 13\%-15\% (Mark Anderson et al., 2013), and the number of cigarettes consumed by smokers also decreases, leading to cost savings of $\$ 4.6-\$ 6.9$ billion per year in tobacco-related health care (Choi et al., 2019).

Although short-term impairment effects may be similar, the long-term consequences of chronic cannabis consumption appear to be better than those from long-term opioid, alcohol, or tobacco use. In particular, no deaths have been documented as a result of the negative health consequences of cannabis. Meanwhile, opioid overdoses have killed 47,000 people in

6 Carrieri et al. (2019) find - from Italy - that even legalization of light cannabis led to a decrease in cannabis confiscations and drug-related offences. 
2017 (Scholl et al., 2019), and on average, 88,000 people die from alcohol-related causes annually (Centers for Disease Control \& Prevention, 2013). Cigarette smoking is accountable for $>480,000$ deaths per year in the United States, including $>41,000$ deaths caused by secondhand smoking exposure (U.S. Department of Health and Human Services, 2014).

Although potential health benefits from legal medical use have been documented, only a handful of previous studies have focused on the effects of MMLs on the labor market. Sabia and Nguyen (2018), using data from the Current Population Survey (CPS) Outgoing Rotation Groups, found no evidence of MMLs affecting working-age adult employment and work hours. Even though they found a decrease in wages among young men (aged 20-39 years) of 2\%, there is no evidence of a reduction in the overall hourly wage. Using Health and Retirement Study data, Nicholas and Maclean (2019) found that state MMLs led to an increase in labor supply among older adults, both on the intensive and extensive margins, implying that MMLs may increase both whether and how much older adults work.

Although studies have documented increased reporting of cannabis use from legalization, the lack of a negative effect on labor market supply in the literature may be because the majority of cannabis users were already consuming cannabis prior to recreational cannabis legalization. In other words, even if cannabis use (and not just reporting) increased, a significant portion of recreational cannabis sales after legalization still may come from individuals who previously purchased cannabis on the illicit market. Due to prior use, these individuals may be less likely than new users to experience significant changes in health or labor productivity as a result of legalization. Supporting that those who previously bought on the illicit market are now purchasing legally, Hunt and Pacula (2017) report responses from a survey on cannabis purchase before and after recreational cannabis legalization in Colorado; all survey respondents who had previously bought their cannabis from a "dealer" or "friend" reported purchasing cannabis from either a medical or recreational dispensary after legalization. In other words, the existence of an illicit market probably limits the magnitude of labor supply-side effects from legal recreational dispensary entry relative to effects that would be experienced in the absence of the illicit market.

\subsection{Cannabis and labor demand}

Legal cannabis sales have a long supply chain that includes cannabis cultivators, extraction services, product manufacturers, testing facilities, distributors, and retail cannabis stores. Technology is exploding in the legal cannabis industry, with innovations in THC and cannabidiol (CBD) extraction and concentration, product standardization, and consumption methods ranging from vaporizing flowers and concentrates to inserting suppositories and ingesting pills. At the same time, production methods often can be labor-intensive, with, e.g., hand-trimming of individual cannabis flowers still common among commercial cultivators (Hennings, 2018). Regulatory requirements also result in demand for packaging and testing materials and services. The legalization of delivery services further fuels industry growth.

Although illegal cannabis suppliers existed prior to legalization and continue to exist, most of the growth in the cannabis industry likely is driven by new, legal entities. Given licensing restrictions and technology innovation, it is unlikely that the same cannabis suppliers who previously operated in the illicit market were able to transition their facilities into producing for and selling into the legal market. The state also regularly inspects all commercial cultivation 
and processing facilities and retail businesses. Product innovation and regulatory requirements mean demand for new, more sophisticated growing, processing, testing, and packaging methods. Similarly, tourism-related expansion is due to legal access. Catering directly to cannabis tourism was illegal prior to recreational legalization, and the number of people willing to travel to Colorado to buy legal cannabis is surely much larger than the number who were willing to travel across the country to illegally buy cannabis in Colorado prior to legalization (Armijo, 2019; Mitchell, 2019).

In summation, the legalization of recreational cannabis might affect the demand for labor via multiple mechanisms. With the increase in demand for cannabis, we expect an increase in the labor demanded to support increases in cannabis production and retail sales, with spillovers to the tourism industry. Given this increase in the demand for labor, assuming no changes in labor supply, we would expect an increase in the number of jobs or employees and a decrease in the unemployment rate. If labor markets are sufficiently tight, this could translate into higher wages for hired workers as well.

However, forces on the labor supply side may mediate effects from labor demand. On the one hand, if the harmful effects of cannabis consumption dominate, then we would expect a reduction in labor force participation. (This decrease in labor supply would reduce the unemployment rate without any effect on the number of employees.) If consumption affects productivity, we might also expect a decrease in the equilibrium wage, although a sufficient decline in labor supply also could increase wages among those who are still working.

On the other hand, if the positive effects of cannabis consumption dominate, then we should observe an increase in labor force participation and an associated increase in the unemployment rate, in the absence of any demand-side effects. The effect on wages is ambiguous and would depend on changes in workers' distribution and productivity.

An increase in labor demand seems a largely unambiguous prediction from the creation of a new market. The effects on labor supply are less clear, increasing the potential range of equilibrium outcomes. If both demand and supply for labor increase, the number of employees will increase unambiguously; however, the effects of dispensary entry on the unemployment rate and wages will depend on the relative size of the shifts in supply and demand. If labor demand increases, but labor supply decreases, then we would expect wages to increase and the unemployment rate to decrease, but the effect on the number of employees will again depend on the relative size of the shifts in supply and demand.

\section{Data}

We assembled data for all 64 counties in Colorado in terms of labor market outcomes, recreational access, and county characteristics from various federal and state-level agencies. Table A1 in the Appendix summarizes a timeline for the period covered by each variable type we use and its data sources.

\subsection{Labor market outcomes}

The data on labor market outcomes are from the U.S. Bureau of Labor Statistics (BLS). The employment and labor force participation data are from the LAUS, a joint federal-state 
initiative that provides monthly estimates of total employment and unemployment. The LAUS data's underlying concepts and definitions come from the CPS, a household survey that is the source of the national unemployment rate. The county-level LAUS data are cross-validated and updated using data from multiple sources, including the CPS, Community Expenditure Survey, state unemployment insurance systems, and the American Community Survey.

Data containing the monthly number of employees and average quarterly wages by industry are from the QCEW. The QCEW reports quarterly county-level payroll data on private employment and wages for defined industries. In accordance with the national unemployment insurance program, these details must be filed by employers. The North American Industrial Coding System (NAICS) defines each industry in the data and then aggregates the data by county, industry, and quarter. Specifically, the analysis in this paper uses the number of employees and average weekly wage data for each county, overall and by industry category; the categories are Natural Resources and Mining (Agriculture, Forestry, Fishing, and Mining), Construction, Manufacturing, and Service-Providing (Trade, Information, Financial Activities, Education, and Health Services).

The county-level data from the QCEW have some advantages. Compared with other data sets, QCEW is the only source with census observations of employment and wages reported in detail, covering $>95 \%$ of U.S. jobs. Data on county-level monthly employment and average quarterly wages are available by industry and based on mandated quarterly reports filed by employers through state unemployment insurance programs.

However, there are some drawbacks to the QCEW data set. The monthly dependent variable, employees, and the quarterly dependent variable, average weekly wage, have data points missing for some counties. ' There is also no distinction between part-time and full-time employees nor is there a measure of the average hours worked by county, and the unincorporated self-employed are excluded. The only information on earnings is the average weekly wage per worker overall and by industry subgroup, measured at the county level. ${ }^{8}$ Nonetheless, the QCEW provides the most complete and precise county-level data on employment and earnings, with county-level information required for our identification strategy.

\subsection{Recreational dispensary and medical cannabis patients}

Our key variable of interest, the location and timing of recreational dispensary entry in Colorado counties, was compiled from publicly available data of the CDOR. Focusing on dispensary entry rather than legalization alone is important because we are testing for demand-side effects generated by dispensary operations, the cannabis dispensary supply chain, and the tourism generated by dispensary availability. In addition, even for the effects of medical legalization on outcomes such as opioid use, prior studies have found that dispensary access may be the crucial driver of effects rather than cannabis or dispensary legalization alone (Powell et al., 2018; Smith, 2020b; Anderson and Rees, 2014). These data come from the Marijuana Sales Report (CDOR, 2019) and are available starting in January 2014. The Marijuana Sales Reports

7 BLS withholds the release of data to protect the identity and data of cooperating employers when necessary. Since QCEW receives reports from each U.S. employer, there are cases where QCEW detailed data could consist of a single employer in a county in some industries. In QCEW publications, these data are retained or "suppressed." State and national totals include the undisclosed data suppressed in the county-level data.

8 Wages include bonuses, stock options, severance pay, the cash value of meals and lodging, tips, and other gratuities. 
reflect sales made in each county by month. Although the data show whether any cannabis sales occurred for all Colorado counties, the amount of sales for some counties is not released for reasons of confidentiality, i.e., sales data are disclosed only when there are at least three taxpayers in a given category, and none of them accounts for $>80 \%$ of the total. Data on the number of medical cannabis patients by month were obtained from the Colorado Department of Public Health and Environment (CDPHE). Their website reports medical cannabis patients by month for each county in Colorado (CDPHE, 2019).

Using these data sets from the CDOR, the CDPHE, the LAUS, and the QWEC, we construct a county-level panel data set for the period 2011-2018, in order to compare changes in labor market outcomes in counties with recreational dispensaries to those counties without.

In Table 1, we present the overall summary statistics for the main dependent and independent variables. The full monthly data sample includes 6,144 observations, and the quarterly data has 2,048 observations. However, some observations are missing for the construction, manufacturing, and natural resource and mining industries due to the reasons mentioned in the previous section. In the subindustry analysis, we only include the counties with consistent documentation over time and exclude the counties with missing observations. In this way, for each subindustry, we analyze different sets of counties: 34 selling counties ${ }^{9}$ and 18

Table 1 County-level summary statistics

\begin{tabular}{lrrrrr}
\hline & Mean & SD & Min & Max & N \\
\hline Panel A: monthly & & & & & \\
\hline Unemployment rate (\%) & \multicolumn{1}{c}{5.23} & 2.77 & 1.1 & 17.4 & 6,144 \\
Labor force & 44,682 & 90,397 & 273 & 417,717 & 6,144 \\
Unemployed & 2,268 & 5,017 & 7 & 33,083 & 6,144 \\
All industry employees & 37,909 & 84,671 & 195 & 524,919 & 6,144 \\
Construction employees & 2,720 & 5,099 & 14 & 24,163 & 4,992 \\
Manufacturing sector employees & 2,929 & 5,427 & 10 & 21,436 & 4,512 \\
Natural resource and mining employees & 802 & 1,821 & 8 & 13,120 & 5,088 \\
Service-providing employees & 26,692 & 62,824 & 81 & 401,921 & 6,144 \\
Amount of recreational sales & 629,296 & $2,712,311$ & 0 & $35,343,772$ & 6,144 \\
Number of medical patients & 1,622 & 3,568 & 2 & 20,976 & 6,144 \\
\hline Panel B: quarterly & & & & & \\
\hline All industry wages & 749.06 & 200.83 & 410 & 2,102 & 2,048 \\
Construction wages & 881.75 & 227.47 & 415 & 2,489 & 1,664 \\
Manufacturing wages & 844.94 & 339.17 & 310 & 2,650 & 1,504 \\
Natural resource and mining wages & $1,071.30$ & 641.53 & 376 & 6,475 & 1,696 \\
Service-providing wages & 684.91 & 216.46 & 294 & 2,619 & 2,048 \\
\hline
\end{tabular}

Notes: The data cover the period from 2011 to 2018. Our monthly sample includes 6,144 county-month observations, while our quarterly sample includes 2,048 county-quarter observations. Subindustry measures are based on fewer observations due to BLS suppression of county-level information for confidentiality reasons.

BLS, U.S. Bureau of Labor Statistics; Min, minimum; Max, maximum; SD, standard deviation.

9 Counties in which legal recreational cannabis was sold at any point of time between 2011 and 2018. 
not-selling counties ${ }^{10}$ for Construction, 32 selling and 15 not-selling counties for Manufacturing, and 32 selling and 21 not-selling counties for Natural Resources and Mining. The differences between the minimum and maximum values for our outcome variables (other than the unemployment rate) are substantial and support using a natural log transformation. (Table A2 in the Appendix provides further summary statistics, differentiating between counties with and without dispensaries, pre- and post-dispensary entry and January 2014, respectively, and testing the changes over time.)

In addition to the summary statistics, we include Figures A3, A4, and A5 in the Appendix comparing the changes for our dependent variables over time for counties with dispensaries to those counties without. Apparent differences in levels exist for most of our variables between selling and not-selling counties, which persist over time, indicating the importance of controlling for county and time fixed effects in our regression analysis. An informal evaluation of parallel trends suggests that parallel trends exist for the unemployment rate, labor force, the number unemployed, and wages. Although we do not see strong evidence of violation of the parallel trends assumption for our other outcomes, we do see potentially small differences in the pre-trends for employees overall and for the Manufacturing and Natural Resources and Mining sectors, as well as for wages in Manufacturing. The obvious seasonality in the data supports the inclusion of month fixed effects.

\section{Empirical Strategy}

In order to estimate the impact of recreational dispensary entry on our variables of interest, we use a DID model with fixed effects. The variation in the location and timing of dispensary entry across counties in Colorado is exploited to accurately identify local labor market spillovers. We analyze the unemployment rate, the size of the labor force, the number of unemployed, and the number of employees, as well as the average weekly wages overall and by industry sector. All the dependent variables except the unemployment rate have been transformed using the natural logarithm to reduce the impact of outliers.

We estimate the following two specifications of our model:

$$
\begin{aligned}
& \ln \left(Y_{c m y}\right)=\alpha_{0}+\beta R_{c m y}+\theta X_{c m y}+\delta_{y}+\delta_{m}+\gamma_{c}+c_{c m y} \\
& \ln \left(Y_{c m y}\right)=\alpha_{1}+\lambda_{1} \text { sales }_{c m y}^{l o w}+\lambda_{2} \text { sales }_{c m y}^{h i g h}+\theta X_{c m y}+\delta_{y}+\delta_{m}+\gamma_{c}+c_{c m y}
\end{aligned}
$$

$Y_{c m y}$ is our main outcome variable for county $c$ in month/quarter $m$ and year $y . R_{c m y}$ in Eq. (1) and sales $s_{c m y}^{i}$ in Eq. (2) are the two types of treatment that we consider. $R_{c m y}$ is a dummy variable indicating any recreational cannabis sales, whereas sales cmy $_{\text {low }}$ indicates when $\$ 0<$ sales $\leq$ $\$ 500,000$ and sales $s_{c m y}^{\text {high }}$ when sales $>\$ 500,000$. $\beta$ reports the average effect with the commencement of the sale of recreational cannabis, and $\lambda_{1}$ and $\lambda_{2}$ report the average effects of lower and higher levels of recreational cannabis sales relative to no sales. Thus, $\beta$ in Eq. (1), and $\lambda_{1}$ and $\lambda_{2}$ in Eq. (2) are our primary coefficients of interest, summarizing the effect of access a recreational cannabis dispensary. $X_{c m y}$ controls for the natural log of the number of medical cannabis patients. $\delta_{y}, \delta_{m}$, and $\gamma_{c}$ are the fixed effects at the year, month/quarter, and county levels,

10 Counties in which legal recreational cannabis dispensaries never sold cannabis between 2011 and 2018. 
which capture the year and month/quarter effects that are common across counties and the time-invariant county-level factors.

County-level fixed effects enable us to control for population density and demographics (e.g., age and socioeconomic status), which do not change over time during our sample period from 2011 to 2018. Month fixed effects account for seasonality, which affects all counties and differs only in levels, not in terms of which months are peak tourism months. For example, even though some counties always have more tourism than others (captured by the county fixed effects), most Colorado counties have spikes in tourism in the summer and ski seasons. Robust standard errors, $c_{c m y}$, are clustered at the county (treatment) level to correct for arbitrary correlation among observations in a given county.

The opening of dispensaries may be endogenous, although ideological factors probably play a role in outright bans (Bradford and Bradford, 2017), and initial licenses were restricted to existing medical licensees, potentially limiting the choice of entry location. It is plausible that dispensaries open earlier in counties with favorable economic conditions and where expected demand for recreational cannabis is high. Therefore, a dispensary opening may not be a random event. Although we use county, month, and year fixed effects, they may not fully absorb the unobservable differences between treated and control counties leading to the opening of a dispensary. We attempt to address this potential endogeneity by using event studies to assess pre-trends, attempting to predict entry with preexisting trends in our outcome variables, capitalizing on the institutional factor that only existing medical dispensaries were allowed to sell initially, and using a GSC method.

Our identification is based on both the timing and location of new dispensaries; thus, we use an "event study" research design to ensure that preimplementation factors do not drive the heterogeneity in the timing of implementation and to assess effects that change over time (Autor, 2003; Lovenheim, 2009; Lee and Mas, 2012). We estimate Eq. (3) for our event study model.

$\ln \left(Y_{c m y}\right)=\alpha_{0}+k \sum \tau_{k} Z^{k}+\theta X_{c m y}+\delta_{y}+\delta_{m}+\gamma_{c}+c_{c m y}$

More specifically, we regress our outcomes, $Y_{c m y}$, on a series of "event-time" dummies $Z_{c m y}^{k}$

$Z_{c m y}^{k}$ equals one when county $c$ is $k$ months/quarters from the commencement of recreational cannabis sale in month/quarter $m$ and year $y$. These indicator variables are set to zero for counties that never sell recreational cannabis during our given sample period from 2011 to 2018. Periods $>40$ months (10 quarters) before or after dispensary entry are collapsed into the first and last periods.

Following Borusyak and Jaravel (2017) and to abstract away from seasonality around the time of dispensary entry, the reference period is a half year prior to dispensary entry. ${ }^{11}$ Thus, for our assumption of strict exogeneity to hold, $\tau_{k}=0$ for all $k<0$ for event study regressions at the month and quarter levels. ${ }^{12}$

11 For our event study regressions, we normalize $\tau_{-6}=0$ for monthly data and $\tau_{-2}=0$ for quarterly data.

12 To summarize, the $\tau_{k}$ coefficients represent the time path of our dependent variables relative to the date of commencement of recreational cannabis sales. Through this specification, we are able to assess whether trends in our outcome variables precede the commencement of recreational cannabis sales or whether the effects change over time postdispensary entry. 
An additional reason for using the event study approach is that the DID estimate, i.e., the $\beta$ coefficient in Eq. (1), differentially weights the effects close to the initial timing of the treatment from the effects of later treatment (Borusyak and Jaravel, 2017; Athey and Imbens, 2021; Goodman-Bacon, 2021; De Chaisemartin and d'Haultfoeuille, 2020). One way to address this concern is to estimate the dynamic treatment effect over the post-treatment period and take the average or weighted average of the coefficients (Borusyak and Jaravel, 2017). Therefore, we also run our event study including only the $\tau_{k}$ variables for the post-dispensary entry period, but otherwise following Eq. (3). We calculate the simple average and the weighted average with the weighted average coefficient calculated as ${ }_{k=0}^{42} \tau_{k} * s_{k}, \sum_{k=0}^{42}$ where $s_{k}$ is the share of observations in the post-dispensary entry period after the counties started selling recreational cannabis. ${ }^{13}$

Along with the event studies, we test for endogeneity by regressing the binary variable for dispensary entry in county $c$ at month/quarter $m$ and year $y$ on preexisting trends in the labor market outcome variables used in our study. We create the preexisting trend variable by calculating the change in the variable's value relative to that 1 year and 6 months prior to entry. ${ }^{14}$

We conduct additional robustness checks on our main specification, including controlling for population, county-specific seasonality (county-month fixed effects), and countyyear trends; and omitting counties with the highest recreational sales overall (Denver) and per capita (Las Animas), both potential indicators of significant sales to out-of-state customers and potentially much larger demand-side effects than those experienced by counties serving primarily local consumers. Further robustness checks include comparing early entrants ${ }^{15}$ to counties in which dispensaries never entered and comparing later entrants to counties in which dispensaries never entered during our sample period. Lastly, we assess the existence of spillovers across county lines, evaluating the effects of proximity to existing not-selling or selling counties.

The benefits of dispensary opening may spill over to nearby counties, especially to nondispensary counties. For example, dispensary opening in treated counties may draw workers out of nondispensary counties so that the employment level declines in nondispensary counties, thereby, creating negative spillovers. Similarly, neighboring counties may benefit from positive spillovers related to improved supply chains. Failure to capture such spillovers may lead to biased estimates of the average treatment effect. Therefore, to remove the bias arising from average spillovers to both the nearby dispensary as well as nondispensary counties, following Butts (2021), we create an indicator variable border,

$$
\ln \left(Y_{c m y}\right)=\alpha_{0}+\beta R_{c m y}+\lambda R_{c m y} * \operatorname{border}_{c m y}+\theta X_{c m y}+\delta_{y}+\delta_{m}+\gamma_{c}+c_{c m y}
$$

which equals one if a county $c$ is within $50 \mathrm{~km}$ (approximately 30 miles) ${ }^{16,17}$ of a treated county at month $m$ and year $y$. We include an interaction of this variable with the treatment variable

13 Standard errors are calculated using the delta method.

$14 R_{c m y}=\alpha_{0}+\beta Y$ change $_{c m y}+\delta_{y}+\delta_{m}+\gamma_{c}+E_{c m y}$ where $Y$ change $e_{c m y}=Y_{t}-Y_{t-12 \text { months }}$ or $Y_{t}-Y_{t-6 \text { months }}$

15 Early entrants are defined as dispensaries opening by June 2014, when only previously licensed medical dispensaries were allowed to sell.

16 Based on the proposal by Jeffrey Beall (2021), the maximum average commute is 29.2 minutes in Colorado. If people travel by freeway at $65 \mathrm{~m} /$ hour, then the maximum distance they travel is within 30 miles. We also check and confirm our results with $60 \mathrm{~km}$ (37.82 miles) and $70 \mathrm{~km}$ (43.5 miles).

17 We find the distance between counties using the centered latitude and longitude for each county. 
$R_{c m y}$, which partials out the average spillover effects. Therefore, $\mathrm{b}$ provides an estimate of the direct effect of dispensary opening.

In addition to corroborating the validity of our main results, an absence of spillovers would support the use of a county-level GSC method as better approximating our main analyses than a state-level synthetic control approach.

We further address how endogeneity may be affecting our results, using a GSC method to corroborate our results. The aim of this additional specification is to address potential endogeneity due to the violations of the parallel trends assumption, as observed from Figure 2, and improve the credibility of our estimates by utilizing the GSC methodology suggested by $\mathrm{Xu}$ (2017). This method is used to minimize the bias by creating an appropriate comparison group, especially in cases when the parallel trends assumption does not hold and data have untreated units serving as control units. The GSC method combines the synthetic control method proposed by Abadie et al. (2010) with linear fixed effects models and allows the treatment to be correlated with unit and time unobservables. This method is appropriate for our case as we have multiple treated units with heterogeneous treatment periods. It uses a parametric bootstrap procedure that provides valid inference. A cross-validation scheme selects the number of factors in the interactive fixed effect (IFE) model automatically and thus reduces the risk of overfitting. Similar to the synthetic control method (SCM), GSC uses the pretreatment outcome data for the treated units to choose weights for the control units and correlations between the control and treatment groups to predict the counterfactual. As units move from the control group to the treatment group over the study period, with some units untreated at the end of the period, GSC addresses the breakdown of the units into the treatment and control groups.

The GSC model from Xu (2017) has the following functional form:

$$
y_{c t}=\delta_{c t} R_{c t}+\gamma_{c} f_{t}+\mu_{c t}
$$

where the treatment dummy indicator $R_{c t}$ lets different counties experience the treatment in different years, $\delta_{c t}$ is the heterogeneous treatment effect on county $c$ at time $t ; \gamma_{c}$ is the vector of unobserved common factors; and $f_{t}$ denotes unknown factor loadings. ${ }^{18} x_{c t}$ is the time-varying $\log$ number of medical patients, similar to the DID model, $\beta=\left[\beta_{1}, \beta_{k}\right]$ is a $(\mathrm{k} \times 1)$ vector of unknown parameters, and $\mu_{c t}$ is the idiosyncratic error term with $E\left(\mu_{c t}\right)=0$. To estimate the impact of dispensary opening-induced changes in recreational cannabis on our outcomes, we need to identify the counterfactual path of outcomes that would have occurred in the absence of the dispensary opening. The estimation of the counterfactual $\hat{y}^{0}$ involves three steps:

Step 1. Estimate the interactive fixed effects model ${ }^{19}$ using the observations from the control group only and obtain $\hat{\beta}$ (Bai, 2009),

$$
y_{c t}=x_{c t} \beta+\gamma^{l} c f_{t}+\mu_{c t} .
$$

18 The time-varying coefficients are the (latent) factors, while the unit-specific intercepts are factor loadings in the paper by Xu (2017).

19 Our outcome variables may be spatially correlated across counties. Interactive effect models not only control for spatial correlations but also allow for cross-sectional dependence on account of similarity in economic dimensions other than geographic characteristics (Gobillon and Magnac, 2016). Another issue is that the treatment might be correlated with unobservables affecting the outcome. Interactive effect models allow the set of unobserved heterogeneity terms or factor loadings. 
Step 2. Estimate $\gamma_{c}$ (factor loadings) by minimizing the mean squared prediction error (MSPE) of each treated outcome in the pretreatment period:

$$
\begin{aligned}
\hat{\gamma}_{1}= & \arg \min \left(y_{1}-\boldsymbol{X}_{1} \hat{\boldsymbol{\beta}}-\hat{\boldsymbol{F}} \gamma_{1}\right)^{l}\left(y_{1}-\boldsymbol{X}_{1} \hat{\boldsymbol{\beta}}-\hat{\boldsymbol{F}} \gamma_{1}\right) \\
& =\left(\hat{\boldsymbol{F}}^{l} \hat{\boldsymbol{F}}\right)^{-1} \hat{\boldsymbol{F}}^{l}\left(\boldsymbol{y}_{1}-\boldsymbol{X}_{1} \hat{\boldsymbol{\beta}}\right),
\end{aligned}
$$

where $y_{1}=\left(y_{11}, \ldots, y_{1 T}\right), \hat{\boldsymbol{F}}=(\hat{\boldsymbol{f}}, \ldots, \hat{\boldsymbol{f}})^{l}$, and $\boldsymbol{X}_{1}=\left(\boldsymbol{x}_{11}, \ldots, \boldsymbol{x}_{1 T}\right)^{l}$.

Step 3. Compute counterfactuals for the treated units using the estimates $\hat{\beta}, \hat{\boldsymbol{F}}$, and $\hat{\gamma}_{1}$.

Therefore, an estimate for the treatment effect on the treated group is given by

$$
\hat{\Delta}_{c t}=y_{c t}-\hat{y}^{\mathrm{O}}, \text { for } t>T_{O} .
$$

Because the optimal number of included factors in the vector $\gamma_{c}$ is unknown, GSC implements a leave-one-out cross-validating procedure before calculating the causal effect [for more details, see Xu (2017)]. As discussed by Xu (2017), the GSC estimation framework has one key limitation, namely, the "incidental parameters" problem if the number of pretreatment periods is small or if there are too few control units. In our case, such concerns are minimized as almost half our counties are never treated and we have relatively long pretreatment periods.

This method combines the synthetic control method with IFE models and is less sensitive to small sample size than the traditional synthetic control method. It is being used by a rapidly growing literature using panel data models with U.S. county-level treatment (Cook, 2021; Cengiz and Tekgüç, 2018; Nguyen, 2020), or with treatment measured in similar smaller geographic areas in other countries (Skorobogatov, 2021; Mäkelä, 2017). As the GSC eliminates confounding factors that violate the identifying parallel trends assumption in event study designs, particularly for unemployment rate in our case, our use of the GSC provides causally interpretable results.

\section{Results}

We first report the results from event study models to assess pre-trends, then turn to DID regressions, and finally, we present our GSC model results that estimate the average treatment effect on the treated (ATT) of recreational cannabis dispensary entry.

\subsection{Event study}

The event study allows us to assess whether trends in labor market outcomes determine or even simply precede dispensary entry rather than dispensary entry affecting labor market outcomes. In other words, we expect that the coefficient $\tau_{k}$ for the pretreatment period, $-40 \leq$ $k \leq 0$ for monthly data and $-10 \leq k \leq 0$ for quarterly data, would be clustered around zero in the absence of pre-trends. Figures $2-4$ plot the estimated $\tau_{k}$ coefficients from Eq. (3).

For Figures 2-4, we generally observe no pretreatment trend in the coefficients except for the unemployment rate. For the natural logs of the total labor force, unemployed, all industry 
Figure 2 Effect of recreational cannabis entry on the unemployment rate, Ln(labor force) and Ln(unemployed) event study.
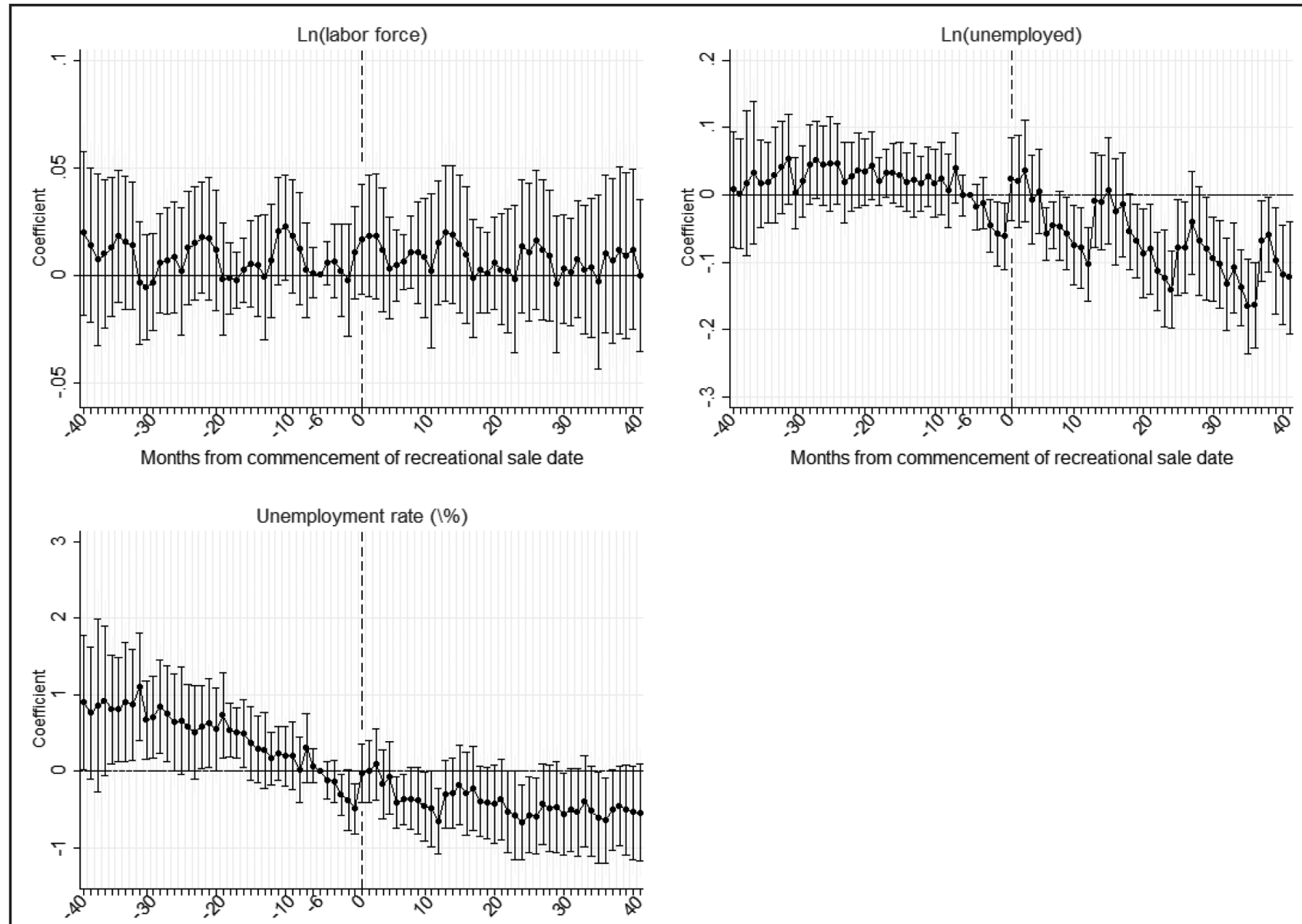

Months from commencement of recreational sale date

Notes: The points represent the $\tau_{k}$ coefficient estimates from the estimation of Eq. (3), omitting $\tau_{-6^{*}}$. The bars extending from each point represent a $95 \%$ confidence interval calculated from the standard errors that are clustered at the county level. There are no standard error bars for the relative half-year $k=-6$ as the plot reflects that zero is imposed rather than estimated. The $x$-axis denotes time with respect to the commencement of the sale. Period 0 is when the sale begins. All regressions include county, month, and year fixed effects. Standard errors are clustered at the county level and are reported in parentheses.

employees, and employees in manufacturing, construction, service-providing industries, and natural resource and mining, and for the average wages overall and by industry sector, our assumption of no pre-trends holds. Because of its usefulness as a policy benchmark, we continue to include the unemployment rate as an outcome. Even for the unemployment rate, we still observe a significant change. From Figure 2, we observe that the unemployment rate is higher in the preimplementation period, whereas it declines post-dispensary entry in recreational cannabis-selling counties. Similarly, the number of unemployed appears to be declining post-dispensary entry, while no obvious changes in labor force exist over time. The declines in unemployment and the number unemployed begin in anticipation of the market opening, about 6 months prior to dispensary entry. In order to stock stores on the day dispensaries open, growing and processing must begin in advance. ${ }^{20}$

20 Growing cannabis can take 3-8 months, with additional processing time that varies by product type. https://www. leafly.com/learn/growing/marijuana-growth-stages. Accessed 07/16/2021. 
Figure 3 Effect of recreational cannabis entry on Ln(employees), by industry - event study.
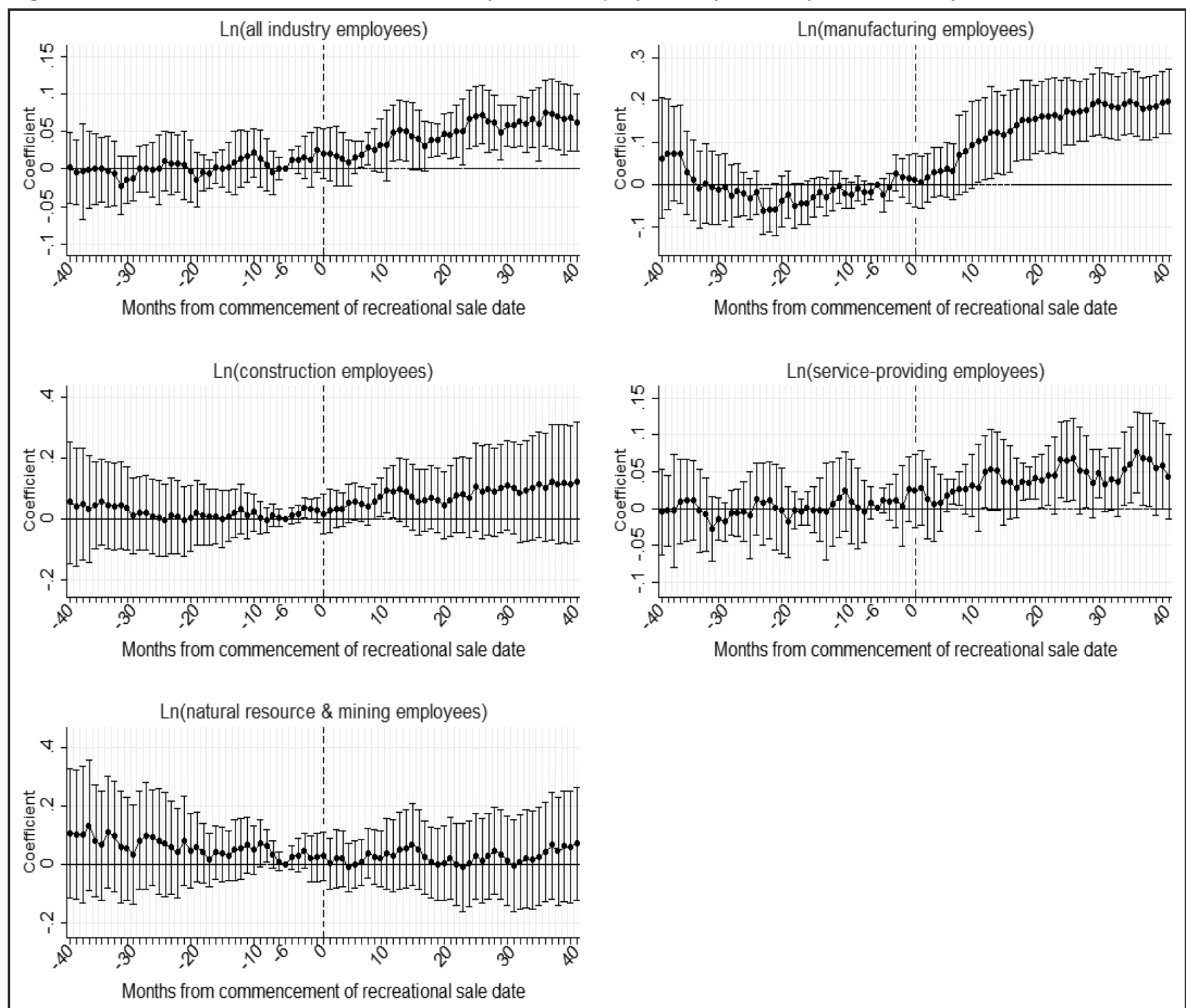

Notes: The points represent the $\tau_{k}$ coefficient estimates from the estimation of Eq. (3), omitting $\tau_{-6}$. The bars extending from each point represent a $95 \%$ confidence interval calculated from the standard errors that are clustered at the county level. There are no standard error bars for the relative half-year $k=-6$ as the plot reflects that zero is imposed rather than estimated. The $x$-axis denotes time with respect to the commencement of the sale. Period 0 is when the sale begins. All regressions include county, month, and year fixed effects. Standard errors are clustered at the county level and are reported in parentheses.

From the event study in Figure 3, we observe that the number of employees for all industries combined has a sustained and significant increase after dispensary entry for treated counties. The increase in employees overall appears to be driven by the manufacturing sector, which experiences a sustained increase about 10 months post-dispensary entry for treated counties. These results also show that the sector arguably least likely to be affected by recreational cannabis dispensary entry, namely, Natural Resources and Mining, shows no trend pre- or post-dispensary entry, as expected.

Figure 4 shows some evidence of an increasing trend in wages, but the differences in the coefficients are not generally statistically significant. 
Figure 4 Effect of recreational cannabis entry on Ln(wage), by industry - event study.
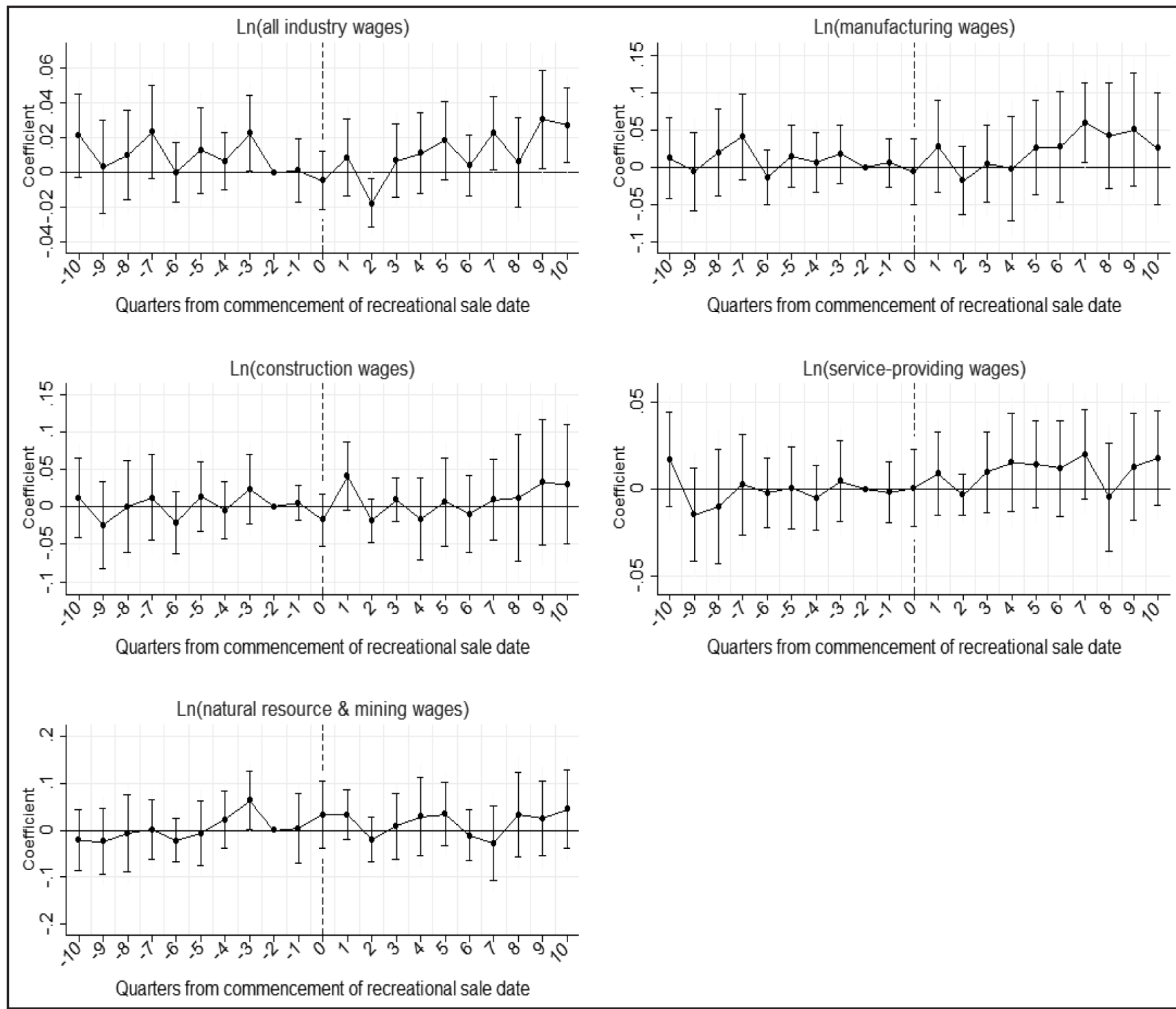

Notes: The points represent the $\tau_{k}$ coefficient estimates from the estimation of Eq. (3), omitting $\tau_{-2}$. The bars extending from each point represent a $95 \%$ confidence interval calculated from the standard errors that are clustered at the county level. There are no standard error bars for the relative half-year $k=-2$ as the plot reflects that zero is imposed rather than estimated. The $x$-axis denotes time with respect to the commencement of the sale. Period 0 is when the sale begins. All regressions include county, month, and year fixed effects. Standard errors are clustered at the county level and are reported in parentheses.

\subsection{DID analysis}

With the exception of the unemployment rate, our event study results show no significant pretrends. Instead, they provide evidence that the commencement of recreational cannabis sales is associated with an increase in the total number of employees overall, driven by the manufacturing sector. This is again confirmed in Table 2, where we do not find any change in the probability of recreational dispensaries entering a county in response to preexisting trends in the labor market outcome variables. The only statistically significant results are for the unemployment rate. Contrary to the possible pre-trend suggested by the event study, Table 2 indicates that dispensary entry is more likely to occur in counties with growing rather than falling unemployment rates. Therefore, we proceed with our DID analysis, presenting our results in 
Table 2 Effect of preexisting county-level economic conditions on dispensary entry

\begin{tabular}{|c|c|c|}
\hline Dependent variable $=\boldsymbol{R}_{c m y}$ & 6-month change & 1-year change \\
\hline \multirow[t]{2}{*}{ Pop change } & $0.000^{\star}$ & 0.000 \\
\hline & $(0.0000)$ & $(0.0000)$ \\
\hline \multirow[t]{2}{*}{ Unrate change } & $0.013^{\star}$ & $0.039^{\star}$ \\
\hline & $(0.0050)$ & $(0.0191)$ \\
\hline \multirow[t]{2}{*}{ Ln(labor force change) } & -0.049 & -0.379 \\
\hline & $(0.0497)$ & $(0.3405)$ \\
\hline \multirow[t]{2}{*}{ Ln(Unemp change) } & 0.021 & -0.005 \\
\hline & $(0.0256)$ & $(0.0554)$ \\
\hline \multirow[t]{2}{*}{ Ln(All Emp change) } & 0.007 & -0.032 \\
\hline & $(0.0345)$ & $(0.1537)$ \\
\hline \multirow[t]{2}{*}{ Ln(Cons Emp change) } & 0.022 & 0.026 \\
\hline & $(0.0478)$ & $(0.0593)$ \\
\hline \multirow[t]{2}{*}{ Ln(Manu Emp change) } & 0.097 & 0.149 \\
\hline & $(0.0839)$ & $(0.0926)$ \\
\hline \multirow[t]{2}{*}{ Ln(NR Emp change) } & 0.028 & 0.030 \\
\hline & $(0.0381)$ & $(0.0874)$ \\
\hline \multirow[t]{2}{*}{ Ln(Service Emp change) } & -0.002 & -0.122 \\
\hline & $(0.0186)$ & $(0.1650)$ \\
\hline \multirow[t]{2}{*}{ Ln(All wage change) } & 0.053 & 0.084 \\
\hline & $(0.0549)$ & $(0.1125)$ \\
\hline \multirow[t]{2}{*}{ Ln(Cons wage change) } & 0.022 & 0.019 \\
\hline & $(0.0473)$ & $(0.080)$ \\
\hline \multirow[t]{2}{*}{ Ln(Manu wage change) } & -0.009 & -0.028 \\
\hline & $(0.0407)$ & $(0.0875)$ \\
\hline \multirow[t]{2}{*}{ Ln(NR wage change) } & -0.011 & -0.100 \\
\hline & $(0.019)$ & $(0.0697)$ \\
\hline \multirow[t]{2}{*}{ Ln(Service wage change) } & -0.024 & -0.001 \\
\hline & $(0.0310)$ & $(0.1016)$ \\
\hline
\end{tabular}

Notes: Each cell indicates a separate regression of dispensary entry in county $c$ at month/ quarter $m$ and year $y$ on the preexisting trends in the labor market outcome variables used in our study. Columns 1 and 2 show results with 6-month and 1-year changes of each labor market variable, respectively. All regressions include county, month, and year fixed effects. Standard errors are clustered at the county level and are reported in parentheses.

${ }^{+} p<0.1,{ }^{*} p<0.05,{ }^{* *} p<0.01$.

Cons, construction; Emp, employment; Manu, manufacturing; NR, natural resources; Unemp, unemployment; Unrate, unemployment rate.

Tables 3-5, each of which are split into two panels. Panel A presents our results using our $\{0,1\}$ dispensary entry variable, and Panel B shows how the intensive margin or level of sales affects our outcomes. As a check on the robustness of the DID results, the simple average and the weighted average of the $\tau_{k}$ coefficients from the event study including only the post-dispensary entry period are reported after the DID results in Panel A of Tables 3-5. (The underlying coefficients are reported in Tables A3-A5 in the Appendix.)

We begin by first discussing the results from Panel A of Tables 3-5 before exploring the intensive margin results from Panel B of those tables. 
Table 3 Effect of recreational dispensary entry and sales on the unemployment rate (Unrate), Ln(labor force), and Ln(unemployed) - regression analysis

\begin{tabular}{|c|c|c|c|}
\hline & Unrate & Ln(labor force) & Ln(unemp) \\
\hline & (1) & $(2)$ & (3) \\
\hline \multicolumn{4}{|l|}{ Panel A: start of sales } \\
\hline \multirow{2}{*}{ Recreational sale } & $-0.684^{\star \star}$ & 0.001 & $-0.068^{\star \star}$ \\
\hline & $(0.2522)$ & $(0.0115)$ & $(0.0194)$ \\
\hline \multirow[t]{2}{*}{ Ln(number of medical patients) } & $-0.621^{\star}$ & -0.006 & -0.025 \\
\hline & $(0.2692)$ & $(0.0126)$ & $(0.0249)$ \\
\hline \multicolumn{4}{|l|}{ Linear combination } \\
\hline Coefficient & $-0.407^{\star}$ & 0.008 & $-0.068^{\star \star}$ \\
\hline SE & $(0.2264)$ & $(0.0125)$ & $(0.0238)$ \\
\hline \multicolumn{4}{|l|}{ Weighted linear combination } \\
\hline Coefficient & -0.339 & 0.008 & $-0.060^{\star}$ \\
\hline SE & $(0.2433)$ & $(0.0133)$ & $(0.0243)$ \\
\hline$\overline{R^{2}}$ & 0.881 & 0.999 & \\
\hline Observations & 6,144 & 6,144 & 6,144 \\
\hline \multicolumn{4}{|l|}{ Panel B: amount of sales } \\
\hline \multirow[t]{2}{*}{$\$ 0<$ sales $\leq \$ 500,000$} & $-0.727^{\star \star}$ & 0.003 & $-0.058^{\star \star}$ \\
\hline & $(0.2803)$ & $(0.0109)$ & $(0.0223)$ \\
\hline \multirow[t]{2}{*}{ Sales $>\$ 500,000$} & $-0.630^{\star \star}$ & -0.001 & $-0.081^{\star \star}$ \\
\hline & $(0.2641)$ & $(0.0144)$ & $(0.0245)$ \\
\hline \multirow[t]{2}{*}{ Ln(number of medical patients) } & $-0.613^{\star \star}$ & -0.006 & -0.027 \\
\hline & $(0.2724)$ & $(0.0128)$ & $(0.0261)$ \\
\hline$\overline{R^{2}}$ & 0.882 & 0.999 & 0.995 \\
\hline Observations & 6,144 & 6,144 & 6,144 \\
\hline
\end{tabular}

Notes: Panel A uses a $\{0,1\}$ any sales as the treatment variable, while Panel B compares counties with sales between $\$ 0$ and $\$ 500,000$ or sales $>\$ 500,000$ with counties with zero sales. All regressions include county, month, and year fixed effects. Each column represents a separate regression. Below each column in Panel A, we report the average and weighted average of the $\tau_{k}$ coefficients from the event study, including only the $\tau_{k}$ coefficients for the periods post-dispensary entry. Standard errors are clustered at the county level and are reported in parentheses.

${ }^{+} p<0.1,{ }^{\star} p<0.05,{ }^{\star \star} p<0.01$.

SE, standard error.

The effect of recreational cannabis law implementation on the unemployment rate, labor force, and number of unemployed are presented in Table 3. From Panel A, our results provide evidence that after recreational dispensary entry, there is a significant decrease in unemployment with a 0.684 percentage point $(p<0.01)$ decrease in the unemployment rate and a $6.6 \%$ $(p<0.01)$ decrease in the number of unemployed. The lack of a statistically significant effect on the labor force indicates that an increase in the number employed is driving the effect. In Panel A of Table 4, estimates for employees, overall and by sector, suggest that demand for labor has increased employment; recreational sale is associated with a $4.4 \%(p<0.01)$ increase in overall employment, driven by a $12.9 \%(p<0.01)$ increase in the number of manufacturing sector 
Table 4 The effect of recreational dispensary entry and sales on employment - regression analysis

\begin{tabular}{|c|c|c|c|c|c|}
\hline & $\operatorname{Ln}(A l l)$ & Ln(Cons) & Ln(Manu) & $\operatorname{Ln}(N R)$ & Ln(Service) \\
\hline & (1) & (2) & (3) & (4) & (5) \\
\hline \multicolumn{6}{|l|}{ Panel A: start of sales } \\
\hline \multirow[t]{2}{*}{$\overline{\text { Recreational sale }}$} & $0.044^{\star \star}$ & 0.058 & $0.129^{\star \star}$ & -0.015 & $0.038^{\star}$ \\
\hline & $(0.0151)$ & $(0.0546)$ & $(0.0352)$ & $(0.0665)$ & $(0.0153)$ \\
\hline \multirow[t]{2}{*}{ Ln(number of medical patients) } & -0.022 & $-0.175^{+}$ & $-0.187^{\star \star}$ & 0.172 & -0.026 \\
\hline & $(0.0144)$ & $(0.0914)$ & $(0.0597)$ & $(0.1163)$ & $(0.0183)$ \\
\hline \multicolumn{6}{|l|}{ Linear combination } \\
\hline Coefficient & $0.047^{\star}$ & 0.080 & $0.134^{\star *}$ & 0.028 & $0.042^{*}$ \\
\hline SE & $(0.0145)$ & $(0.0542)$ & $(0.0333)$ & $(0.0563)$ & $(0.0188)$ \\
\hline \multicolumn{6}{|l|}{ Weighted linear combination } \\
\hline Coefficient & $0.054^{\star \star}$ & 0.086 & $0.142^{\star \star}$ & 0.046 & $0.044^{\star}$ \\
\hline SE & $(0.0154)$ & $(0.0657)$ & $(0.0328)$ & $(0.0642)$ & $(0.0204)$ \\
\hline$\overline{R^{2}}$ & 0.998 & 0.989 & 0.996 & 0.970 & 0.988 \\
\hline Observations & 6,144 & 4,608 & 3,936 & 4,608 & 6,144 \\
\hline \multicolumn{6}{|l|}{ Panel B: amount of sales } \\
\hline \multirow[t]{2}{*}{$\$ 0<$ sales $\leq \$ 500,000$} & $0.029^{+}$ & 0.054 & $0.147^{\star \star}$ & -0.031 & 0.025 \\
\hline & $(0.0155)$ & $(0.0486)$ & $(0.0379)$ & $(0.0659)$ & $(0.0173)$ \\
\hline \multirow[t]{2}{*}{ Sales $>\$ 500,000$} & $0.063^{\star \star}$ & 0.062 & $0.108^{\star \star}$ & 0.003 & $0.056^{\star \star}$ \\
\hline & $(0.0177)$ & $(0.0662)$ & $(0.0370)$ & $(0.0804)$ & $(0.0169)$ \\
\hline \multirow[t]{2}{*}{ Ln(number of medical patients) } & -0.019 & $-0.174^{+}$ & $-0.192^{\star \star}$ & 0.175 & -0.024 \\
\hline & $(0.0149)$ & $(0.0918)$ & $(0.0582)$ & $(0.1168)$ & $(0.0180)$ \\
\hline$\overline{R^{2}}$ & 0.998 & 0.989 & 0.996 & 0.970 & 0.998 \\
\hline Observations & 6,144 & 4,608 & 3,936 & 4,608 & 6,144 \\
\hline
\end{tabular}

Notes: Panel A uses a $\{0,1\}$ any sales as the treatment variable, while Panel B compares counties with sales between $\$ 0$ and $\$ 500,000$ or sales $>\$ 500,000$ with counties with zero sales. All regressions include county, month, and year fixed effects. Each column represents a separate regression. The industry subsectors are Construction, Manufacturing, Natural Resources and Mining, and Service. Below each column in Panel A, we report the average and weighted average of the $\tau_{k}$ coefficients from the event study, including only the $\tau_{k}$ coefficients for the periods post-dispensary entry. Standard errors are clustered at the county level and are reported in parentheses.

${ }^{+} p<0.1,{ }^{\star} p<0.05,{ }^{\star \star} p<0.01$. SE, standard error.

employees and a 3.8\% $(p<0.05)$ increase in the number of service sector employees. The effects on employees are larger than those predicted by the change in unemployment, suggesting that cannabis-related labor markets are drawing from not just the unemployed, but that individuals are taking on additional jobs or transitioning out of self-employment and becoming employees. Based on the logged whole-sample averages, the logged unemployed results suggest a decline of about 64 unemployed individuals with dispensary entry, while the results for logged employees indicate an increase of 407 jobs. The estimated increases for the manufacturing and service sectors are 59 and 206 employees, respectively. In Panel A of Table 5, we find no effect from dispensary entry on wages, which is consistent with some level of continued unemployment or excess supply of labor, i.e., the labor market has tightened but not so much as to increase wages. 
Table 5 The effect of recreational dispensary entry and sales on wages - regression analysis

\begin{tabular}{|c|c|c|c|c|c|}
\hline & $\operatorname{Ln}($ All $)$ & Ln(Cons) & Ln(Manu) & $\operatorname{Ln}(N R)$ & Ln(Service) \\
\hline & (1) & $(2)$ & (3) & $(4)$ & (5) \\
\hline \multicolumn{6}{|l|}{ Panel A: start of sales } \\
\hline \multirow[t]{2}{*}{ Recreational sale } & 0.001 & 0.008 & 0.010 & 0.025 & 0.004 \\
\hline & $(0.0100)$ & $(0.0264)$ & $(0.0192)$ & $(0.0316)$ & $(0.0126)$ \\
\hline \multirow[t]{2}{*}{ Ln(number of medical patients) } & 0.003 & $-0.082^{+}$ & -0.035 & $0.063^{+}$ & 0.002 \\
\hline & $(0.0112)$ & $(0.0466)$ & $(0.0268)$ & $(0.0337)$ & $(0.0175)$ \\
\hline \multicolumn{6}{|l|}{ Linear combination } \\
\hline Coefficient & 0.011 & 0.009 & 0.022 & 0.019 & 0.008 \\
\hline SE & $(0.0076)$ & $(0.0239)$ & $(0.0265)$ & $(0.0269)$ & $(0.0093)$ \\
\hline \multicolumn{6}{|l|}{ Weighted linear combination } \\
\hline Coefficient & 0.013 & 0.017 & 0.022 & 0.026 & 0.004 \\
\hline SE & $(0.0092)$ & $(0.0314)$ & $(0.0298)$ & $(0.0323)$ & $(0.0105)$ \\
\hline$\overline{R^{2}}$ & 0.937 & 0.777 & 0.932 & 0.909 & 0.925 \\
\hline Observations & 2,048 & 1,536 & 1,312 & 1,536 & 2,048 \\
\hline \multicolumn{6}{|l|}{ Panel B: amount of sales } \\
\hline \multirow[t]{2}{*}{$\$ 0<$ sales $\leq \$ 500,000$} & 0.006 & 0.009 & 0.026 & 0.029 & 0.010 \\
\hline & $(0.0106)$ & $(0.0254)$ & $(0.0248)$ & $(0.0293)$ & $(0.0138)$ \\
\hline \multirow[t]{2}{*}{ Sales $>\$ 500,000$} & -0.006 & 0.007 & -0.010 & 0.022 & -0.003 \\
\hline & $(0.0116)$ & $(0.0331)$ & $(0.0190)$ & $(0.0376)$ & $(0.0132)$ \\
\hline \multirow[t]{2}{*}{ Ln(number of medical patients) } & 0.002 & $-0.082^{+}$ & -0.039 & $0.063^{+}$ & 0.001 \\
\hline & $(0.0109)$ & $(0.0467)$ & $(0.0276)$ & $(0.0334)$ & $(0.0172)$ \\
\hline$\overline{R^{2}}$ & 0.937 & 0.777 & 0.933 & 0.909 & 0.925 \\
\hline Observations & 2,048 & 1,536 & 1,312 & 1,536 & 2,048 \\
\hline
\end{tabular}

Notes: Panel A uses a $\{0,1\}$ any sales as the treatment variable, while Panel B compares counties with sales between $\$ 0$ and $\$ 500,000$ or sales $>\$ 500,000$ with counties with zero sales. All regressions include county, month, and year fixed effects. Each column represents a separate regression. The industry subsectors are Construction (Cons), Manufacturing (Manu), Natural Resources and Mining (NR), and Service. Below each column in Panel A, we report the average and weighted average of the $\tau_{k}$ coefficients from the event study, including only the $\tau_{k}$ coefficients for the periods post-dispensary entry. Standard errors are clustered at the county level and are reported in parentheses.

${ }^{+} p<0.1,{ }^{\star} p<0.05,{ }^{\star *} p<0.01$.

We observe that the DID estimates and the average and weighted average coefficients are similar in magnitude, except in the case of the unemployment rate, for which the weighted coefficient is negative but insignificant. ${ }^{21}$

Expanding our $\{0,1\}$ dispensary entry treatment variable to account for the amount of sales in Panel B of Tables 3-5, we do not find that effects are strictly increasing with sales. ${ }^{22}$ The reduction in the unemployment rate and the increase in manufacturing sector employees are greater with entry than with subsequent expansion, as measured by the amount of sales.

21 We note that the tables report $R$-squared values of $\geq 0.97$ for all outcomes except the unemploy ment rate. Year, month, and county fixed effects together account for an $R$-squared value of about 0.88 across specifications (other than unemployment), leaving $\sim 10 \%$ of the variation accounted for by the other variables.

22 Results are robust to other thresholds $(\$ 400,000, \$ 600,000$, and 1,700,000) and are available upon request. (1,700,000 corresponds to the 75 th percentile in sales). 
For the number of unemployed and the number of employees in the service sector, we find that larger recreational cannabis markets generate more significant effects on these outcomes. One possible explanation for the difference across sectors is that labor may be more of a variable cost in the service sector but more fixed in manufacturing. Concerning our primary control variable, the natural log of the number of medical cannabis patients, we find that counties with growing populations of medical patients experience even greater unemployment reductions. However, for manufacturing employees, the natural log of the number of medical patients decreases the effect of dispensary entry, which is consistent with generally smaller effects from expansion of sales than from entry, i.e., newer markets experience greater returns to entry in terms of employment in manufacturing, an industry that may have relatively less variable labor costs. Although the coefficients are similar in some cases for dispensary entry and for the natural log of the number of medical patients, the magnitude of the effect is substantially smaller for the number of medical patients. For example, an increase of $1 \%$ in the number of medical cannabis patients leads to a decrease of $0.187 \%$ in the number of employees in the manufacturing industry. For this decrease to completely negate the positive effect of recreational access, the number of medical patients would have to increase by $68.9 \%$, which never occurs during our sampling period and seems unlikely more generally given the lack of evidence of major changes in the medical market during our sample period, as shown in Figure 1A.

We test the sensitivity of our DID results by considering alternative specifications and samples with the results available in the Online Appendix. More specifically, we run regressions including the natural log of the population (Tables A6-A8 in the Appendix), countymonth fixed effects (Tables A9-A11), and a county-year trend (Tables A12-A14), restricting our sample to omit Denver (Tables A15-A17) and Las Animas (Tables A18-A20). We furthermore include a specification splitting sales into four bins: $\$ 0$ (base); $\$ 0<$ sales $<\$ 250,000$; $\$ 250,000<$ sales $<\$ 500,000 ;$ sales $>\$ 500,000$ in Tables A21-A23. We find that our results are generally robust to these alternative specifications. Including population increases the standard errors for the outcomes for overall and service-providing employees; reduced precision is consistent with population changing in response to cannabis access (Zambiasi and Stillman, 2020). ${ }^{23}$ County-month fixed effects have little effect on the statistical significance or magnitude of the coefficients. However, even though including a county-year trend may be excessive (Angrist and Pischke, 2008; Borusyak and Jaravel; 2017), it does affect the statistical significance and magnitude of some of our coefficients. More specifically, for our dichotomous dispensary entry measure, we lose magnitude and statistical significance for all outcomes except the log of unemployment, which is marginally significant. The sign of the effect continues to be negative for the unemployment rate and the number unemployed and is positive for employees, overall and by sector. The results using sales intensity indicate that, even after controlling for county-year trends, large enough cannabis markets still experience a decrease in the unemployment rate and the number unemployed and show increases in overall employment and employment in the service sector. Our results for manufacturing are statistically insignificant for both treatment measures, although the coefficients are still positive in the presence of a county-year trend. Our results are robust to omission of Denver and Las Animas. Splitting our sales intensity into four bins suggests that an inverted U-shape may exist. Higher sales are

23 We consider migrants as part of the general equilibrium effect on Colorado's labor market. 
associated with a greater effect up to a certain point, after which increasing sales has a diminishing effect on labor market outcomes. We have additional regressions comparing the entrants in the first six months of 2014 with never-selling counties, as well as entrants within the rest of our sample with never-selling counties (Tables A24-A26 and A27-A29 in the Appendix, respectively). Corresponding event studies for early and not-selling counties are shown in Figures A6-A8 and those for late and not-selling counties are shown in Figures A9-A11. These results indicate little difference across these groups of entrants, supporting the consistency of our results over time and documenting that entry effects are similar, even when institutional factors do not constrain entry to specific locations. The effects of early entry appear to exhibit more seasonality, perhaps reflecting a shift toward indoor growing over time. The pre-trend in the unemployment rate does not exist for later entrants, but the beneficial effects of entry are, though still significant, more muted for the number of employees.

Across specifications and subgroups, we see consistent evidence that recreational cannabis dispensary entry leads to a decrease in the unemployment rate and the number of unemployed, as well as an increase in the number of employees overall and for the manufacturing and service sectors, with no effect on wages.

Our results assessing spillovers are presented in Tables 6-8. ${ }^{24}$ These spillover results support the idea that cross-border spillover effects are unlikely to affect our estimates substantially and that using Colorado counties to build our GSC is a valid approach.

Table 6 The effect of recreational dispensary entry and sales on the Unemployment Rate (Unrate), Ln(labor force), and Ln(unemployed) - regression analysis

\begin{tabular}{lccc}
\hline & Unrate & Ln(labor force) & Ln(unemp) \\
\cline { 2 - 4 } & $\mathbf{( 1 )}$ & $\mathbf{( 2 )}$ & $\mathbf{( 3 )}$ \\
\hline Panel A: amount of sales & & & \\
\hline Recreational sale & $-0.689^{\star}$ & -0.002 & $-0.073^{\star \star}$ \\
& $(0.2745)$ & $(0.0131)$ & $(0.0210)$ \\
Recreational sale=1 $<50 \mathrm{~km}$ not-sellingmy $=1$ & 0.014 & 0.010 & 0.015 \\
& $(0.3418)$ & $(0.0132)$ & $(0.0369)$ \\
Ln(number of medical patients) & $-0.622^{\star}$ & -0.006 & -0.026 \\
& $(0.2704)$ & $(0.0126)$ & $(0.0255)$ \\
\hline$R^{2}$ & 0.881 & 0.999 & 0.995 \\
Observations & 6,144 & 6,144 & 6,144 \\
\hline Month FE & & & \\
Year FE & & & \\
County FE & & & \\
\hline
\end{tabular}

Notes: Table reports the $\tau_{k}$ coefficients for $k \geq 0$ from the event study regressions. Each column represents a separate regression. Below the table, we report the average and weighted average of the $\tau_{k}$ coefficients from the event study, including only the $\tau_{k}$ coefficients for the periods post-dispensary entry. Standard errors are clustered at the county level and reported in parentheses.

${ }^{+} p<0.1,{ }^{\star} p<0.05,{ }^{\star \star} p<0.01$.

FE, fixed effect.

24 We run additional analyses using cut-points of 60 and $70 \mathrm{~km}$ as shown in Tables A30-A35. We find limited evidence of positive wage spillovers for the seven counties with dispensary entry that lie within $60 \mathrm{~km}$ of a selling county. The positive wage effect is driven primarily by construction. Manufacturing wages are unaffected. 
Table 7 The effect of recreational dispensary entry and sales on employment - regression analysis

\begin{tabular}{lccccc}
\hline & All & Cons & Manu & NR & Service \\
\cline { 2 - 6 } & $\mathbf{( 1 )}$ & $\mathbf{( 2 )}$ & $\mathbf{( 3 )}$ & $\mathbf{( 4 )}$ & $\mathbf{( 5 )}$ \\
\hline Panel A: amount of sales & & & & & \\
\hline Recreational sale & $0.048^{\star \star}$ & 0.064 & $0.139^{\star \star}$ & -0.021 & $0.043^{\star}$ \\
& $(0.0172)$ & $(0.0599)$ & $(0.0407)$ & $(0.0750)$ & $(0.0167)$ \\
Recreational sale=1 $\times 50 \mathrm{~km}$ & -0.012 & -0.019 & -0.037 & 0.021 & -0.013 \\
not-sellingmy=1 & $(0.0202)$ & $(0.0630)$ & $(0.0487)$ & $(0.0995)$ & $(0.0228)$ \\
Ln(number of medical patients) & -0.022 & $-0.176+$ & $-0.186^{\star \star}$ & 0.170 & -0.026 \\
& $(0.0144)$ & $(0.0906)$ & $(0.0609)$ & $(0.1154)$ & $(0.0180)$ \\
\hline$R^{2}$ & 0.998 & 0.989 & 0.996 & 0.970 & 0.998 \\
Observations & 6,144 & 4,608 & 3,936 & 4,608 & 6,144 \\
\hline \hline Month FE & & & & & \\
Year FE & & & & & \\
County FE & & & & & \\
\hline \hline
\end{tabular}

Notes: Table reports the $\tau_{k}$ coefficients for $k \geq 0$ from the event study regressions. Each column represents a separate regression. Below the table, we report the average and weighted average of the $\tau_{k}$ coefficients from the event study, including only the $\tau_{k}$ coefficients for the periods post-dispensary entry. Standard errors are clustered at the county level and are reported in parentheses. The industry subsectors are Construction (Cons), Manufacturing (Manu), Natural Resources and Mining (NR), and Service.

${ }^{+} p<0.1,{ }^{*} p<0.05,{ }^{\star *} p<0.01$.

$F E$, fixed effect.

As a final check on our DID estimates, we address the issue that testing many hypotheses on the same data increases the probability that at least one test will reject a null hypothesis incorrectly (a false-positive result). ${ }^{25}$ To control for the false discovery rate (FDR), we present the sharpened $q$-values with the original $p$-values noted by Benjamini et al. (2006). We show in Tables A36-A40 that the conclusions of our hypothesis testing do not significantly change after the adjustment of $p$-values controlling the FDR. Therefore, our results are robust to adjusting for multiple inferences.

\subsection{GSC method}

Results from the $\mathrm{SCM}^{26}$ are shown in Figures 5-7. We observe that, prior to opening a dispensary, the treated and the control counties follow the same trajectory. However, after dispensary opening, the trajectory for our counterfactual counties starts to diverge for unemployment rate and manufacturing sector employees. The gaps become significant approximately 1 year after the recreational cannabis sale started. These effects are similar to the effects we observed from our event study graphs. Moreover, from Tables A37-A39 in the Appendix, we observe that the ATT for the unemployment rate is 0.566 , which is close to our DID coefficients from Table 3.

25 Anderson (2008) describes the FDR as the expected proportion of rejections that are Type I errors.

26 We also conduct a falsification test by assigning the treatment to 1 year post-dispensary opening. We find from Figures A10-A12 that our results still hold and the gap between the treated counties and counterfactual starts to increase exactly from " 0 " (1 year post-dispensary opening). 
Table 8 The effect of recreational dispensary entry and sales on wages - regression analysis

\begin{tabular}{lccccc}
\hline & All & Cons & Manu & NR & Service \\
\cline { 2 - 6 } & $\mathbf{( 1 )}$ & $\mathbf{( 2 )}$ & $\mathbf{( 3 )}$ & $\mathbf{( 4 )}$ & $\mathbf{( 5 )}$ \\
\hline Panel A: amount of sales & & & & & \\
\hline Recreational sale & 0.002 & 0.018 & 0.007 & 0.041 & 0.002 \\
& $(0.0114)$ & $(0.0269)$ & $(0.0229)$ & $(0.0326)$ & $(0.0136)$ \\
Recreational sale=1 $\times 50 \mathrm{~km}$ & -0.004 & -0.035 & 0.014 & $-0.051^{*}$ & 0.006 \\
not-sellingmy=1 & $(0.0114)$ & $(0.0363)$ & $(0.0385)$ & $(0.0227)$ & $(0.0140)$ \\
Ln(number of medical patients) & 0.004 & $-0.084^{+}$ & -0.035 & $0.066^{+}$ & 0.002 \\
& $(0.0113)$ & $(0.0459)$ & $(0.0271)$ & $(0.0340)$ & $(0.0173)$ \\
\hline$R^{2}$ & 0.937 & 0.778 & 0.932 & 0.910 & 0.925 \\
Observations & 2,048 & 1,536 & 1,312 & 1,536 & 2,048 \\
\hline \hline Quarter FE & & & & & \\
Year FE & & & & & \\
County FE & & & & & \\
\hline \hline
\end{tabular}

Notes: Table reports the $\tau_{k}$ coefficients for $k \geq 0$ from the event study regressions. Each column represents a separate regression. Below the table, we report the average and weighted average of the $\tau_{k}$ coefficients from the event study, including only the $\tau_{k}$ coefficients for the periods post-dispensary entry. Standard errors are clustered at the county level and reported in parentheses. The industry subsectors are Construction (Cons), Manufacturing (Manu), Natural Resources and Mining (NR), and Service.

${ }^{+} p<0.1,{ }^{*} p<0.05,{ }^{\star *} p<0.01$.

$F E$, fixed effect.

Although we do not find any significant effect for all industry employees, we find manufacturing sector employees in dispensary counties to increase by $13.7 \%$. In addition to the event studies and DID regressions, these results provide evidence of a positive effect of a dispensary opening on the unemployment rate and manufacturing sector employees.

\section{Discussion}

While prior studies have focused on the effects of self-reported cannabis use or state-level medical cannabis legalization on labor outcomes, this study contributes to the literature by exploring the relationship between recreational cannabis dispensary access and labor market outcomes, distinguishing between supply- and demand-side effects. In addition, rather than focus on state-level differences, which a variety of unobservable factors may mediate, we exploit county-level variation in the timing of commencement of sale in Colorado, lending potentially greater internal validity to our results. Furthermore, we assess changes in labor market outcomes across industries, as this has not yet been explored in the literature on illegal, medical, or recreational cannabis legalization and use.

Using a DID estimation strategy and event studies, corroborated by a GSC model, we find consistent evidence of a decrease in unemployment and increases in the number of employees in manufacturing. A large decrease in the unemployment rate suffers from pre-trends in our event studies, but this is supported by the results of the GSC method. Our results showing a 
Figure 5 The effect of recreational dispensary entry on the unemployment rate, Ln(labor force), and Ln(unemployed) - GSC.
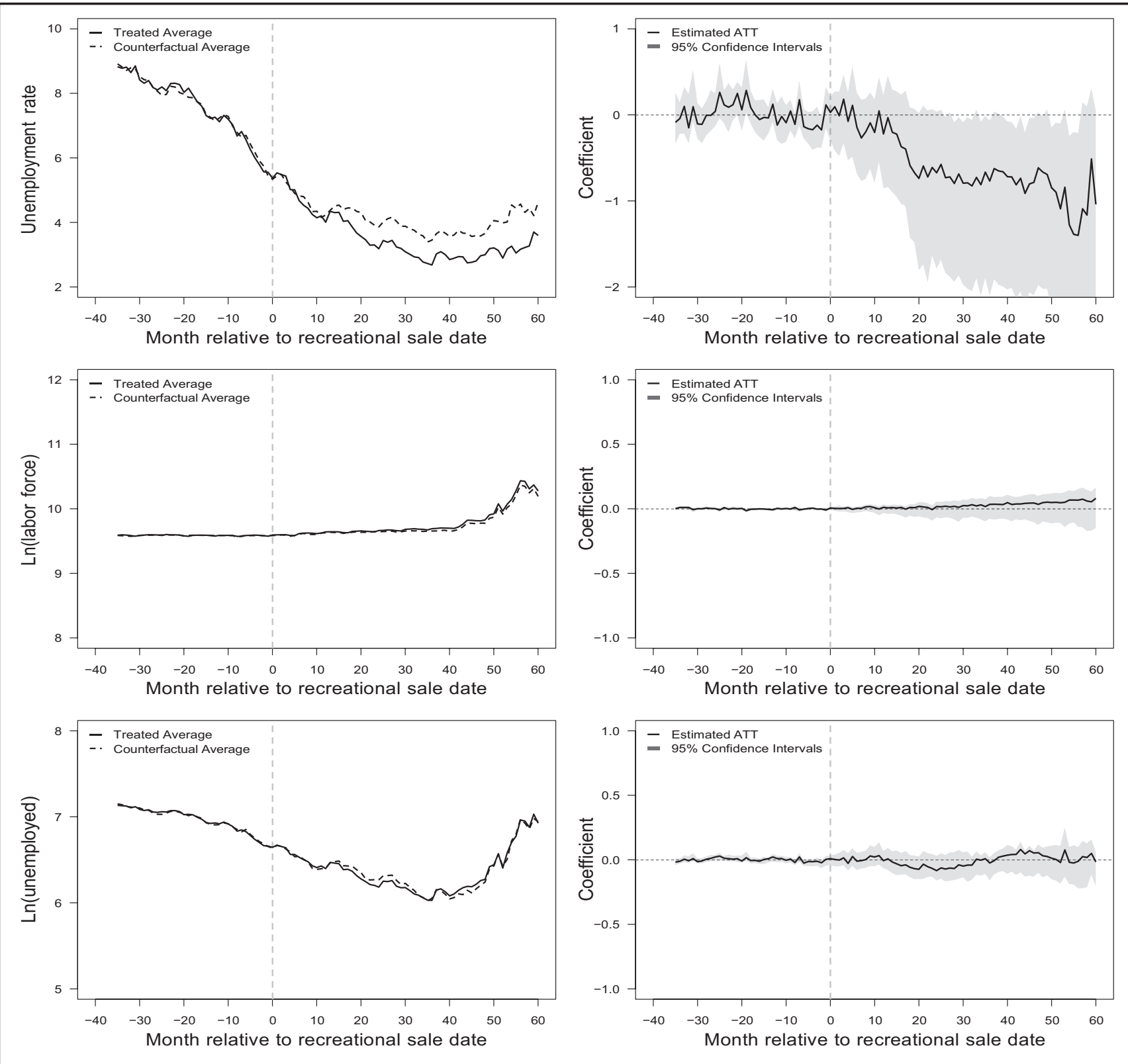

Notes: This figure shows the estimates for the main GSC results with the same set of controls as in the DID estimations. The $x$-axis denotes time with respect to the commencement of the sale. Period 0 is when dispensaries start selling. The path of counties where recreational sale started and counterfactuals are on the left column. The right column shows the difference between the two from the column in terms of months relative to the dispensary sale starting. The standard errors are bootstrapped, and in the mean squared prediction error (MSPE), there is an optimal number of unobserved factors $\left(r^{\star}\right)$ selected from the model. DID, difference-in-differences; GSC, generalized synthetic control.

decrease in the number of unemployed and increases both in the number employed overall and in the service sector are only weakly supported by the synthetic control method results and, in the case of the overall effects, may be somewhat transient. We did not find any effect on the size of the labor force or on average wages overall or by industry sector.

The decrease in unemployment without a change in the size of the labor force suggests a tightening of the labor market driven by demand-side effects rather than by a decrease in labor 
Figure 6 The effect of recreational dispensary entry on employment - GSC.

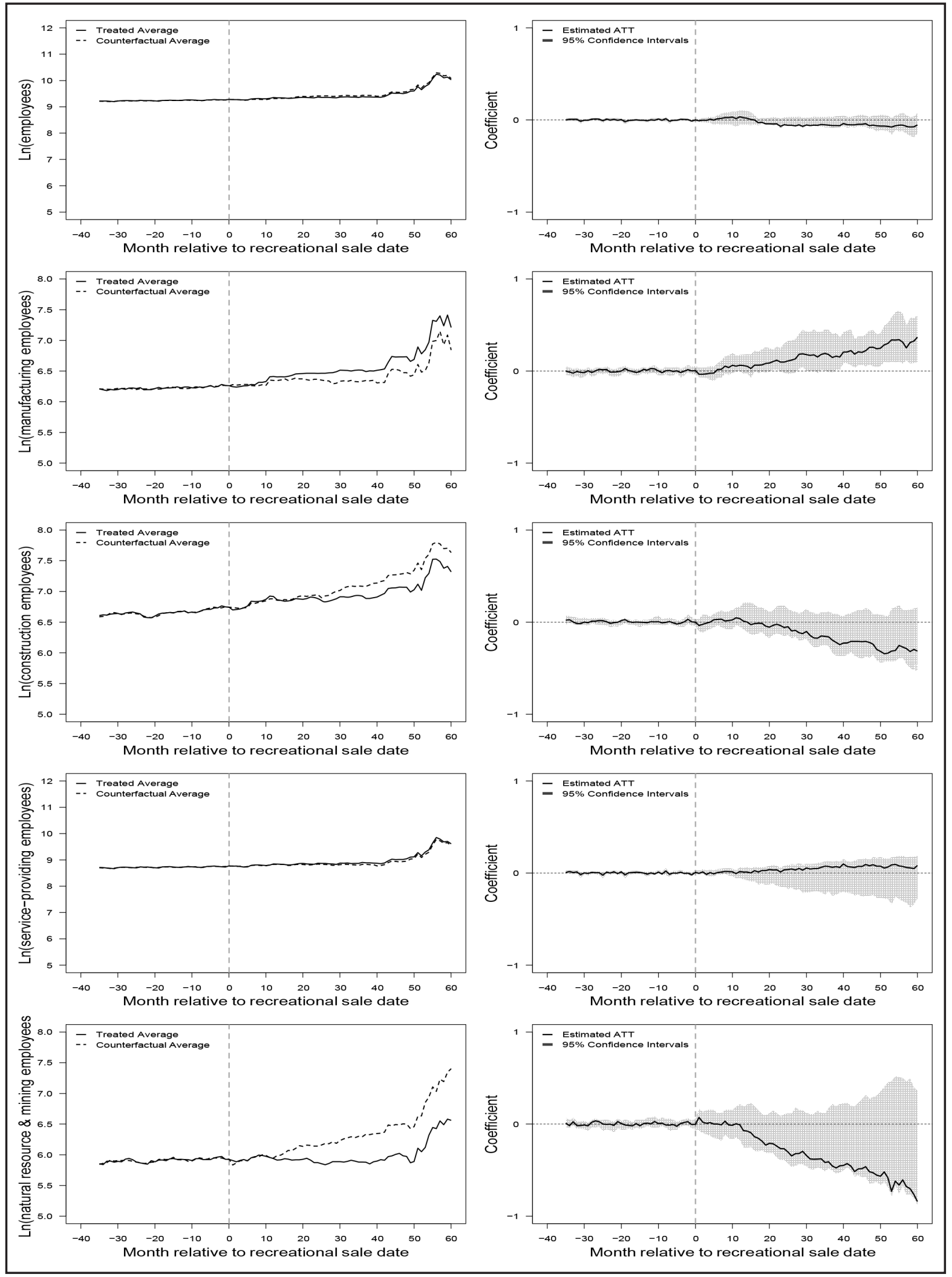

Notes: This figure shows the estimates for the main GSC results with the same set of controls as in the DID estimations. The $x$-axis denotes time with respect to the commencement of the sale. Period 0 is when dispensaries start selling. The path of counties where recreational sale started and counterfactuals are shown on the left column. The right column shows the difference between the two from the column in terms of months relative to the dispensary sale starting. The standard errors are bootstrapped, and in the mean squared prediction error (MSPE), there is an optimal number of unobserved factors $\left(r^{\star}\right)$ selected from the model. DID, difference-in-differences; GSC, generalized synthetic control. 
Figure 7 The effect of recreational dispensary entry on wages - GSC.
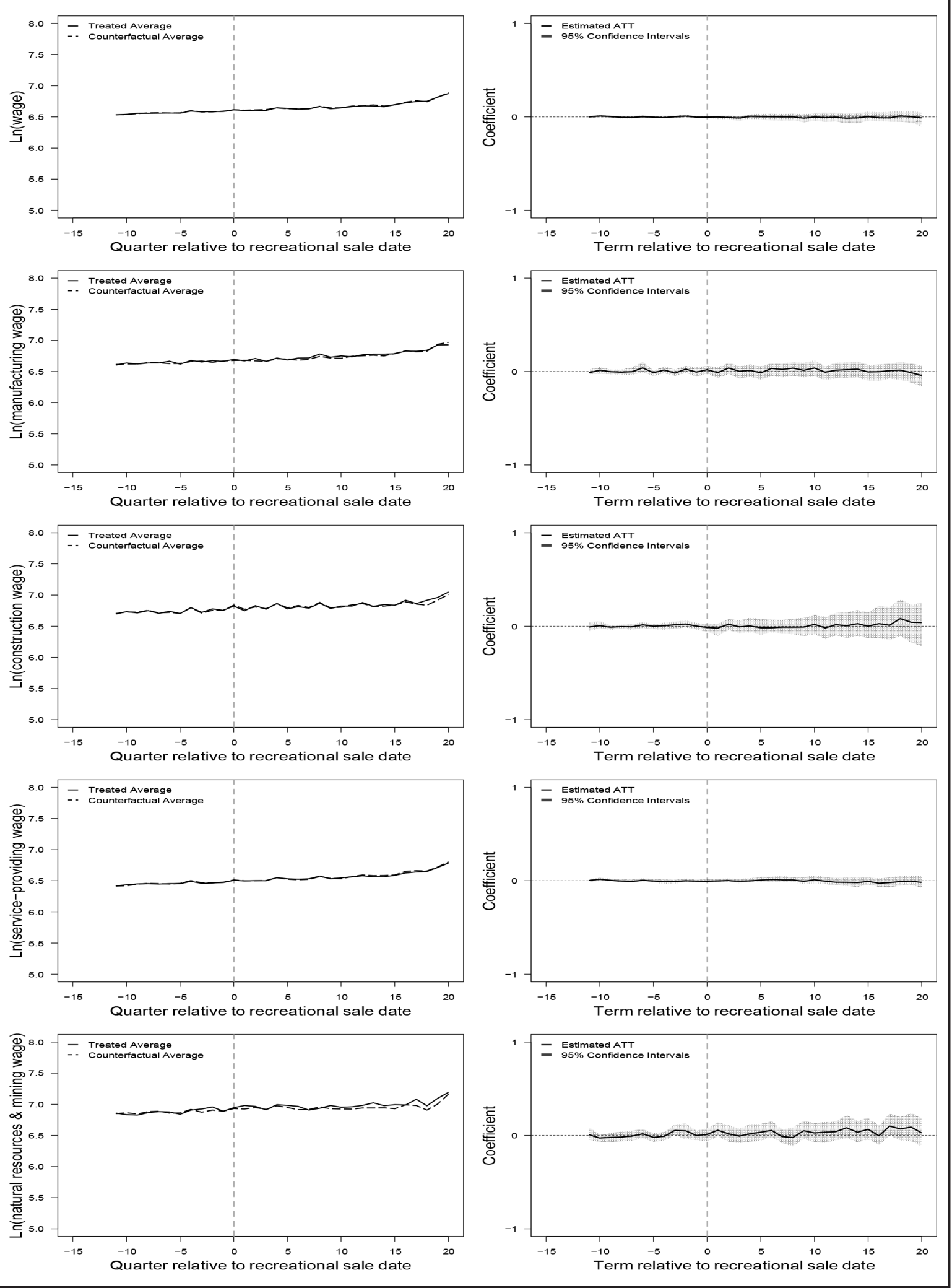

Notes: This figure shows the estimates for the main GSC results with the same set of controls as in the DID estimations. The $x$-axis denotes time with respect to the commencement of the sale. Period 0 is when dispensaries start selling. The path of counties where recreational sale started and counterfactuals are shown on the left column. The right column shows the difference between the two from the column in terms of quarters relative to the dispensary sale starting. The standard errors are bootstrapped, and in the mean squared prediction error (MSPE), there is an optimal number of unobserved factors $\left(r^{\star}\right)$ selected from the model. DID, difference-in-differences; GSC, generalized synthetic control. 
supply. The lack of an effect on wages most likely arises from labor supply continuing to exceed labor demand in excess of frictional unemployment. These results match those found by Sabia and Nguyen (2018) in that we find no overall effect on wages. The lack of an effect on wages also means the tighter labor market is unlikely to negatively affect firms in unrelated industries (Black et al., 2005). Unlike Nicholas and Maclean (2019), we do not find an effect on the size of the labor force. However, this could be explained by their smaller affected population (elderly adults), a likely higher prevalence of medical conditions potentially treatable by cannabis, and a different treatment variable, namely, state-level medical cannabis access, rather than county-level recreational dispensary access in Colorado.

The predominance of the labor demand-side effect could be explained by the limited effects of cannabis on health and labor productivity, but it could also be influenced by the amount of cannabis-related tourism and an illicit market that existed prior to legalization. Tourists do not fill jobs, but they increase demand for primarily recreational, nonmedical cannabis, which - in turn - increases labor demand from recreational cannabis suppliers. Cannabis use by tourists has no effect on the health and productivity of the local labor supply. With respect to the illicit market, if individuals legally purchasing cannabis after legalization previously purchased on the illicit market and did not substantially change their consumption habits, then one would expect little effect on labor supply. As reported by Hunt and Pacula (2017), respondents from the Colorado survey, who had previously bought their cannabis from a "dealer" or "friend", reported purchasing cannabis from either a medical or recreational dispensary after legalization. Potentially reconciling our results with the increased labor supply documented by Nicholas and Maclean (2019), older medical cannabis users may be less likely to be tourists and may be less likely to previously have bought cannabis on the illicit market than those purchasing cannabis from legal recreational dispensaries.

Our findings that cannabis dispensaries can trigger employment growth are in keeping with employment effects from the legalization of another previously illegal activity, namely, gambling. Opening a casino connects residents to a potentially addictive entertainment option while, at the same time, attracting even distant tourists, leading to spillovers into the service sector through effects on leisure and hospitality markets (Cotti, 2008; Reece, 2010; Humphreys and Marchand, 2013; Garrett et al., 2004).

Our industry-level results indicate that the increase in labor demand arose primarily from changes in demand for manufacturing sector employees. Manufacturing effects seem to primarily arise with entry, which could be explained by labor being a relatively a fixed cost in manufacturing. The fact that the magnitude of the effect on employees is larger than the apparent effect on the unemployment rate suggests that self-employed individuals are becoming employed by others. Considering that employees tend to experience greater financial stability, this could be an additional benefit from the labor demand shock induced by recreational cannabis dispensary entry.

This study does have limitations with respect to cross-border travel, substitution between medical and recreational cannabis, and the generalizability of results for future recreational legalization. Although we attempted to assess the magnitude of spillovers by controlling for selling in nearby counties, it is possible that we may still not have completely accounted for all spillovers, somewhat influenced by the manner in which our data were collected. On the demand side, we expect that increased employment occurs through the cannabis industry itself 
and spillovers to related industries that are geographically proximate. However, for the supply side, the potential for cross-county border travel to contaminate our results is much higher. Firms are more localized to a specific county than are workers or the labor force more generally, and cannabis users seem likely to cross borders to purchase cannabis, perhaps affecting labor markets in which dispensaries are not located. The different data sources we use could also lead to differing precision levels with respect to demand versus supply. Our data on employees are derived from payroll information reported by firms in a county, but our data on unemployment and labor force participation rely on household reporting, meaning some affected households may not be showing up as treated because they live in an untreated county but work in a county in which a dispensary entered.

The medical market for cannabis in Colorado was quite mature at the time of recreational cannabis legalization, and graphing sales over time for medical cannabis shows little change with recreational legalization. However, we did find that, while increases in the number of medical patients may augment the effect of recreational dispensary entry on the unemployment rate, an increase in the number of medical patients is associated with a reversal of some of the increase in the number of manufacturing sector employees associated with recreational dispensary entry. The magnitude of the effect from increases in the number of medical patients is much smaller than for recreational dispensary entry, but the opposite sign associated with the number of manufacturing sector employees suggests that markets in which the number of medical patients is growing may experience fewer benefits from dispensary entry, perhaps through market saturation or heterogeneity in the quality of dispensary entrants. Future studies should be conducted to understand the level of substitution between recreational and medical cannabis and how differences in the preexisting structure of the market into which a dispensary enters could lead to different labor market effects from entry.

Lastly, while this study finds that the introduction of a legal recreational cannabis market has a statistically significant impact on the number of employees in counties with dispensaries, this evidence should be extrapolated carefully because the industry's long-term evolution is uncertain and substantial heterogeneity exists in how states are choosing to legalize cannabis (Pacula et al., 2015). If the past is an indicator, states will continue to enact heterogeneous state-level policies with respect to cannabis, even in the presence of federal legalization, meaning that the effects of state-level recreational cannabis laws likely will differ from those experienced by Colorado in line with differences in the underlying laws. The other factor limiting the generalizability of Colorado's experience is that Colorado likely benefited from being one of the first states to legalize recreational cannabis. Even by the end of our sample period in 2018, as we observe from Figure A1 in the Appendix, Colorado was the only state among its neighbors with legal recreational cannabis sales. It is also closer to the Midwest and East Coast than Washington, California, and Oregon, making it the closest cannabis tourism destination for a large portion of the U.S. population. However, by April 2020, Alaska, Massachusetts, Nevada, Michigan, and Illinois also had legal recreational cannabis dispensaries, potentially reducing the labor market benefits of cannabis legalization even within Colorado. 


\section{Conclusion}

In June 2019, Colorado Governor Jared Polis stated concerning the cannabis industry, "It's going very well.... It's creating tens of thousands of jobs, tax revenue for the state, filling up buildings for landlords, and reducing crime..." (Rosenbaum, 2019). Overall, the findings in this paper provide evidence that recreational cannabis dispensaries improved county-level labor market conditions in Colorado. Although some studies in the literature show adverse effects on labor markets, the equilibrium outcomes that we observe suggest that labor demand-side effects have a substantial impact on employment through the creation of jobs in the cannabis industry and associated spillover effects to other industries.

These positive effects on labor markets should be weighed against potential negative effects on public health. However, even the existence of a net negative public health effect from cannabis legalization is not consistently supported by the literature. Van Ours (2020) states that legalizing cannabis will lead to complex outcomes regarding public health but also will increase knowledge of the therapeutic potential of cannabis for mental health. Medical cannabis legalization has been shown to increase consumption (Martins et al., 2016), and excessive use of cannabis may lead to adverse health issues (Van Ours, 2007; Van Ours and Williams 2011, 2012; Van Ours et al., 2013; Volkow et al., 2014; Irons et al., 2014). It seems likely that recreational cannabis access increases use as well. At the same time, even these documented negative effects from use need to be calibrated by the substitution or harm reduction potential of cannabis, which has been shown to decrease the use of more harmful substances, such as alcohol (Baggio et al., 2018; Mark Anderson et al., 2013) and opioids (Vigil et al., 2017; Bradford et al., 2018; Stith et al., 2019; Carrieri et al., 2020), with Carrieri et al. (2020) documenting this effect even for cannabis containing low levels of THC.

Although this study focuses solely on Colorado and is limited by the data available, it represents an important step in understanding the impact of recreational cannabis laws on labor markets. Our results suggest that policymakers considering recreational access to cannabis should consider employment effects as a potential outcome from recreational cannabis legalization but should also account for significant differences for counties with and without recreational dispensaries. As more states are likely to consider legalizing recreational cannabis, understanding how local effects vary with greater access at the regional and national levels is an open question for future research.

\section{References}

Abadie, A.; A. Diamond; J. Hainmueller (2010): Synthetic Control Methods for Comparative Case Studies: Estimating the Effect of California's Tobacco Control Program. Journal of the American Statistical Association 105(490), 493-505.

Abouk, R.; J. C. Maclean; D. Powell (2021): Does Marijuana Legalization Affect Work Capacity? Evidence from Workers' Compensation Benefits. National Bureau of Economic Research, 28471.

Anderson, D. M.; D. I. Rees (2014): The Role of Dispensaries: The Devil is in Details. Journal of Policy Analysis and Management 53(1), 1-7.

Anderson, D. M.; D. I. Rees; J. J. Sabia (2014): Medical Marijuana Laws and Suicides By Gender and Age. American Journal of Public Health 104(12), 2369-2376.

Anderson, D. M.; D. I. Rees; E. Tekin (2018): Medical Marijuana Laws and Workplace Fatalities in the United States. International Journal of Drug Policy 60, 33-39.

Anderson, M. L. (2008): Multiple Inference and Gender Differences in the Effects of Early Intervention: A Reevaluation of the Abecedarian, Perry Preschool, and Early Training Projects. Journal of the American Statistical Association 103(484), 1481-1495. 
Angrist, J. D.; J.-S. Pischke (2008): Mostly Harmless Econometrics: An Empiricist's Companion, Princeton, NJ: Princeton University Press.

Armijo, P. (2019): Southwest Colorado Tourism Rising from the Ashes. https://the-journal.com/articles/140620.

Athey, S.; G. W. Imbens (2021): Design-Based Analysis in Difference-In-Differences Settings with Staggered Adoption. Journal of Econometrics. [Available online 21 April 2021, In Press].

Autor, D. H. (2003): Outsourcing at Will: The Contribution of Unjust Dismissal Doctrine to the Growth of Employment Outsourcing. Journal of Labor Economics 21(1), 1-42.

Baggio, M.; A. Chong: S. Kwon (2018): Marijuana and Alcohol Evidence Using Border Analysis and Retail Sales Data. Available at SSRN 3063288.

Bai, J. (2009): Panel Data Models with Interactive Fixed Effects. Econometrica 77(4), 1229-1279.

Benjamini, Y.; A. M. Krieger; D. Yekutieli (2006): Adaptive Linear Step-up Procedures that Control the False Discovery Rate. Biometrika 93(3), 491-507.

Black, D.; T. McKinnish; S. Sanders (2005): The Economic Impact of the Coal Boom and Bust. The Economic Journal 115(503), 449-476.

Bonn-Miller, M. O.; M. J. Zvolensky; A. Bernstein (2007): Marijuana use Motives: Concurrent Relations to Frequency of Past 30-day Use and Anxiety Sensitivity Among Young Adult Marijuana Smokers. Addictive Behaviors 32(1), 49-62.

Borusyak, K.; X. Jaravel (2017): Revisiting Event Study Designs. Available at SSRN 2826228.

Bradford, A. C.; W. D. Bradford (2017): Factors Driving Diffusion of Medical Marijuana Legalisation in the United States. Drugs, Education, Prevention, and Policy 24, 75-84.

Bradford, A. C.; W. D. Bradford (2018): The Impact of Medical Cannabis Legalization on Prescription Medication Use and Costs Under Medicare Part D. The Journal of Law and Economics 61(3), 461-487.

Bradford, A. C.; W. D. Bradford; A. Abraham; G. B. Adams (2018): Association Between US State Medical Cannabis Laws and Opioid Prescribing in the Medicare Part D Population. JAMA Internal Medicine 178(5), 667672.

Butts, K. (2021): Difference-in-differences Estimation with Spatial Spillovers. arXiv preprint arXiv: 2105.03737.

Carrieri, V.; L. Madio; F. Principe (2019): Light Cannabis and Organized Crime: Evidence from (Unintended) Liberalization in Italy. European Economic Review 113, 63-76.

Carrieri, V.; L. Madio; F. Principe (2020): Do-it-yourself medicine? The Impact of Light Cannabis Liberalization on Prescription Drugs. Journal of Health Economics 74, 102371.

Cengiz, D.; H. Tekgüç (2018): Is it Merely A Labor Supply Shock? Impacts of Syrian Migrants on Local Economies in Turkey. ILR Review p. 0019793920978365.

Centers for Disease Control \& Prevention (2013): Alcohol and Public Health: Alcohol- Related Disease Impact (ARDI): Average for United States 2006-2010: Alcohol- Attributable Deaths Due to Excessive Alcohol Use.

Cerdá, M.; C. Mauro; A. Hamilton; N. S. Levy; J. Santaella-Tenorio; D. Hasin; M. M. Wall; K. M. Keyes; S. S. Martins (2020): Association Between Recreational Mari- Juana Legalization in the United States and Changes in Marijuana Use and Cannabis Use Disorder from 2008 to 2016. JAMA Psychiatry 77(2), 165-171.

Chatterji, P. (2006): Illicit Drug Use and Educational Attainment. Health Economics 15(5), 489-511.

Choi, A.; D. Dave; J. J. Sabia (2019): Smoke Gets in Your Eyes: Medical Marijuana Laws and Tobacco Cigarette Use. American Journal of Health Economics 5(3), 303-333.

Chu, Y.-W. L. (2014): The Effects of Medical Marijuana Laws on Illegal Marijuana Use. Journal of Health Economics 38, 43-61.

Chu, Y.-W. L. (2015): Do Medical Marijuana Laws Increase Hard-drug Use? The Journal of Law and Economics 58(2), 481-517.

Colorado Department of Public Health and Environment. (2019): Medical Marijuana Registry Program Statistics. www.colorado.gov/cdphe/medicalmarijuana

Colorado Department of Revenue, Office of Research and Analysis. (2019): Marijuana sales report. https:// cdor.colorado.gov/data-and-reports/marijuana-data/marijuana-sales-reports

Cook, A. (2021): Saving Lives: The 2006 Expansion of Daylight Saving in Indiana. Journal of Population Economics, 1-31. Available online: https://cdor.colorado.gov/data-and-reports/marijuana-data/marijuana-sales-reports

Cotti, C. (2008): The Effect of Casinos on Local Labor Markets: A County Level Analysis. Journal of Gambling Business and Economics 2(2), 17-41.

De Chaisemartin, C.; X. d'Haultfoeuille (2020): Two-way Fixed Effects Estimators with Heterogeneous Treatment Effects. American Economic Review 110(9), 2964-2996.

Doremus, J. M.; S. S. Stith; J. M. Vigil (2019): Using Recreational Cannabis to Treat insomnia: Evidence from Over-the-counter Sleep Aid Sales in Colorado. Complementary Therapies in Medicine 47, 102207. 
Garrett, T. A. (2004): Casino Gaming and Local Employment Trends. Review-Federal Reserve Bank of Saint Louis 86(1), 9-22.

Ghimire, K. M.; J. C. Maclean (2020): Medical Marijuana and Workers' Compensation Claiming. Health Economics 29(4), 419-434.

Gobillon, L.; T. Magnac (2016): Regional Policy Evaluation: Interactive Fixed Effects and Synthetic Controls. Review of Economics and Statistics 98(3), 535-551.

Goodman-Bacon, A. (2021): Difference-in-differences with Variation in Treatment Timing. Journal of Econometrics 225(2), 254-277.

Hanson, K. L.; J. L. Winward; A. D. Schweinsburg; K. L. Medina; S. A. Brown; S. F. Tapert (2010): Longitudinal Study of Cognition Among Adolescent Marijuana Users Over Three Weeks of Abstinence. Addictive Behaviors 35(11), 970-976.

Hennings, T. (2018): Hand-trimmed vs. Machine-Trimmed Cannabis: Which is Better? https://www.leafly.com/ news/growing/hand-trimmed-vs-machine-trimmed-cannabis-which-is-better.

Humphreys, B. R.; J. Marchand (2013): New Casinos and Local Labor Markets: Evidence from Canada. Labour Economics 24, 151-160.

Hunt, P.; R. L. Pacula (2017): Early Impacts of Marijuana Legalization: an Evaluation of Prices in Colorado and Washington. The Journal of Primary Prevention 38(3), 221- 248.

Irons, J. G.; K. A. Babson; C. L. Bergeria; M. O. Bonn-Miller (2014): Physical Activity and Cannabis Cessation. The American Journal on Addictions 23(5), 485-492.

Jeffrey, B. (2021): Counties with the Most Super Commuters in Colorado. Available online: https://stacker. com/colorado/counties-most-super-commuters-colorado [Accessed, Oct 31, 2021]

Jiang, S.; K. Miller (2021): Watching the Grass Grow: Does Recreational Cannabis Legalization Affect Labor Outcomes? Technical Report, Working Paper.

Kaestner, R. (1994): New Estimates of the Effect of Marijuana and Cocaine use on Wages. ILR Review 47(3), 454-470.

Lee, D. S.; A. Mas (2012): Long-run Impacts of Unions on Firms: New Evidence from Financial Markets, 19611999. The Quarterly Journal of Economics 127(1), 333-378.

Li, X.; J. M. Vigil; S. S. Stith; F. Brockelman; K. Keeling; B. Hall (2019): The Effectiveness of Self-Directed Medical Cannabis Treatment for Pain. Complementary Therapies in Medicine 46, 123-130.

Lovenheim, M. F. (2009): The Effect of Teachers' Unions on Education Production: Evidence from Union Election Certifications in Three Midwestern States. Journal of Labor Economics 27(4), 525-587.

Low, S. A.; A. M. Isserman (2009): Ethanol and the Local Economy: Industry Trends, Location Factors, Economic Impacts, and Risks. Economic Development Quarterly 23(1), 71-88.

MacDonald, Z.; S. Pudney (2000): Illicit Drug Use, Unemployment, and Occupational Attainment. Journal of Health Economics 19(6), 1089-1115.

Maclean, J. C.; K. M. Ghimire; L. H. Nicholas (2021): Marijuana Legalization and Disability Claiming. Health Economics 30, 453-469.

Mäkelä, E. (2017): The Effect of Mass Influx on Labor Markets: Portuguese 1974 Evidence Revisited. European Economic Review 98, 240-263.

Mark Anderson, D.; B. Hansen; D. I. Rees (2013): Medical Marijuana Laws, Traffic Fatalities, and Alcohol Consumption. The Journal of Law and Economics 56(2), 333- 369.

Martins, S. S.; C. M. Mauro; J. Santaella-Tenorio; J. H. Kim; M. Cerda; K. M. Keyes; D. S. Hasin; S. Galea; M. Wall (2016): State-level Medical Marijuana Laws, Marijuana Use and Perceived Availability of Marijuana among the General US Population. Drug and Alcohol Dependence 169, 26-32.

Mitchell, T. (2019): Marijuana Broker Explains Why Weed Prices Rose 60 Percent in One Year. https://www. westword.com/marijuana/Colorado-mountain-town-dispensaries-worth-a-visit-11580651.

Nguyen, H. (2020): Free College? Assessing Enrollment Responses to the Tennessee Promise Program. Labour Economics 66, 101882.

Nicholas, L. H.; J. C. Maclean (2019): The Effect of Medical Marijuana Laws on the Health and Labor Supply of Older Adults: Evidence from the Health and Retirement Study. Journal of Policy Analysis and Management 38(2), 455-480.

Pacula, R. L.; D. Powell; P. Heaton; E. L. Sevigny (2015): Assessing the Effects of Medical Marijuana Laws on Marijuana Use: The Devil is in the Details. Journal of Policy Analysis and Management 34(1), 7-31.

Powell, D.; R. L. Pacula; M. Jacobson (2018): Do Medical Marijuana Laws Reduce Addictions and Deaths Related to Pain Killers? Journal of Health Economics 58, 29-42.

Reece, W. S. (2010): Casinos, Hotels, and Crime. Contemporary Economic Policy 28(2), 145-161.

Register, C. A.; D. R. Williams (1992): Labor Market Effects of Marijuana and Cocaine Use among Young Men. ILR Review 45(3), 435-448. 
Rosenbaum, E. (2019): Colorado Passes \$1 Billion in Marijuana State Revenue. https://www.cnbc. com/2019/06/12/Colorado-passes-1-billion-in-marijuana-state-revenue.html.

Sabia, J. J.; T. T. Nguyen (2018): The Effect of Medical Marijuana Laws on Labor Market Outcomes. The Journal of Law and Economics 61(3), 361-396.

Scholl, L.; P. Seth; M. Kariisa; N. Wilson; G. Baldwin (2019): Drug and Opioid- Involved Overdose DeathsUnited States, 2013-2017. Morbidity and Mortality Weekly Report 67(5152), 1419.

Skorobogatov, A. S. (2021): The Effect of Alcohol Sales Restrictions on Alcohol Poisoning Mortality: Evidence from Russia. Health Economics 30(6), 1417-1442. https://onlinelibrary.wiley.com/doi/abs/10.1002/ hec.4251.

Smith, R. A. (2020a): The Effects of Medical Marijuana Dispensaries on Adverse Opioid Outcomes. Economic Inquiry 58(2), 569-588.

Smith, R. A. (2020b): The Effects of Medical Marijuana Dispensaries on Adverse Opioid Outcomes. Economic Inquiry 58(2), 569-588.

Stith, S. S.; J. M. Vigil (2016): Federal Barriers to Cannabis Research. Science 352(6290), 1182-1182.

Stith, S. S.; J. M. Vigil; F. Brockelman; K. Keeling; B. Hall (2018): Patient-reported symptom Relief Following Medical Cannabis Consumption. Frontiers in Pharmacology 9, 916.

Stith, S. S.; J. M. Vigil; F. Brockelman; K. Keeling; B. Hall (2019): The Association Between Cannabis Product Characteristics and Symptom Relief. Scientific Reports 9(1), 2712.

Ullman, D. F. (2017): The Effect of Medical Marijuana on Sickness Absence. Health Economics 26(10), 1322-1327.

U.S. Department of Health and Human Services (2014). The Health Consequences of Smoking-50 Years of Progress: A Report of the Surgeon General. Atlanta, GA: U.S. Department of Health and Human Services, Centers for Disease Control and Prevention, National Center for Chronic Disease Prevention and Health Promotion, Office on Smoking and Health, 2014.

Van Ours, J. C. (2007): The Effects of Cannabis Use on Wages of Prime-Age Males. Oxford Bulletin of Economics and Statistics 69(5), 619-634.

Van Ours, J. C. (2020): Legalizing Recreational Cannabis Use: A Promising Journey into the Unknown. World Psychiatry 19(2), 196.

Van Ours, J. C.; J. Williams (2011): Cannabis Use and Mental Health Problems. Journal of Applied Econometrics 26(7), 1137-1156.

Van Ours, J. C.; J. Williams (2012): The Effects of Cannabis use on Physical and Mental Health. Journal of Health Economics 31(4), 564-577.

Van Ours, J. C.; J. Williams; D. Fergusson; L. J. Horwood (2013): Cannabis Use and Suicidal Ideation. Journal of Health Economics 32(3), 524-537.

Vigil, J. M.; S. S. Stith, I. M. Adams; A. P. Reeve (2017): Associations between Medical Cannabis and Prescription Opioid Use in Chronic Pain Patients: A Preliminary Cohort Study. PloS ONE 12(11), e0187795.

Vigil, J. M.; S. S. Stith; J. Diviant; F. Brockelman; K. Keeling; B. Hall (2018): Effectiveness of Raw, Natural Medical Cannabis Flower for Treating Insomnia Under Naturalistic Conditions. Medicines 5(3), 75.

Volkow, N. D.; R. D. Baler; W. M. Compton; S. R. Weiss (2014): Adverse Health Effects of Marijuana Use. New England Journal of Medicine 370(23), 2219-2227.

Volkow, N. D.; J. M. Swanson; A. E. Evins; L. E. DeLisi; M. H. Meier; R. Gonzalez; M. A. Bloomfield; H. V. Curran; R. Baler (2016): Effects of Cannabis Use on Human Behavior, Including Cognition, Motivation, and Psychosis: A Review. JAMA Psychiatry 73(3), 292-297.

Wen, H.; J. M. Hockenberry; J. R. Cummings (2015): The Effect of Medical Marijuana Laws on Adolescent and Adult Use of Marijuana, Alcohol, and Other Substances. Journal of Health Economics 42, 64-80.

Williams, J.; J. C. Van Ours (2020): Hazardous or Not? Cannabis Use and Early Labor Market Experiences of Young Men. Health Economics 29(10), 1148-1160.

Winward, J. L.; K. L. Hanson; S. F. Tapert; S. A. Brown (2014): Heavy Alcohol Use, Marijuana Use, and Concomitant Use by Adolescents are Associated with Unique and Shared Cognitive Decrements. Journal of the International Neuropsychological Society 20(8), 784-795.

Xu, Y. (2017): Generalized Synthetic Control Method: Causal Inference with Interactive Fixed Effects Models. Political Analysis 25(1), 57-76.

Zambiasi, D., S. Stillman (2020): The Pot Rush: Is Legalized Marijuana A Positive Local Amenity? Economic Inquiry 58(2), 667-679. 


\section{Online Appendix}

\section{Appendix A: Online-Only Figures}

Figure A1 State Cannabis Laws in 2018.

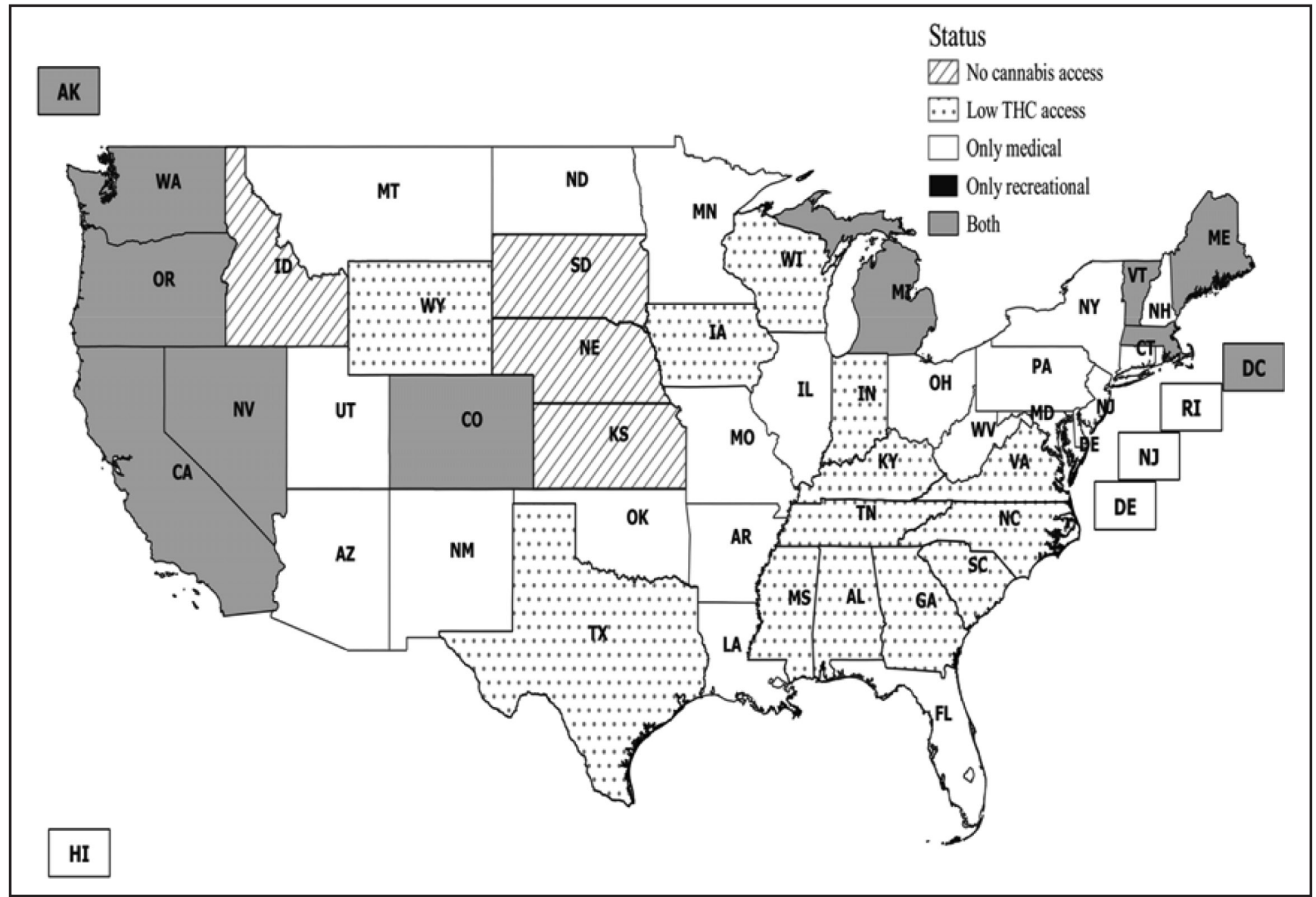

Note: Data were obtained from the National Conference of State Legislatures. 
Figure A2 Counties with cannabis-selling dispensaries.

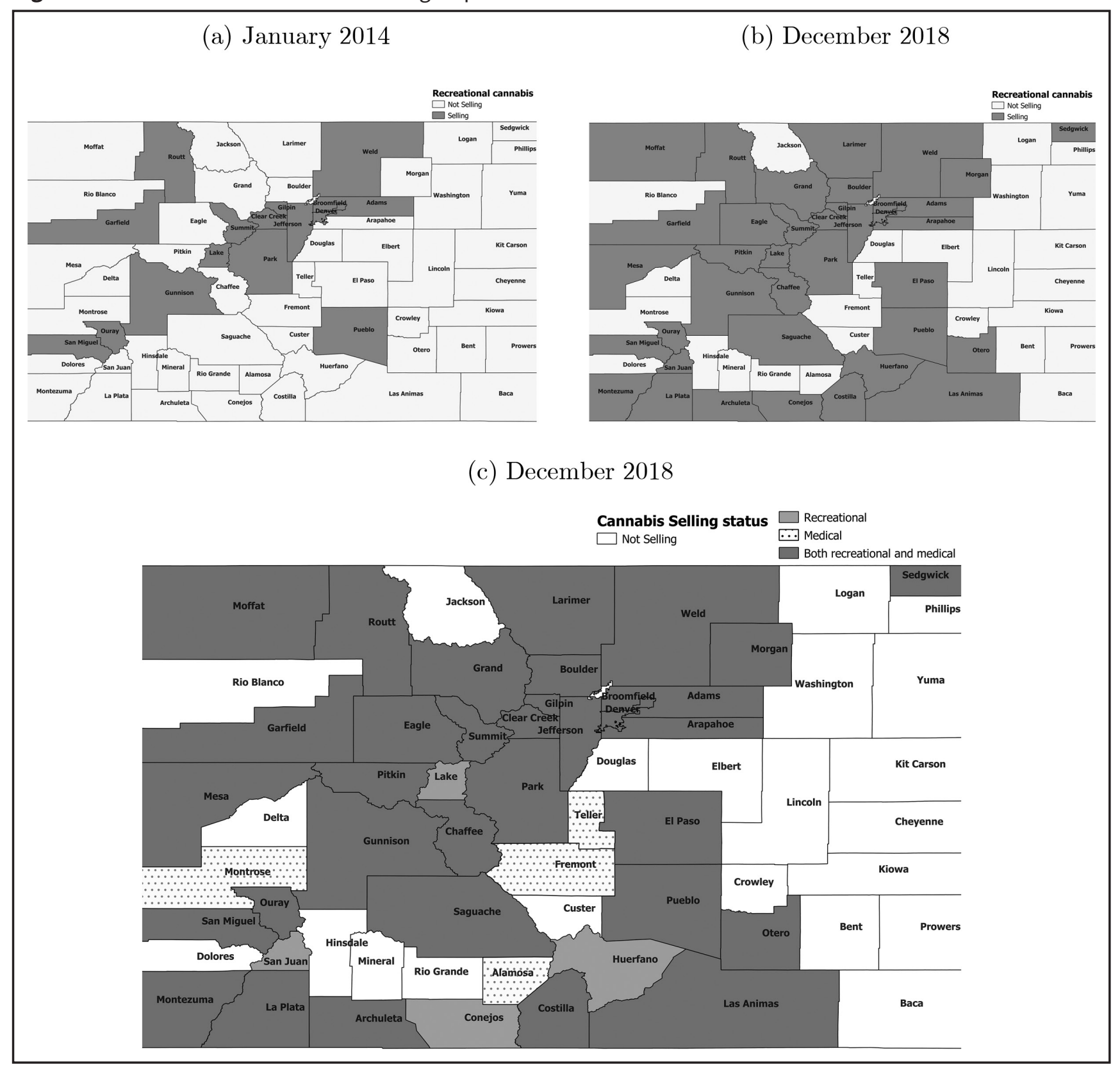

Note: The underlying data were obtained from the Colorado Department of Revenue. 
Figure A3 Unemployment rate, Ln(labor force), and Ln(unemployed) over time.
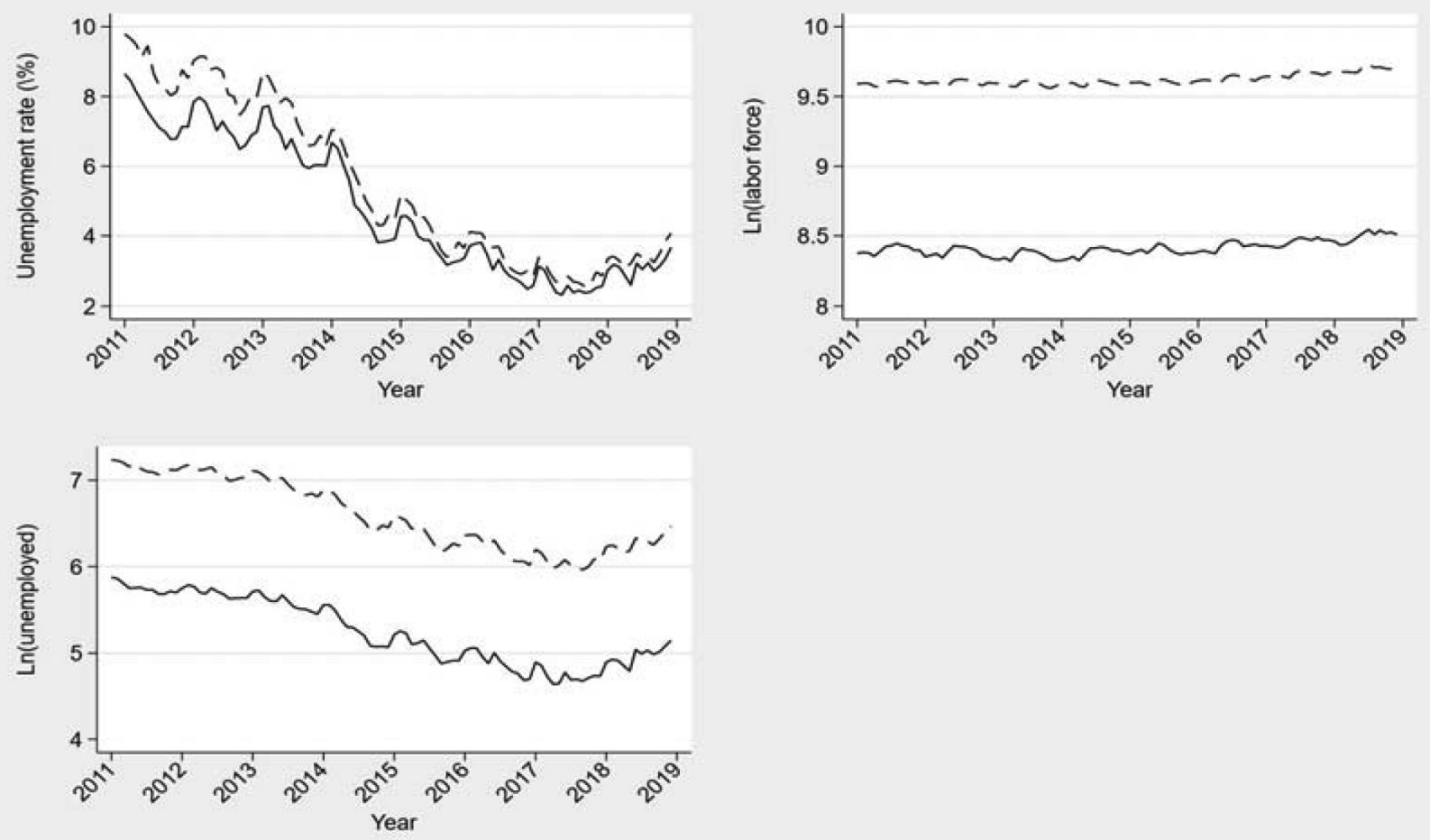

Not-selling counties

- - - - Selling counties

Note: The underlying data were obtained from the Local Area Unemployment Statistics. 
Figure A4 Ln(employees) over time.

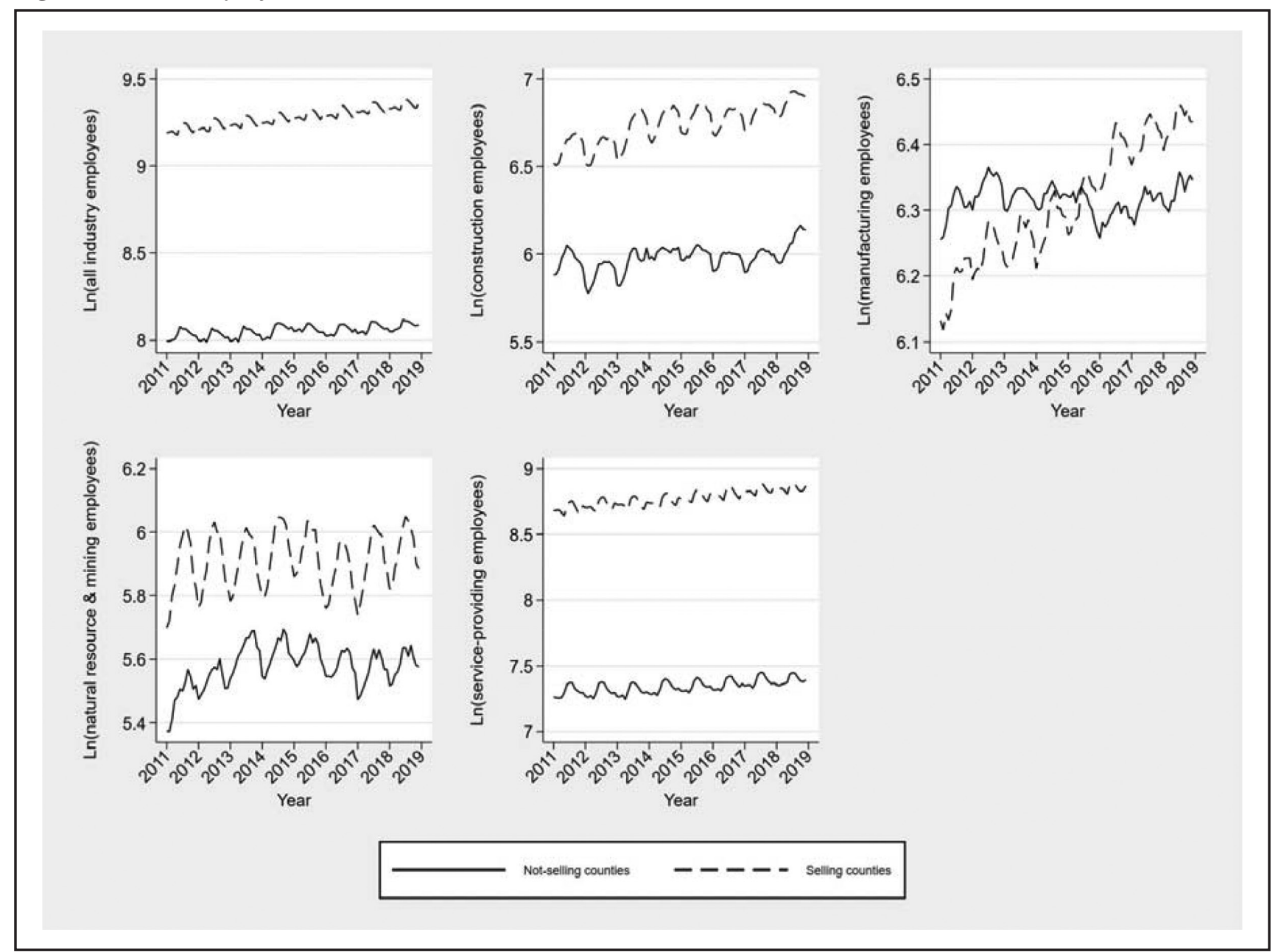

Note: The underlying data were obtained from the Quarterly Census of Employment and Wages. 
Figure A5 Ln(wages) over time.
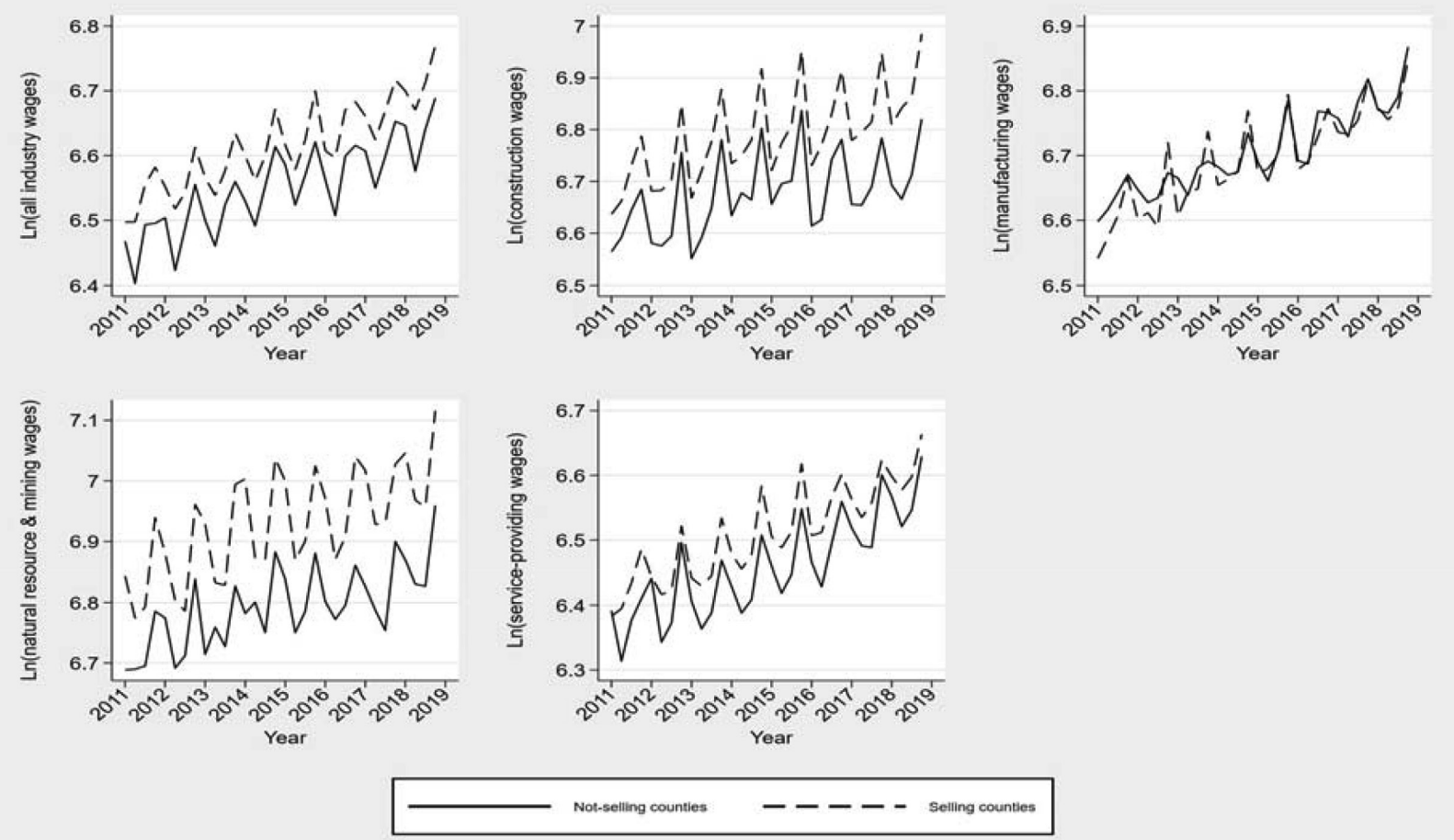

Note: The underlying data were obtained from the Quarterly Census of Employment and Wages. 


\section{Event Study: Early Versus Nonadopters}

Figure A6 Effect of recreational cannabis entry on the unemployment rate, Ln(labor force), and Ln(unemployed) - event study.
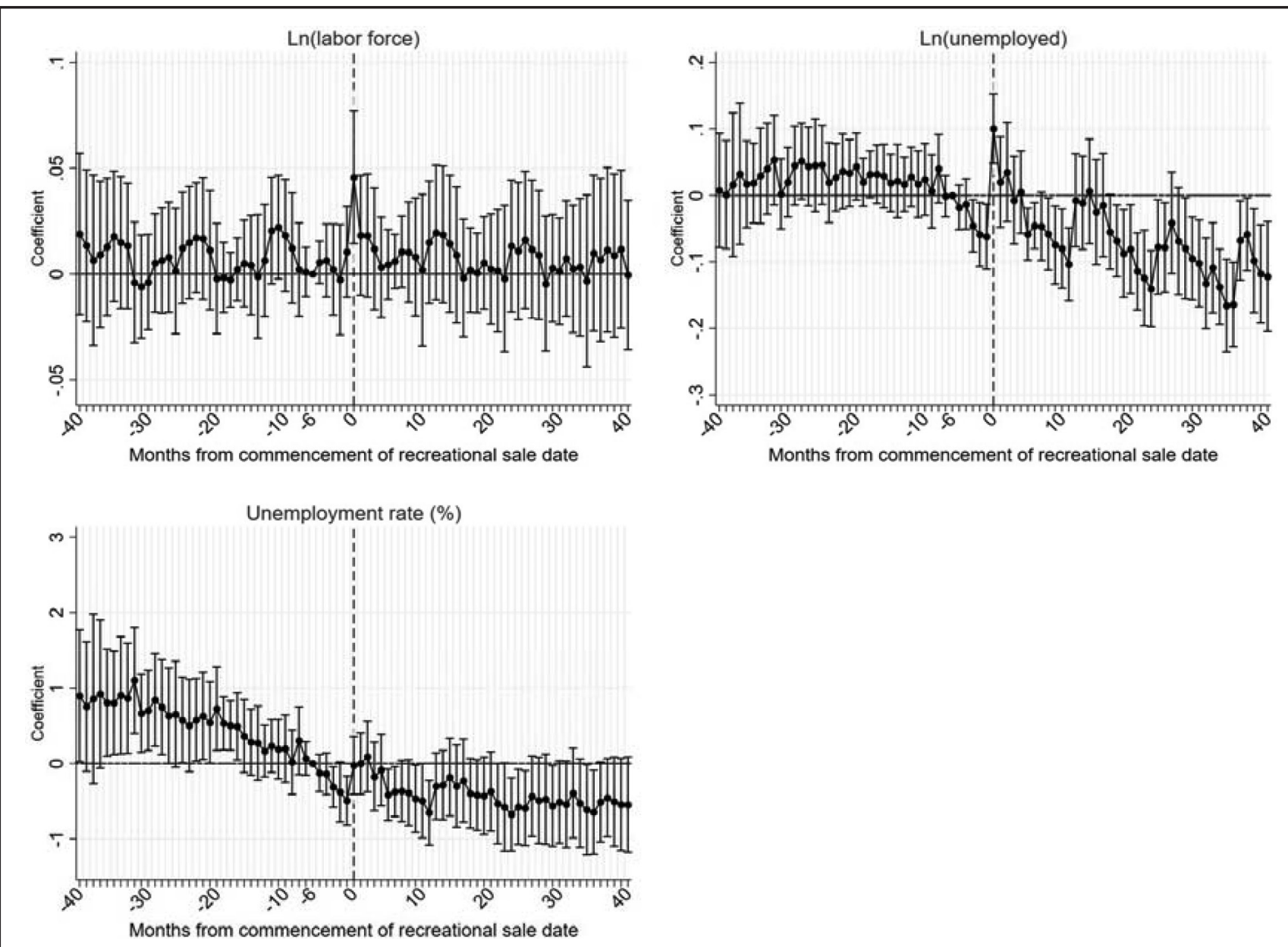

Notes: The points represent the $\tau_{k}$ coefficient estimates from the estimation of Eq. (3), omitting $\tau_{-6}$. The bars extending from each point represent a 95\% confidence interval calculated from the standard errors that are clustered at the county level. There are no standard error bars for the relative half-year $k=-6$ as the plot reflects that zero is imposed rather than estimated. The $x$-axis denotes time with respect to the commencement of the sale. Period 0 is when the sale begins. All regressions include county, month, and year fixed effects. Standard errors are clustered at the county level and reported in parentheses. 
Figure A7 Effect of recreational cannabis entry on Ln(employees) by industry - event study.

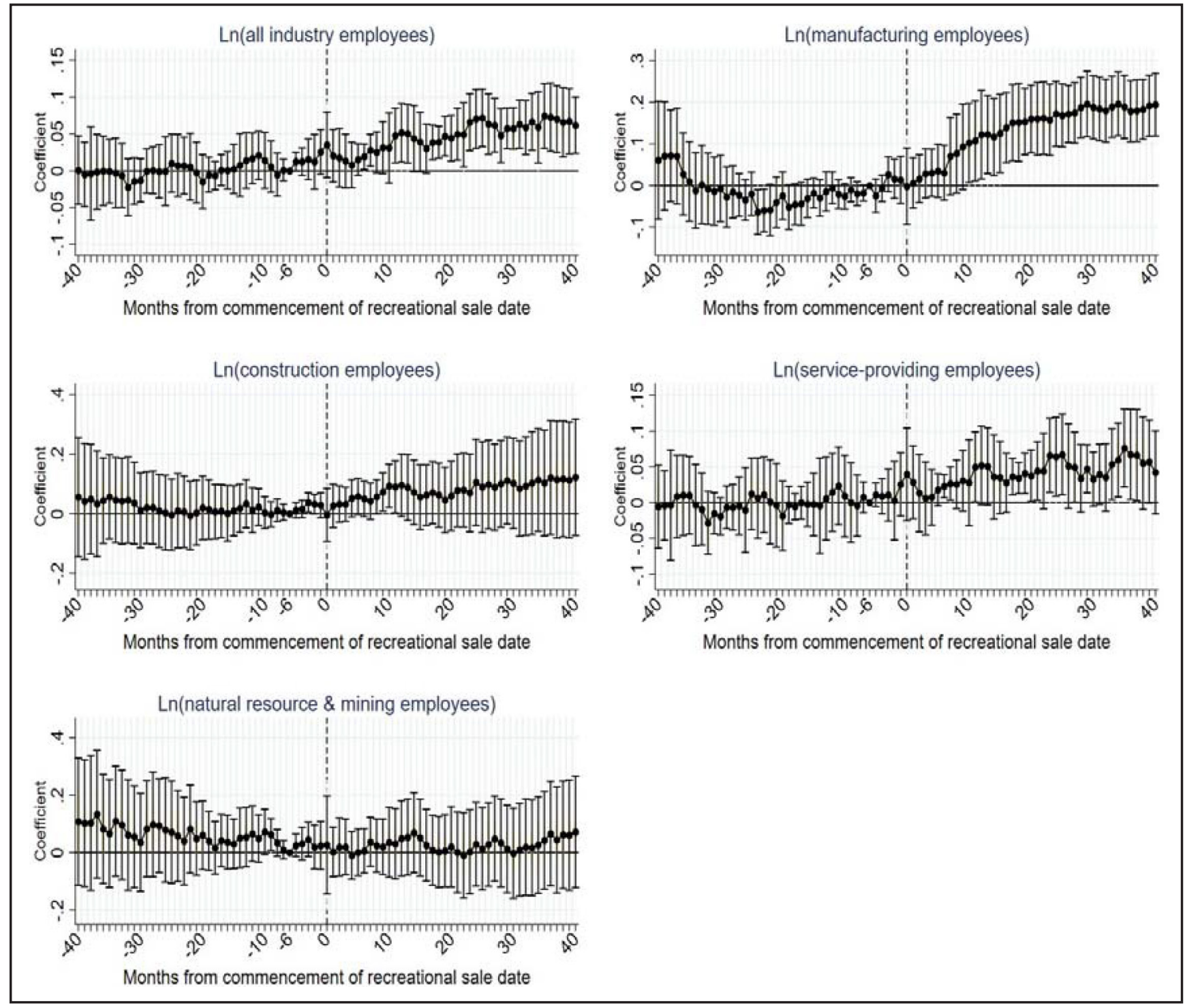

Notes: The points represent the $\tau_{k}$ coefficient estimates from the estimation of Eq. (3), omitting $\tau_{-6}$. The bars extending from each point represent a $95 \%$ confidence interval calculated from the standard errors that are clustered at the county level. There are no standard error bars for the relative half-year $k=-6$ as the plot reflects that zero is imposed rather than estimated. The $x$-axis denotes time with respect to the commencement of the sale. Period 0 is when the sale begins. All regressions include county, month, and year fixed effects. Standard errors are clustered at the county level and reported in parentheses. 
Figure A8 Effect of recreational cannabis entry on Ln(wage) by industry - event study.

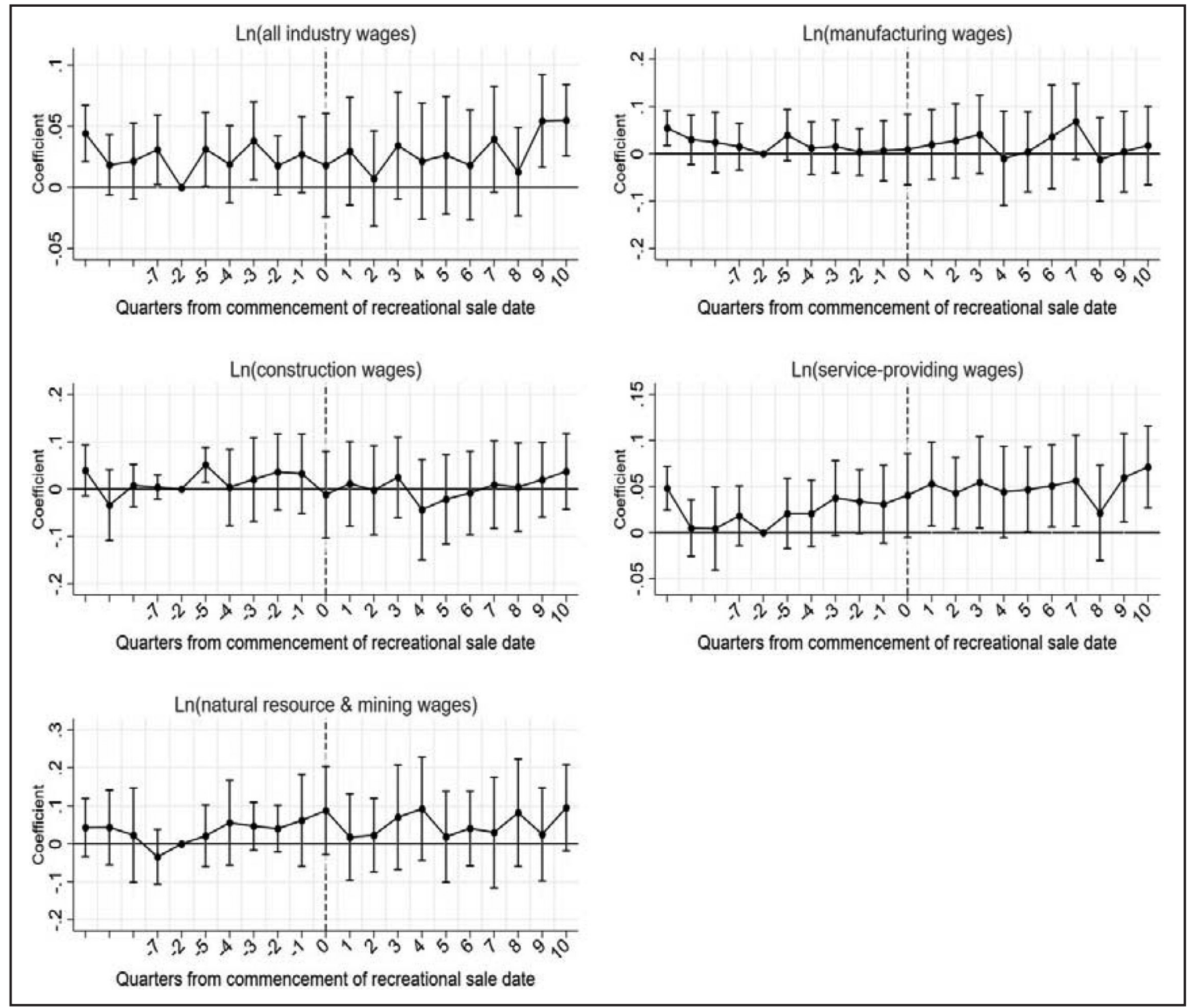

Notes: The points represent the $\tau_{k}$ coefficient estimates from the estimation of Eq. (3), omitting $\tau_{-2}$. The bars extending from each point represent a 95\% confidence interval calculated from the standard errors that are clustered at the county level. There are no standard error bars for the relative half-year $k=-2$ as the plot reflects that zero is imposed rather than estimated. The $x$-axis denotes time with respect to the commencement of the sale. Period 0 is when the sale begins. All regressions include county, month, and year fixed effects. Standard errors are clustered at the county level and reported in parentheses. 


\section{Event Study: Late Versus Nonadopters}

Figure A9 Effect of recreational cannabis entry on the unemployment rate, Ln(labor force), and Ln(unemployed) - event study.

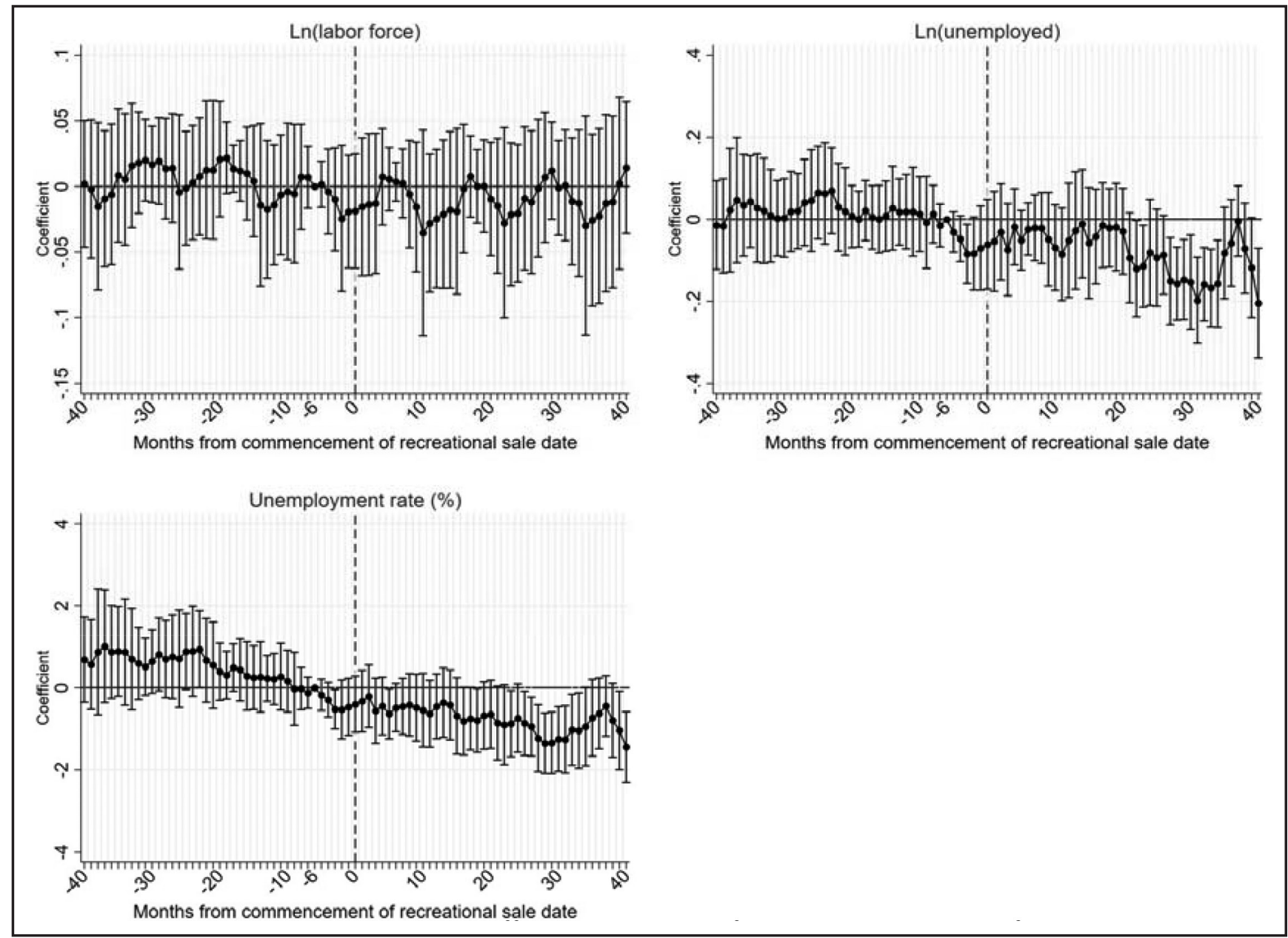

Notes: The points represent the $\tau_{k}$ coefficient estimates from the estimation of Eq. (3), omitting $\tau_{-6}$. The bars extending from each point represent a $95 \%$ confidence interval calculated from the standard errors that are clustered at the county level. There are no standard error bars for the relative half-year $k=-6$ as the plot reflects that zero is imposed rather than estimated. The $x$-axis denotes time with respect to the commencement of the sale. Period 0 is when the sale begins. All regressions include county, month, and year fixed effects. Standard errors are clustered at the county level and reported in parentheses. 
Figure A10 Effect of recreational cannabis entry on Ln(employees) by industry - event study.

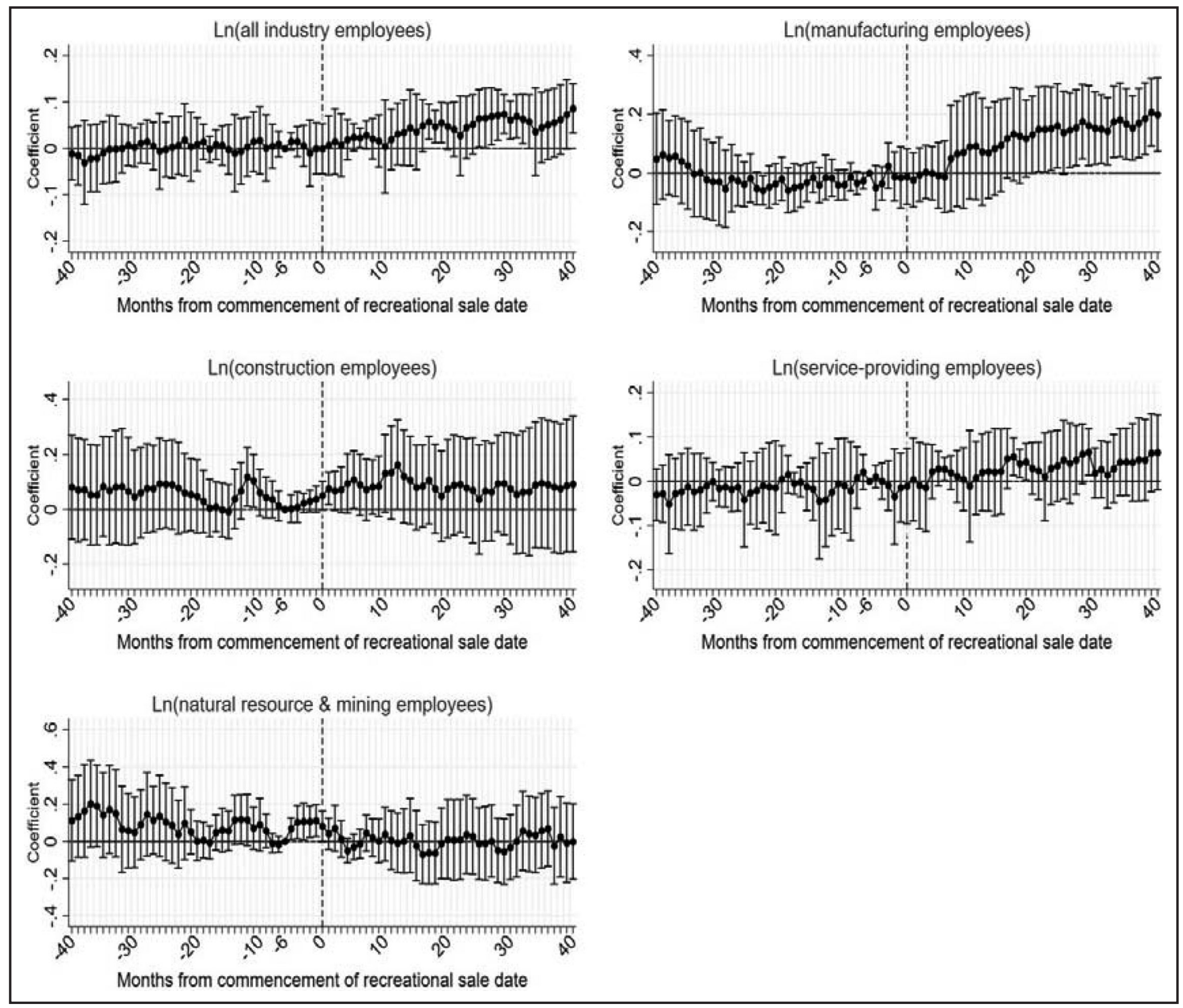

Notes: The points represent the $\tau_{k}$ coefficient estimates from the estimation of Eq. (3), omitting $\tau_{-6}$. The bars extending from each point represent a 95\% confidence interval calculated from the standard errors that are clustered at the county level. There are no standard error bars for the relative half-year $k=-6$ as the plot reflects that zero is imposed rather than estimated. The $x$-axis denotes time with respect to the commencement of the sale. Period 0 is when the sale begins. All regressions include county, month, and year fixed effects. Standard errors are clustered at the county level and reported in parentheses. 
Figure A11 Effect of recreational cannabis entry on Ln(wage) by industry - event study.
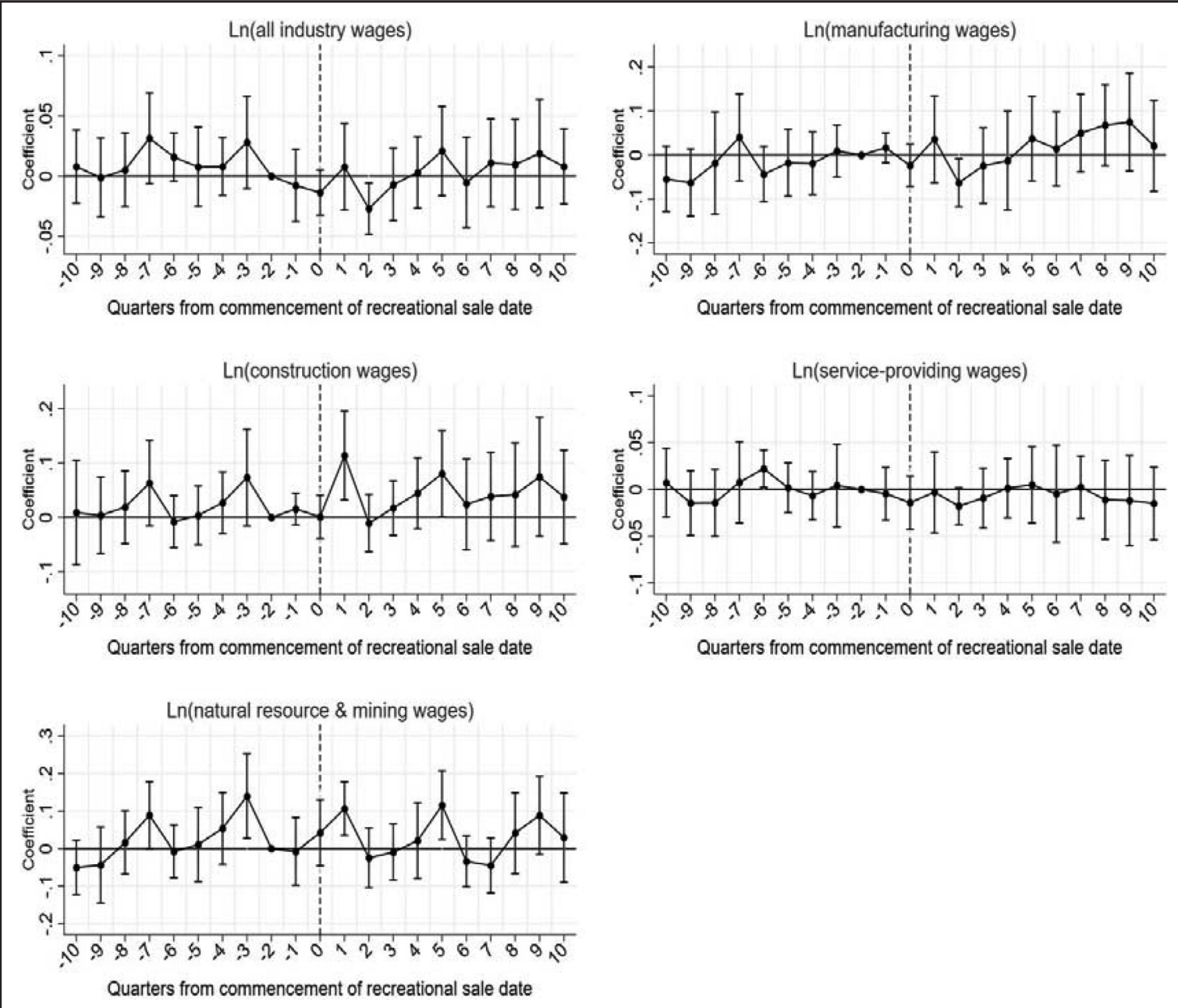

Notes: The points represent the $\tau_{k}$ coefficient estimates from the estimation of Eq. (3), omitting $\tau_{-2}$. The bars extending from each point represent a 95\% confidence interval calculated from the standard errors that are clustered at the county level. There are no standard error bars for the relative half-year $k=-2$ as the plot reflects that zero is imposed rather than estimated. The $x$-axis denotes time with respect to the commencement of the sale. Period 0 is when the sale begins. All regressions include county, month, and year fixed effects. Standard errors are clustered at the county level and reported in parentheses. 


\section{Falsification}

Figure A12 The effect of recreational dispensary entry on the unemployment rate, Ln(labor force), and Ln(unemployed) - GSC.
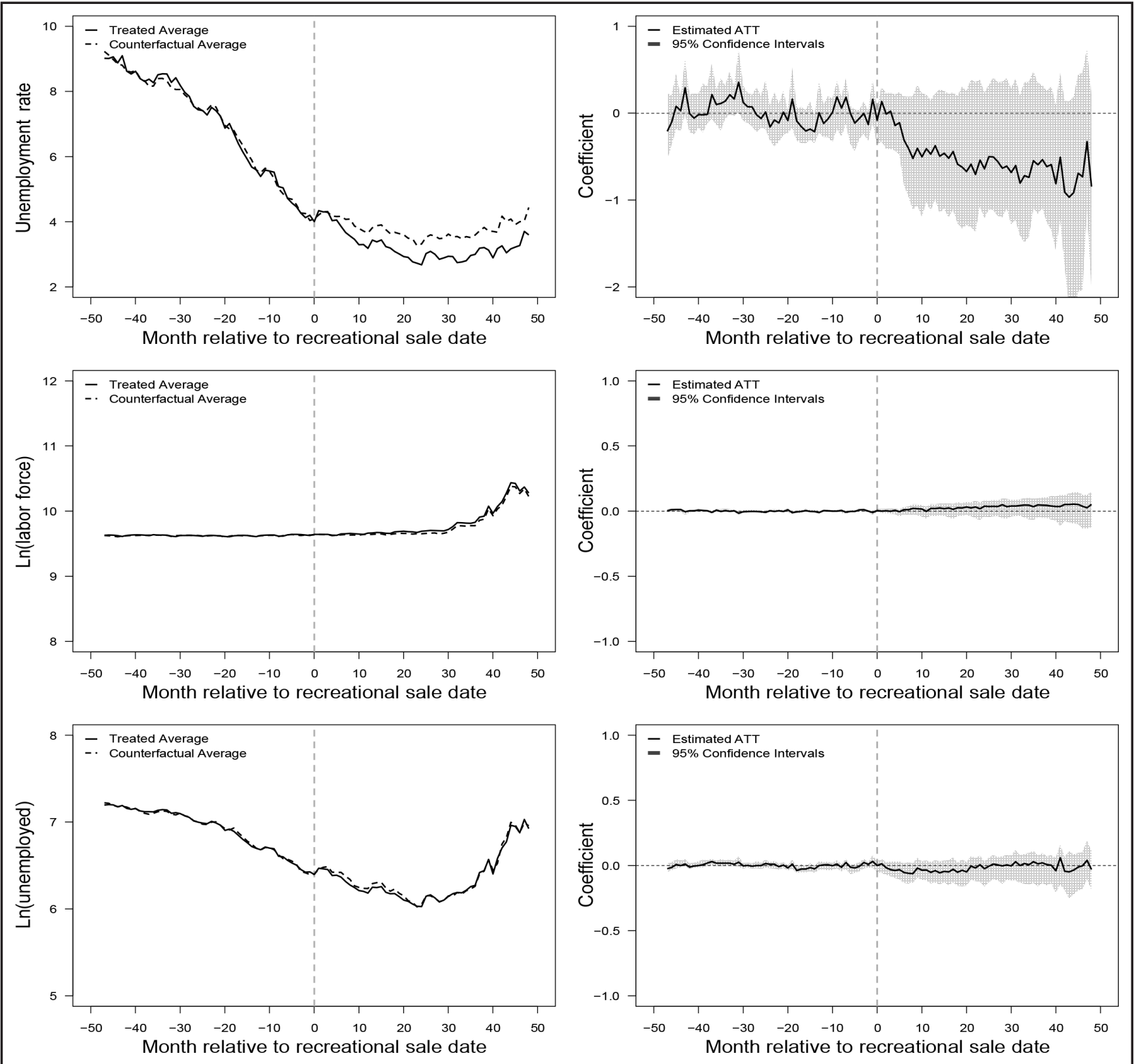

Notes: This figure shows the estimates for the main GSC results with the same set of controls as in the DID estimations. The $x$-axis denotes time with respect to the commencement of the sale. Period 0 is 1 year after dispensaries started selling. The path of counties where recreational sale started and counterfactuals are shown on the left column. The right column shows the difference between the two from the column in terms of months relative to the dispensary sale starting. The standard errors are bootstrapped, and in the mean squared prediction error (MSPE), there is an optimal number of unobserved factors $\left(r^{*}\right)$ selected from the model. DID, difference-in-differences; GSC, generalized synthetic control. 
Figure A13 The effect of recreational dispensary entry on employment - GSC.

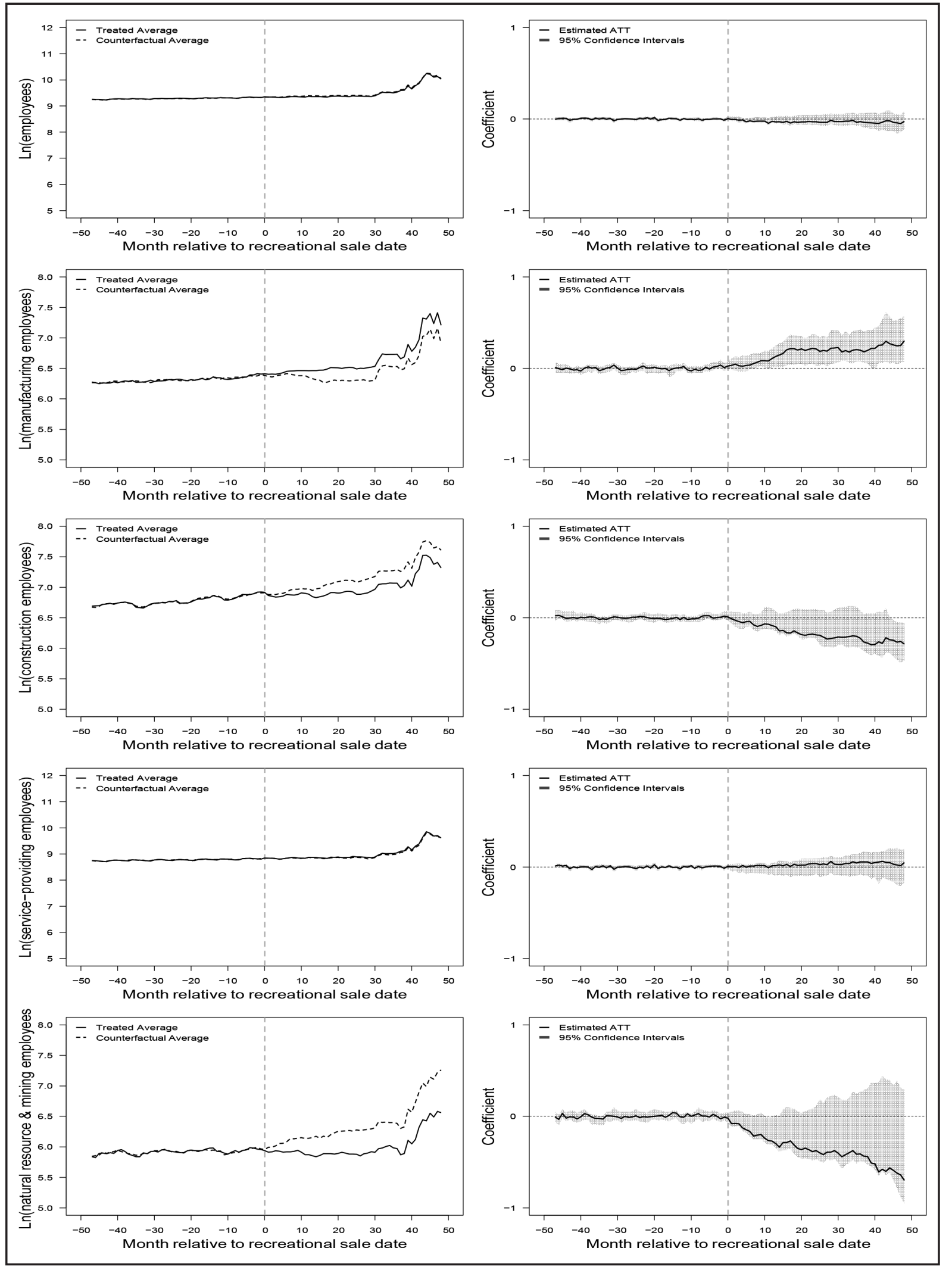

Notes: This figure shows the estimates for the main GSC results with the same set of controls as in the DID estimations. The $x$-axis denotes time with respect to the commencement of the sale. Period 0 is 1 year after dispensaries started selling. The path of counties where recreational sale started and counterfactuals are on the left column. The right column shows the difference between the two from the column in terms of months relative to the dispensary sale starting. The standard errors are bootstrapped, and in the mean squared prediction error s(MSPE), there is an optimal number of unobserved factors $\left(r^{\star}\right)$ selected from the model. DID, difference-in-differences; GSC, generalized synthetic control. 
Figure A14 The effect of recreational dispensary entry on wages - GSC.
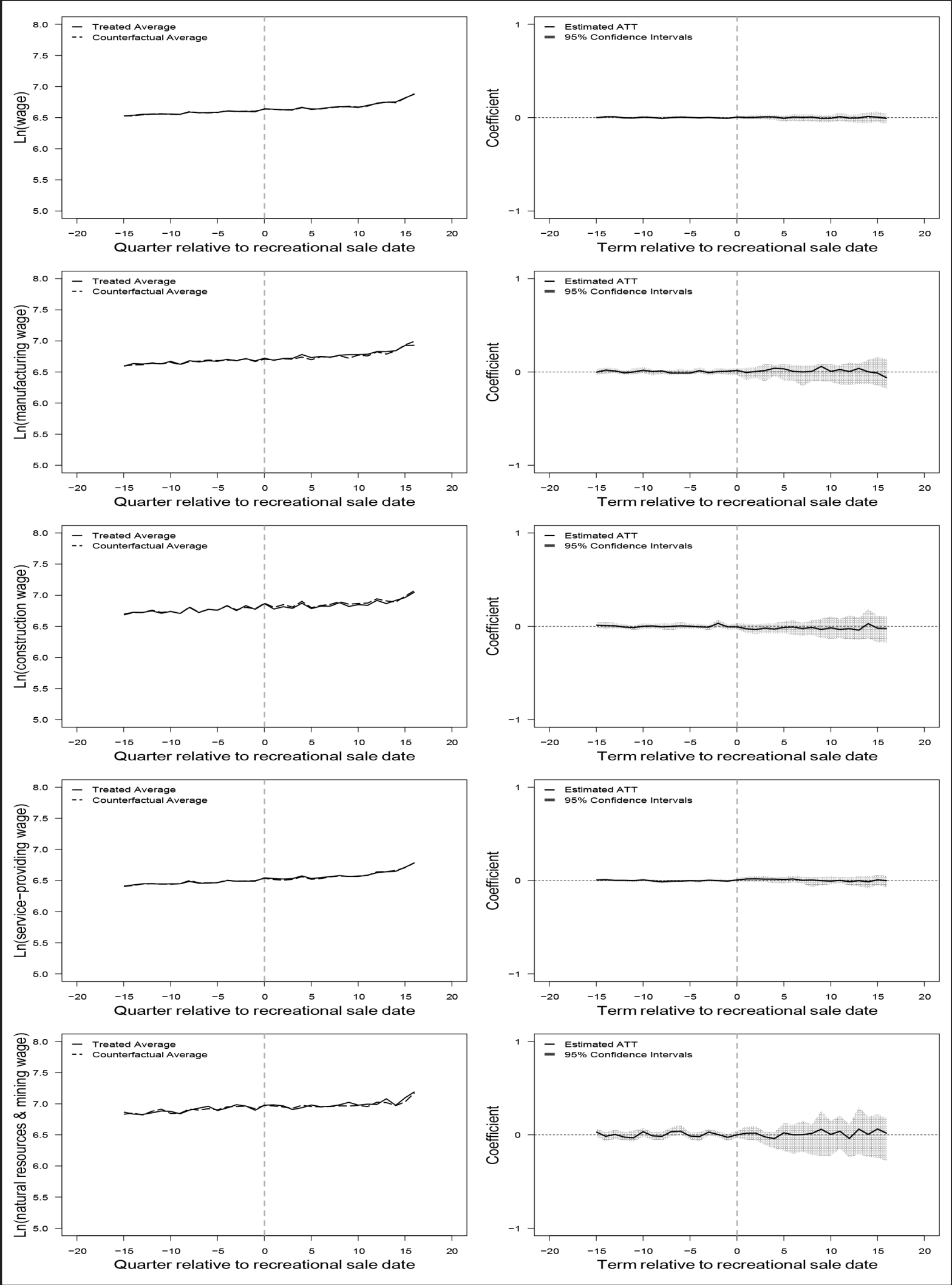

Notes: This figure shows the estimates for the main GSC results with the same set of controls as in the DID estimations. The $x$-axis denotes time with respect to the commencement of the sale. Period 0 is 1 year after dispensaries started selling. The path of counties where recreational sale started and counterfactuals are on the left column. The right column shows the difference between the two from the column in terms of quarter relative to the dispensary sale starting. The standard errors are bootstrapped, and in the mean squared prediction error (MSPE), there is an optimal number of unobserved factors $\left(r^{\star}\right)$ selected from the model. DID, difference-in-differences; GSC, generalized synthetic control. 


\section{Appendix B: Tables}

Table A1 Sources for our variable of interest

\begin{tabular}{lll}
\hline Variable type & Source & Chronology \\
\hline Unemployed, Labor force, and & Local Area Unemployment & Statistics (LAUS) \\
Unemployment rate (2011-2018) & $\begin{array}{l}\text { Quarterly Census of Employment } \\
\text { and Wages (QCEW) }\end{array}$ & \\
Employees and wages (2011-2018) & $\begin{array}{l}\text { Colorado Department of Revenue } \\
\text { (CDOR) }\end{array}$ & Colorado Department of Public \\
Medical cannabis patients (2011-2018) & Health and Environment (CDPHE) & 2010 \\
Population (2011-2018) & United States Census Bureau & 2010 \\
\hline
\end{tabular}

Notes: All variables are monthly, except average wage, which is quarterly. 
Table A2 Descriptive statistics by treatment status

\begin{tabular}{|c|c|c|c|c|c|c|c|c|}
\hline & \multirow{2}{*}{$\begin{array}{c}\text { All } \\
\text { counties }\end{array}$} & \multicolumn{2}{|c|}{ Selling } & \multicolumn{2}{|c|}{ Not selling } & \multicolumn{3}{|c|}{ Differences } \\
\hline & & Before & After & Before & After & Diff & Diff & Diff \\
\hline & (1) & $(2)$ & (3) & (4) & (5) & $(6)=(3)-(2)$ & $(7)=(5)-(4)$ & $(8)=(6)-(7)$ \\
\hline \multicolumn{9}{|l|}{ Panel A: monthly } \\
\hline \multirow[t]{2}{*}{ Unemployment rate, \% } & 5.23 & 7.86 & 3.59 & 7.09 & 3.49 & $-4.268^{\star \star}$ & $-3.605^{\star \star}$ & $-0.663^{\star \star}$ \\
\hline & 6,144 & 1,604 & 1,948 & 972 & 1,620 & & & \\
\hline \multirow[t]{2}{*}{ Ln(labor force) } & 9.11 & 9.48 & 9.74 & 8.38 & 8.43 & $0.258^{\star \star}$ & 0.048 & $0.21^{\star \star}$ \\
\hline & 6,144 & 1,604 & 1,948 & 972 & 1,620 & & & \\
\hline \multirow[t]{2}{*}{ Ln(unemployed) } & 6.02 & 6.89 & 6.35 & 5.68 & 4.99 & $-0.539^{\star \star}$ & $-0.691^{\star \star}$ & $0.152^{\star \star}$ \\
\hline & 6,144 & 1,604 & 1,948 & 972 & 1,620 & & & \\
\hline \multirow[t]{2}{*}{ Ln(all industry employees) } & 8.76 & 9.11 & 9.42 & 8.03 & 8.07 & $0.318^{\star \star}$ & 0.035 & $0.282^{\star \star}$ \\
\hline & 6,144 & 1,604 & 1,948 & 972 & 1,620 & & & \\
\hline \multirow[t]{2}{*}{ Ln(construction employees) } & 6.51 & 6.50 & 6.94 & 5.94 & 6.01 & $0.436^{\star \star}$ & 0.072 & $0.364^{\star \star}$ \\
\hline & 4,608 & 1,416 & 1,752 & 540 & 900 & & & \\
\hline \multirow{2}{*}{$\begin{array}{l}\text { Ln(manufacturing sector } \\
\text { employees) }\end{array}$} & 6.31 & 6.06 & 6.53 & 6.32 & 6.31 & $0.470^{\star *}$ & -0.007 & $0.477^{\star \star}$ \\
\hline & 3,936 & 1,281 & 1,503 & 432 & 720 & & & \\
\hline \multirow{2}{*}{$\begin{array}{l}\text { Ln(natural resource and } \\
\text { mining employees) }\end{array}$} & 5.78 & 5.86 & 5.96 & 5.55 & 5.59 & 0.105 & 0.046 & $0.059^{\star \star}$ \\
\hline & 4,608 & 1,274 & 1,510 & 684 & 1,140 & & & \\
\hline \multirow{2}{*}{$\begin{array}{l}\text { Ln(service-providing } \\
\text { employees) }\end{array}$} & 8.17 & 8.58 & 8.93 & 7.31 & 7.36 & $0.349^{\star \star}$ & 0.056 & $0.293^{\star \star}$ \\
\hline & 6,144 & 1,604 & 1,948 & 972 & 1,620 & & & \\
\hline \multicolumn{9}{|l|}{ Panel B: quarterly } \\
\hline \multirow[t]{2}{*}{$\overline{\text { Ln(all industry wages) }}$} & 6.59 & 6.55 & 6.67 & 6.49 & 6.59 & $0.119^{\star \star}$ & $0.097^{\star \star}$ & $0.021^{\star \star}$ \\
\hline & 2,048 & 527 & 657 & 324 & 540 & & & \\
\hline \multirow[t]{2}{*}{ Ln(construction wages) } & 6.76 & 6.73 & 6.84 & 6.63 & 6.71 & $0.116^{\star \star}$ & $0.075^{\star}$ & $0.041^{\star \star}$ \\
\hline & 1,536 & 466 & 590 & 180 & 300 & & & \\
\hline \multirow[t]{2}{*}{ Ln(manufacturing wages) } & 6.70 & 6.62 & 6.76 & 6.65 & 6.74 & $0.137^{\star \star}$ & $0.091^{+}$ & $0.046^{\star \star}$ \\
\hline & 1,312 & 421 & 507 & 144 & 240 & & & \\
\hline \multirow{2}{*}{$\begin{array}{l}\text { Ln(natural resource and } \\
\text { mining wages) }\end{array}$} & 6.87 & 6.86 & 6.98 & 6.74 & 6.82 & $0.119^{\star \star}$ & $0.081^{+}$ & $0.038^{\star \star}$ \\
\hline & 1,536 & 419 & 509 & 228 & 380 & & & \\
\hline \multirow[t]{2}{*}{ Ln(service-providing wages) } & 6.49 & 6.44 & 6.57 & 6.40 & 6.50 & $0.125^{\star \star}$ & $0.098^{\star \star}$ & $0.027^{\star \star}$ \\
\hline & 2,048 & 527 & 657 & 324 & 540 & & & \\
\hline
\end{tabular}

Notes: The row after each variable represents the number of observations for the respective variable by column. Columns (2) and (3) report means for selling counties, before and after they started selling. Columns (4) and (5) report means for not-selling counties, before and after 2014. Columns (6) and (7) report differences in means from a two-sided $t$-test. Column (8) tests the statistical significance of the difference in the differences between selling counties, $\mu_{1}$ in Column (6), and not-selling counties, $\mu_{2}$ in Column (7) by using a $t$-test. For the $t$-test in Column (8), we obtain $\mu_{1}$ using unadjusted regressions of outcomes on a dummy variable for the start of sale for selling counties and obtain $\mu_{2}$ using unadjusted regressions of outcomes on a dummy variable for post-2014 for not-selling counties. We then calculate a $t$-statistic for the null hypothesis $\mu_{1}-\mu_{2}=0$ by using the pooled variance and number of observations of the two groups. ${ }^{+} p<0.1,{ }^{\star} p<0.05,{ }^{\star \star} p<0.01$. 


\section{Event Study}

Table A3 Event study estimates post-dispensary entry periods

\begin{tabular}{|c|c|c|c|}
\hline & Unrate & Ln(labor force) & Ln(unemp) \\
\hline & (1) & (2) & (3) \\
\hline event0:treat & -0.026 & 0.017 & 0.024 \\
\hline event1:treat & -0.001 & 0.018 & 0.020 \\
\hline event2:treat & 0.090 & 0.018 & 0.035 \\
\hline event3:treat & -0.173 & 0.012 & -0.007 \\
\hline event4:treat & -0.085 & 0.003 & 0.005 \\
\hline event5:treat & $-0.414^{\star}$ & 0.004 & $-0.058^{\star \star}$ \\
\hline event6:treat & $-0.373^{\star}$ & 0.006 & $-0.046^{\star}$ \\
\hline event7:treat & $-0.365+$ & 0.011 & $-0.046+$ \\
\hline event8:treat & $-0.388+$ & 0.010 & $-0.057^{\star}$ \\
\hline event9:treat & $-0.466^{\star}$ & 0.008 & $-0.074^{\star}$ \\
\hline event10:treat & $-0.493^{\star}$ & 0.002 & $-0.079^{\star \star}$ \\
\hline event11:treat & $-0.652^{\star \star}$ & 0.015 & $-0.103^{\star \star}$ \\
\hline event12:treat & -0.300 & 0.020 & -0.008 \\
\hline event13:treat & -0.285 & 0.019 & -0.011 \\
\hline event14:treat & -0.181 & 0.015 & 0.006 \\
\hline event15:treat & -0.299 & 0.009 & -0.025 \\
\hline event16:treat & -0.227 & -0.002 & -0.015 \\
\hline event17:treat & $-0.397+$ & 0.002 & $-0.055+$ \\
\hline event18:treat & $-0.420+$ & 0.001 & $-0.068^{\star}$ \\
\hline event19:treat & $-0.429+$ & 0.005 & $-0.087^{\star}$ \\
\hline event20:treat & -0.370 & 0.003 & $-0.080^{\star}$ \\
\hline event21:treat & $-0.532^{\star}$ & 0.002 & $-0.114^{\star \star}$ \\
\hline event22:treat & $-0.578+$ & -0.002 & $-0.124^{\star \star}$ \\
\hline event23:treat & $-0.674^{\star \star}$ & 0.013 & $-0.140^{\star \star}$ \\
\hline event24:treat & $-0.575^{\star}$ & 0.011 & $-0.078^{\star}$ \\
\hline event25:treat & $-0.592^{\star}$ & 0.016 & $-0.078^{\star}$ \\
\hline event26:treat & -0.434 & 0.012 & -0.041 \\
\hline event27:treat & $-0.489+$ & 0.009 & $-0.069+$ \\
\hline event28:treat & -0.473 & -0.004 & $-0.080^{\star}$ \\
\hline event29:treat & $-0.563^{\star}$ & 0.003 & $-0.095^{\star \star}$ \\
\hline event30:treat & $-0.511+$ & 0.001 & $-0.102^{\star \star}$ \\
\hline event31:treat & $-0.542+$ & 0.007 & $-0.132^{\star \star}$ \\
\hline event32:treat & -0.393 & 0.003 & $-0.108^{\star \star}$ \\
\hline event33:treat & $-0.527+$ & 0.003 & $-0.137^{\star \star}$ \\
\hline event34:treat & $-0.612^{\star}$ & -0.003 & $-0.165^{\star \star}$ \\
\hline event35:treat & $-0.647^{\star}$ & 0.010 & $-0.164^{\star \star}$ \\
\hline event36:treat & $-0.510+$ & 0.006 & $-0.069^{\star}$ \\
\hline event37:treat & $-0.454+$ & 0.011 & $-0.059^{\star}$ \\
\hline event38:treat & $-0.506+$ & 0.009 & $-0.098^{\star}$ \\
\hline event39:treat & $-0.544+$ & 0.012 & $-0.118^{\star \star}$ \\
\hline event40:treat & $-0.545+$ & -0.000 & $-0.122^{\star \star}$ \\
\hline event>40:treat & -0.129 & 0.009 & -0.035 \\
\hline
\end{tabular}

(Continued) 
Table A3 Continued

\begin{tabular}{lccc}
\hline & Unrate & Ln(labor force) & Ln(unemp) \\
\cline { 2 - 4 } & $\mathbf{( 1 )}$ & $\mathbf{( 2 )}$ & $\mathbf{( 3 )}$ \\
\hline Linear combination & & & \\
$\quad$ Coefficient & $-0.407^{\star}$ & 0.008 & $-0.068^{\star *}$ \\
$\quad$ SE & 0.2264 & 0.0125 & 0.0238 \\
Weighted linear combination & & & \\
$\quad$ Coefficient & -0.339 & 0.008 & $-0.060^{\star}$ \\
$\quad$ SE & 0.2433 & 0.0133 & 0.0243 \\
\hline$R^{2}$ & 0.887 & 0.999 & 0.995 \\
Observations & 6,144 & 6,144 & 6,144 \\
\hline
\end{tabular}

Notes: Table reports the $\tau_{k}$ coefficients for $k \geq 0$ from the event study regressions. Each column represents a separate regression. Below the table, we report the average and weighted average of the $\tau_{k}$ coefficients from the event study, including only the $\tau_{k}$ coefficients for periods post-dispensary entry. All regressions include month, year, and county fixed effects. Standard errors are clustered at the county level and reported in parentheses.

${ }^{+} p<0.1,{ }^{\star} p<0.05,{ }^{\star \star} p<0.01$.

FE, fixed effect; SE, standard error; Unrate, unemployment rate. 
Table A4 Event study estimates post-dispensary entry periods for employees, by industry

\begin{tabular}{|c|c|c|c|c|c|}
\hline & All & Cons & Manu & NR & Service \\
\hline & (1) & (2) & (3) & (4) & (5) \\
\hline event0:treat & 0.020 & 0.017 & 0.010 & 0.028 & 0.024 \\
\hline event1:treat & 0.020 & 0.027 & 0.006 & 0.003 & 0.028 \\
\hline event2:treat & 0.017 & 0.033 & 0.016 & 0.020 & 0.013 \\
\hline event3:treat & 0.013 & 0.032 & 0.029 & 0.020 & 0.006 \\
\hline event4:treat & 0.008 & $0.052^{+}$ & 0.030 & -0.010 & 0.008 \\
\hline event5:treat & 0.015 & $0.058^{+}$ & 0.036 & 0.001 & 0.018 \\
\hline event6:treat & $0.019^{\star}$ & $0.050^{+}$ & 0.030 & 0.006 & $0.023^{\star \star}$ \\
\hline event7:treat & $0.028^{*}$ & 0.042 & 0.070 & 0.037 & $0.027^{\star}$ \\
\hline event8:treat & $0.025^{+}$ & $0.057^{\star}$ & 0.077 & 0.025 & 0.026 \\
\hline event9:treat & $0.031^{+}$ & $0.073^{\star}$ & $0.093^{+}$ & 0.020 & 0.031 \\
\hline event10:treat & 0.031 & $0.093^{\star}$ & $0.103^{\star}$ & 0.036 & 0.028 \\
\hline event11:treat & $0.048^{\star}$ & $0.090^{\star}$ & $0.108^{\star}$ & 0.030 & $0.050^{\star}$ \\
\hline event12:treat & $0.052^{*}$ & $0.096^{+}$ & $0.123^{\star}$ & 0.049 & $0.052^{+}$ \\
\hline event13:treat & $0.051^{\star}$ & 0.088 & $0.123^{*}$ & 0.053 & $0.051^{+}$ \\
\hline event14:treat & $0.044^{+}$ & 0.072 & $0.117^{\star}$ & 0.069 & 0.036 \\
\hline event15:treat & $0.039^{+}$ & 0.056 & $0.126^{\star}$ & 0.051 & 0.036 \\
\hline event16:treat & $0.030^{+}$ & 0.063 & $0.140^{\star \star}$ & 0.025 & 0.028 \\
\hline event17:treat & $0.039^{\star \star}$ & 0.071 & $0.152^{\star \star}$ & 0.008 & $0.037^{\star \star}$ \\
\hline event18:treat & $0.039^{\star \star}$ & 0.063 & $0.152^{\star \star}$ & 0.002 & $0.035^{\star \star}$ \\
\hline event19:treat & $0.047^{\star \star}$ & 0.046 & $0.154^{\star \star}$ & 0.006 & $0.041^{\star \star}$ \\
\hline event20:treat & $0.044^{\star \star}$ & 0.060 & $0.160^{\star \star}$ & 0.020 & $0.038^{\star}$ \\
\hline event21:treat & $0.050^{\star \star}$ & 0.079 & $0.161^{\star \star}$ & 0.001 & $0.045^{\star}$ \\
\hline event22:treat & $0.049^{\star}$ & 0.080 & $0.163^{\star \star}$ & -0.010 & $0.045^{+}$ \\
\hline event23:treat & $0.066^{\star \star}$ & 0.070 & $0.158^{\star \star}$ & 0.002 & $0.066^{\star}$ \\
\hline event24:treat & $0.070^{\star \star}$ & 0.106 & $0.173^{\star \star}$ & 0.029 & $0.064^{\star}$ \\
\hline event25:treat & $0.072^{\star \star}$ & 0.090 & $0.169^{\star \star}$ & 0.013 & $0.067^{\star}$ \\
\hline event26:treat & $0.063^{\star \star}$ & 0.098 & $0.172^{\star \star}$ & 0.029 & $0.051^{+}$ \\
\hline event27:treat & $0.062^{\star \star}$ & 0.089 & $0.175^{\star \star}$ & 0.048 & $0.050^{\star}$ \\
\hline event28:treat & $0.048^{\star}$ & 0.101 & $0.188^{\star \star}$ & 0.034 & 0.034 \\
\hline event29:treat & $0.057^{\star \star}$ & 0.112 & $0.197^{\star \star}$ & 0.012 & $0.047^{\star *}$ \\
\hline event30:treat & $0.057^{\star \star}$ & 0.102 & $0.188^{\star \star}$ & -0.003 & $0.033^{+}$ \\
\hline event31:treat & $0.063^{\star \star}$ & 0.085 & $0.185^{\star \star}$ & 0.009 & $0.040^{+}$ \\
\hline event32:treat & $0.059^{\star \star}$ & 0.093 & $0.180^{\star \star}$ & 0.019 & 0.036 \\
\hline event33:treat & $0.067^{\star \star}$ & 0.103 & $0.189^{\star \star}$ & 0.017 & $0.054^{\star}$ \\
\hline event34:treat & $0.059^{\star}$ & 0.114 & $0.197^{\star \star}$ & 0.027 & $0.060^{\star}$ \\
\hline event35:treat & $0.074^{\star \star}$ & 0.103 & $0.189^{\star \star}$ & 0.042 & $0.077^{\star \star}$ \\
\hline event36:treat & $0.073^{\star \star}$ & 0.122 & $0.179^{\star \star}$ & 0.065 & $0.067^{\star}$ \\
\hline event37:treat & $0.070^{\star \star}$ & 0.115 & $0.180^{\star \star}$ & 0.044 & $0.067^{\star}$ \\
\hline event38:treat & $0.066^{\star \star}$ & 0.117 & $0.184^{\star \star}$ & 0.062 & $0.055^{+}$ \\
\hline event39:treat & $0.067^{\star \star}$ & 0.113 & $0.193^{\star \star}$ & 0.060 & $0.057^{+}$ \\
\hline event40:treat & $0.062^{\star \star}$ & 0.123 & $0.195^{\star \star}$ & 0.071 & 0.043 \\
\hline event>40:treat & $0.076^{\star \star}$ & 0.107 & $0.171^{\star \star}$ & 0.105 & $0.054^{+}$ \\
\hline
\end{tabular}


Table A4 Continued

\begin{tabular}{lccccc}
\hline & All & Cons & Manu & NR & Service \\
\cline { 2 - 6 } & $\mathbf{( 1 )}$ & $\mathbf{( 2 )}$ & $\mathbf{( 3 )}$ & $\mathbf{( 4 )}$ & $\mathbf{( 5 )}$ \\
\hline $\begin{array}{l}\text { Linear combination } \\
\quad \text { Coefficient } \\
\quad \text { SE }\end{array}$ & $0.047^{\star}$ & 0.080 & $0.134^{\star \star}$ & 0.028 & $0.042^{\star}$ \\
$\begin{array}{l}\text { Weighted linear combination } \\
\quad \text { Coefficient }\end{array}$ & 0.0145 & 0.0542 & 0.0333 & 0.0563 & 0.0188 \\
$\quad$ SE & $0.054^{\star \star}$ & 0.086 & $0.142^{\star \star}$ & 0.046 & $0.044^{\star}$ \\
\hline $\begin{array}{l}R^{2} \\
\text { Observations }\end{array}$ & 0.0154 & 0.0657 & 0.0328 & 0.0642 & 0.0204 \\
\hline
\end{tabular}

Notes: Table reports the $\tau_{k}$ coefficients for $k \geq 0$ from the event study regressions. Each column represents a separate regression. The industry subsectors are Construction (Cons), Manufacturing (Manu), Natural Resources and Mining (NR), and Service. Below the table, we report the average and weighted average of the $\tau_{k}$ coefficients from the event study, including only the $\tau_{k}$ coefficients for the periods post-dispensary entry. All regressions include month, year, and county fixed effects. Standard errors are clustered at the county level and reported in parentheses.

${ }^{+} p<0.1,{ }^{\star} p<0.05,{ }^{\star \star} p<0.01$.

FE, fixed effect; SE, standard error. 
Table A5 Event study estimates post-dispensary entry periods for wages, by industry

\begin{tabular}{|c|c|c|c|c|c|}
\hline & All & Cons & Manu & NR & Service \\
\hline & (1) & (2) & (3) & (4) & (5) \\
\hline event0:treat & -0.005 & -0.017 & -0.006 & 0.033 & 0.000 \\
\hline event1:treat & 0.008 & $0.041^{+}$ & 0.028 & 0.033 & 0.009 \\
\hline event2:treat & $-0.018^{\star}$ & -0.018 & -0.018 & -0.020 & -0.003 \\
\hline event3:treat & 0.007 & 0.010 & 0.005 & 0.008 & 0.010 \\
\hline event4:treat & 0.011 & -0.016 & -0.002 & 0.029 & 0.015 \\
\hline event5:treat & 0.018 & 0.007 & 0.026 & 0.034 & 0.014 \\
\hline event6:treat & 0.004 & -0.010 & 0.027 & -0.011 & 0.012 \\
\hline event7:treat & $0.023^{\star}$ & 0.010 & $0.059^{\star}$ & -0.027 & 0.020 \\
\hline event8:treat & 0.006 & 0.012 & 0.042 & 0.034 & -0.005 \\
\hline event9:treat & $0.030^{\star}$ & 0.033 & 0.051 & 0.025 & 0.013 \\
\hline event10:treat & $0.027^{\star}$ & 0.030 & 0.026 & 0.045 & 0.017 \\
\hline event $>10$ :treat & 0.018 & 0.029 & 0.023 & 0.039 & -0.004 \\
\hline \multicolumn{6}{|c|}{ Linear combination } \\
\hline Coefficient & 0.011 & 0.009 & 0.022 & 0.019 & 0.008 \\
\hline SE & 0.0076 & 0.0239 & 0.0265 & 0.0269 & 0.0093 \\
\hline \multicolumn{6}{|c|}{ Weighted linear combination } \\
\hline Coefficient & 0.013 & 0.017 & 0.022 & 0.026 & 0.004 \\
\hline SE & 0.0092 & 0.0314 & 0.0298 & 0.0323 & 0.0105 \\
\hline$\overline{R^{2}}$ & 0.938 & 0.780 & 0.933 & 0.910 & 0.925 \\
\hline Observations & 2,048 & 1,536 & 1,312 & 1,536 & 2,048 \\
\hline
\end{tabular}

Notes: Table reports the $\tau_{k}$ coefficients for $k \geq 0$ from the event study regressions. Each column represents a separate regression. The industry subsectors are Construction (Cons), Manufacturing (Manu), Natural Resources and Mining (NR), and Service. Below the table, we report the average and weighted average of the $\tau_{k}$ coefficients from the event study, including only the $\tau_{k}$ coefficients for the periods post-dispensary entry. All regressions include month, year, and county fixed effects. Standard errors are clustered at the county level and reported in parentheses.

${ }^{+} p<0.1,{ }^{\star} p<0.05,{ }^{\star \star} p<0.01$.

FE, fixed effect; SE, standard error. 


\section{Robustness with Qualifying Sample}

\section{Including population}

Table A6 The effect of recreational dispensary entry and sales on the unemployment rate, Ln(labor force), and Ln(unemployed) - regression analysis

\begin{tabular}{lccc}
\hline & Unrate & Ln(labor force) & Ln(unemp) \\
\cline { 2 - 4 } & $\mathbf{( 1 )}$ & $\mathbf{( 2 )}$ & $\mathbf{( 3 )}$ \\
\hline Panel A: start of sales & & & \\
\hline Recreational sale & $-0.718^{\star \star}$ & -0.014 & $-0.078^{\star \star}$ \\
& $(0.2428)$ & $(0.0105)$ & $(0.0200)$ \\
Ln(number of medical patients) & $-0.607^{\star}$ & 0.001 & -0.021 \\
& $(0.2714)$ & $(0.0111)$ & $(0.0250)$ \\
Ln(population) & 1.158 & $0.531^{\star \star}$ & $0.338^{+}$ \\
& $(2.4361)$ & $(0.1261)$ & $(0.1900)$ \\
\hline$R^{2}$ & 0.882 & 0.999 & 0.995 \\
Observations & 6,144 & 6,144 & 6,144 \\
\hline Panel B: amount of sales & & & \\
\hline \$0 sales $\leq \$ 500,000$ & $-0.752^{\star \star}$ & -0.009 & $-0.066^{\star \star}$ \\
(0.2720) & $(0.0099)$ & $(0.0224)$ & \\
Sales $>$ \$500,000 & $-0.669^{\star \star}$ & -0.021 & $-0.094^{\star \star}$ \\
(0.2515) & $(0.0125)$ & $(0.0251)$ & \\
Ln(number of medical patients) & $-0.601^{\star \star}$ & 0.000 & -0.023 \\
& $(0.2737)$ & $(0.0108)$ & $(0.0260)$ \\
Ln(population) & 1.069 & $0.543^{\star \star}$ & $0.369^{+}$ \\
& $(2.4483)$ & $(0.1276)$ & $(0.1872)$ \\
\hline$R^{2}$ & 0.882 & 0.999 & 0.995 \\
Observations & 6,144 & 6,144 & 6,144 \\
\hline
\end{tabular}

Notes: Panel A uses a $\{0,1\}$ any sales as the treatment variable, while Panel B compares counties with sales between $\$ 0$ and $\$ 500,000$ or sales $>\$ 500,000$ with counties with zero sales. Each column represents a separate regression. All regressions include month, year, and county fixed effects. Standard errors are clustered at the county level and reported in parentheses.

${ }^{+} p<0.1,{ }^{\star} p<0.05,{ }^{\star \star} p<0.01$.

Unrate, unemployment rate. 
Table A7 The effect of recreational dispensary entry and sales on employment-regression analysis

\begin{tabular}{|c|c|c|c|c|c|}
\hline & All & Cons & Manu & NR & Service \\
\hline & (1) & (2) & (3) & (4) & (5) \\
\hline \multicolumn{6}{|l|}{ Panel A: start of sales } \\
\hline Recreational sale & $\begin{array}{c}0.016 \\
(0.0120)\end{array}$ & $\begin{array}{c}0.020 \\
(0.0633)\end{array}$ & $\begin{array}{c}0.113^{\star \star} \\
(0.0396)\end{array}$ & $\begin{array}{l}-0.066 \\
(0.0712)\end{array}$ & $\begin{array}{c}0.014 \\
(0.0132)\end{array}$ \\
\hline Ln(number of medical patients) & $\begin{array}{l}-0.010 \\
(0.0128)\end{array}$ & $\begin{array}{l}-0.130 \\
(0.0904)\end{array}$ & $\begin{array}{c}-0.166^{\star \star} \\
(0.0541)\end{array}$ & $\begin{array}{l}0.205 \\
(0.1224)\end{array}$ & $\begin{array}{c}-0.015 \\
(0.0158)\end{array}$ \\
\hline Ln(population) & $\begin{array}{c}0.953^{\star *} \\
(0.1578)\end{array}$ & $\begin{array}{c}1.993^{+} \\
(1.0110)\end{array}$ & $\begin{array}{c}0.732 \\
(0.5178) \\
\end{array}$ & $\begin{array}{l}1.576 \\
(1.0049)\end{array}$ & $\begin{array}{r}0.834^{\star \star} \\
(0.1491)\end{array}$ \\
\hline$\overline{R^{2}}$ & 0.998 & 0.989 & 0.996 & 0.970 & 0.998 \\
\hline Observations & 6,144 & 4,608 & 3,936 & 4,608 & 6,144 \\
\hline \multicolumn{6}{|l|}{ Panel B: amount of sales } \\
\hline$\$ 0<$ sales $\leq \$ 500,000$ & $\begin{array}{l}0.007 \\
(0.0138)\end{array}$ & $\begin{array}{l}0.022 \\
(0.0550)\end{array}$ & $\begin{array}{c}0.133^{\star \star} \\
(0.0403)\end{array}$ & $\begin{array}{l}-0.074 \\
(0.0693)\end{array}$ & $\begin{array}{l}0.006 \\
(0.0159)\end{array}$ \\
\hline Sales $>\$ 500,000$ & $\begin{array}{c}0.029^{\star \star} \\
(0.0136)\end{array}$ & $\begin{array}{l}0.017 \\
(0.0757)\end{array}$ & $\begin{array}{c}0.086^{+} \\
(0.0434)\end{array}$ & $\begin{array}{l}-0.057 \\
(0.0860)\end{array}$ & $\begin{array}{c}0.026^{+} \\
(0.0142)\end{array}$ \\
\hline Ln(number of medical patients) & $\begin{array}{l}-0.009 \\
(0.0132)\end{array}$ & $\begin{array}{l}-0.130 \\
(0.0901)\end{array}$ & $\begin{array}{c}-0.171^{\star \star} \\
(0.0522)\end{array}$ & $\begin{array}{l}0.206^{+} \\
(0.1222)\end{array}$ & $\begin{array}{l}-0.014 \\
(0.0159)\end{array}$ \\
\hline Ln(population) & $\begin{array}{r}0.930^{\star *} \\
(0.1612) \\
\end{array}$ & $\begin{array}{c}1.996^{+} \\
(1.0238) \\
\end{array}$ & $\begin{array}{c}0.777 \\
(0.5181) \\
\end{array}$ & $\begin{array}{l}1.561 \\
(1.0195) \\
\end{array}$ & $\begin{array}{c}0.813^{\star \star} \\
(0.1507) \\
\end{array}$ \\
\hline$\overline{R^{2}}$ & 0.998 & 0.989 & 0.996 & 0.970 & 0.998 \\
\hline Observations & 6,144 & 4,608 & 3,936 & 4,608 & 6,144 \\
\hline
\end{tabular}

Notes: Panel A uses a $\{0,1\}$ any sales as the treatment variable, while Panel B compares counties with sales between $\$ 0$ and $\$ 500,000$ or sales $>\$ 500,000$ with counties with zero sales. Each column represents a separate regression. The industry subsectors are Construction (Cons), Manufacturing (Manu), Natural Resources and Mining (NR), and Service. All regressions include month, year, and county fixed effects. Standard errors are clustered at the county level and reported in parentheses.

${ }^{+} p<0.1,{ }^{\star} p<0.05,{ }^{\star *} p<0.01$. 
Table A8 The effect of recreational dispensary entry and sales on wages - regression analysis

\begin{tabular}{lccccc}
\hline & All & Cons & Manu & NR & Service \\
\cline { 2 - 6 } & $\mathbf{( 1 )}$ & $\mathbf{( 2 )}$ & $\mathbf{( 3 )}$ & $\mathbf{( 4 )}$ & $\mathbf{( 5 )}$ \\
\hline Panel A: start of sales & & & & & \\
\hline Recreational sale & -0.005 & 0.001 & 0.019 & 0.037 & -0.004 \\
& $(0.0093)$ & $(0.0290)$ & $(0.0192)$ & $(0.0347)$ & $(0.0116)$ \\
Ln(number of medical patients) & 0.006 & -0.074 & -0.046 & 0.055 & 0.006 \\
& $(0.0118)$ & $(0.0452)$ & $(0.0282)$ & $(0.0343)$ & $(0.0193)$ \\
Ln(population) & 0.191 & 0.359 & -0.391 & -0.368 & $0.291^{+}$ \\
& $(0.1207)$ & $(0.4475)$ & $(0.2890)$ & $(0.2931)$ & $(0.1620)$ \\
\hline$R^{2}$ & 0.937 & 0.778 & 0.933 & 0.910 & 0.926 \\
Observations & 2,048 & 1,536 & 1,312 & 1,536 & 2,048 \\
\hline Panel B: amount of sales & & & & & \\
\hline \$0< sales $\leq \$ 500,000$ & 0.001 & 0.003 & 0.032 & 0.038 & 0.002 \\
& $(0.0100)$ & $(0.0273)$ & $(0.0245)$ & $(0.0318)$ & $(0.0127)$ \\
Sales >\$500,000 & -0.014 & -0.001 & 0.000 & 0.036 & -0.014 \\
Ln(number of medical patients) & $(0.0108)$ & $(0.0364)$ & $(0.0173)$ & $(0.0420)$ & $(0.0125)$ \\
& 0.005 & -0.074 & $-0.049^{+}$ & 0.055 & 0.005 \\
Ln(population) & $(0.0114)$ & $(0.0453)$ & $(0.0281)$ & $(0.0341)$ & $(0.0189)$ \\
& $0.208^{+}$ & 0.362 & -0.358 & -0.366 & $0.310^{+}$ \\
& $(0.1213)$ & $(0.4527)$ & $(0.2822)$ & $(0.2991)$ & $(0.1615)$ \\
\hline$R^{2}$ & 0.937 & 0.778 & 0.933 & 0.910 & 0.926 \\
Observations & 2,048 & 1,536 & 1,312 & 1,536 & 2,048 \\
\hline
\end{tabular}

Notes: Panel A uses a $\{0,1\}$ any sales as the treatment variable, while Panel B compares counties with sales between $\$ 0$ and $\$ 500,000$ or sales $>\$ 500,000$ with counties with zero sales. Each column represents a separate regression. The industry subsectors are Construction (Cons), Manufacturing (Manu), Natural Resources and Mining (NR), and Service. All regressions include quarter, year, and county fixed effects. Standard errors are clustered the county level and reported in parentheses.

${ }^{+} p<0.1,{ }^{*} p<0.05,{ }^{\star *} p<0.01$. 


\section{With County-Month Fixed Effects}

Table A9 The effect of recreational dispensary entry and sales on the unemployment rate (Unrate), Ln(labor force), and Ln(unemployed) - regression analysis

\begin{tabular}{lccc}
\hline & Unrate & Ln(labor force) & Ln(unemp) \\
\cline { 2 - 4 } & $\mathbf{( 1 )}$ & $\mathbf{( 2 )}$ & $\mathbf{( 3 )}$ \\
\hline Panel A: start of sales & & & \\
\hline Recreational sale & $-0.693^{\star \star}$ & 0.002 & $-0.070^{\star \star}$ \\
& $(0.2522)$ & $(0.0116)$ & $(0.0195)$ \\
Ln(number of medical patients) & $-0.588^{\star}$ & -0.009 & -0.021 \\
& $(0.2675)$ & $(0.0127)$ & $(0.0252)$ \\
\hline$R^{2}$ & 0.915 & 0.999 & 0.996 \\
Observations & 6,144 & 6,144 & 6,144 \\
\hline Panel B: amount of sales & & & \\
\hline \$0 sales $\leq \$ 500,000$ & $-0.807^{\star \star}$ & 0.006 & $-0.070^{\star \star}$ \\
& $(0.2798)$ & $(0.0111)$ & $(0.0214)$ \\
Sales $>$ \$500,000 & $-0.552^{\star \star}$ & -0.003 & $-0.070^{\star \star}$ \\
& $(0.2653)$ & $(0.0144)$ & $(0.0244)$ \\
Ln(number of medical patients) & $-0.568^{\star \star}$ & -0.009 & -0.021 \\
& $(0.2727)$ & $(0.0127)$ & $(0.0259)$ \\
\hline$R^{2}$ & 0.915 & 0.999 & 0.996 \\
Observations & 6,144 & 6,144 & 6,144 \\
\hline
\end{tabular}

Notes: Panel A uses a $\{0,1\}$ any sales as the treatment variable, while Panel B compares counties with sales between $\$ 0$ and $\$ 500,000$ or sales $>\$ 500,000$ with counties with zero sales. Each column represents a separate regression. All regressions include month, year, county, and month $x$ county fixed effects. Standard errors are clustered at the county level and reported in parentheses.

${ }^{+} p<0.1,{ }^{\star} p<0.05,{ }^{\star \star} p<0.01$. 
Table A10 The effect of recreational dispensary entry and sales on employment regression analysis

\begin{tabular}{lccccc}
\hline & All & Cons & Manu & NR & Service \\
\cline { 2 - 6 } & $\mathbf{( 1 )}$ & $\mathbf{( 2 )}$ & $\mathbf{( 3 )}$ & $\mathbf{( 4 )}$ & $\mathbf{( 5 )}$ \\
\hline Panel A: start of sales & & & & & \\
\hline Recreational sale & $0.045^{\star \star}$ & 0.056 & $0.131^{\star \star}$ & -0.018 & $0.040^{\star}$ \\
& $(0.0152)$ & $(0.0551)$ & $(0.0357)$ & $(0.0673)$ & $(0.0153)$ \\
Ln(number of medical patients) & $-0.026^{+}$ & $-0.171^{+}$ & $-0.186^{\star \star}$ & 0.170 & $-0.031^{+}$ \\
& $(0.0142)$ & $(0.0917)$ & $(0.0604)$ & $(0.1165)$ & $(0.0179)$ \\
\hline$R^{2}$ & 0.999 & 0.989 & 0.996 & 0.973 & 0.999 \\
Observations & 6,144 & 4,608 & 3,936 & 4,608 & 6,144 \\
\hline Panel B: amount of sales & & & & & \\
\hline \$0< sales $\leq \$ 500,000$ & $0.035^{\star \star}$ & 0.050 & $0.156^{\star \star}$ & -0.035 & $0.034^{+}$ \\
& $(0.0158)$ & $(0.0493)$ & $(0.0394)$ & $(0.0675)$ & $(0.0173)$ \\
Sales $>$ \$500,000 & $0.057^{\star \star}$ & 0.062 & $0.103^{\star \star}$ & 0.000 & $0.046^{\star \star}$ \\
& $(0.0176)$ & $(0.0670)$ & $(0.0366)$ & $(0.0814)$ & $(0.0166)$ \\
Ln(number of medical patients) & -0.024 & $-0.171^{+}$ & $-0.192^{\star \star}$ & 0.173 & $-0.030^{+}$ \\
& $(0.0147)$ & $(0.0922)$ & $(0.0581)$ & $(0.1169)$ & $(0.0179)$ \\
\hline$R^{2}$ & 0.999 & 0.989 & 0.996 & 0.973 & 0.999 \\
Observations & 6,144 & 4,608 & 3,936 & 4,608 & 6,144 \\
\hline
\end{tabular}

Notes: Panel A uses a $\{0,1\}$ any sales as the treatment variable, while Panel $B$ compares counties with sales between $\$ 0$ and $\$ 500,000$ or sales $>\$ 500,000$ with counties with zero sales. Each column represents a separate regression. The industry subsectors are Construction (Cons), Manufacturing (Manu), Natural Resources and Mining (NR), and Service. All regressions include month, year, county, and month $\mathrm{x}$ county fixed effects. Standard errors are clustered at the county level and reported in parentheses.

${ }^{+} p<0.1,{ }^{\star} p<0.05,{ }^{\star \star} p<0.01$. 
Table A11 The effect of recreational dispensary entry and sales on wages - regression analysis

\begin{tabular}{lccccc}
\hline & All & Cons & Manu & NR & Service \\
\cline { 2 - 6 } & $\mathbf{( 1 )}$ & $\mathbf{( 2 )}$ & $\mathbf{( 3 )}$ & $\mathbf{( 4 )}$ & $\mathbf{( 5 )}$ \\
\hline Panel A: start of sales & & & & & \\
\hline Recreational sale & -0.000 & 0.006 & 0.007 & 0.023 & 0.004 \\
& $(0.0100)$ & $(0.0264)$ & $(0.0189)$ & $(0.0319)$ & $(0.0125)$ \\
Ln(number of medical patients) & 0.004 & $-0.082^{+}$ & -0.036 & $0.056^{+}$ & 0.004 \\
& $(0.0109)$ & $(0.0470)$ & $(0.0262)$ & $(0.0320)$ & $(0.0170)$ \\
\hline$R^{2}$ & 0.956 & 0.817 & 0.950 & 0.941 & 0.951 \\
Observations & 2,048 & 1,536 & 1,312 & 1,536 & 2,048 \\
\hline Panel B: amount of sales & & & & & \\
\hline \$0< sales $\leq \$ 500,000$ & 0.004 & 0.004 & 0.021 & 0.025 & 0.009 \\
& $(0.0107)$ & $(0.0253)$ & $(0.0247)$ & $(0.0300)$ & $(0.0141)$ \\
Sales $>$ \$500,000 & 0.007 & 0.009 & -0.011 & 0.020 & -0.002 \\
& $(0.0119)$ & $(0.0332)$ & $(0.0187)$ & $(0.0376)$ & $(0.0131)$ \\
Ln(number of medical patients) & 0.003 & $-0.082^{+}$ & -0.040 & $0.055^{+}$ & 0.003 \\
& $(0.0106)$ & $(0.0470)$ & $(0.0270)$ & $(0.0317)$ & $(0.0168)$ \\
\hline$R^{2}$ & 0.956 & 0.817 & 0.951 & 0.941 & 0.951 \\
Observations & 2,048 & 1,536 & 1,312 & 1,536 & 2,048 \\
\hline
\end{tabular}

Notes: Panel A uses a $\{0,1\}$ any sales as the treatment variable, while Panel B compares counties with sales between $\$ 0$ and $\$ 500,000$ or sales $>\$ 500,000$ with counties with zero sales. Each column represents a separate regression. The industry subsectors are Construction (Cons), Manufacturing (Manu), Natural Resources and Mining (NR), and Service. All regressions include quarter, year, county, and quarter $x$ county fixed effects. Standard errors are clustered at the county level and reported in parentheses.

${ }^{+} p<0.1,{ }^{*} p<0.05,{ }^{\star *} p<0.01$. 


\section{With Trend}

Table A12 The effect of recreational dispensary entry and sales on the unemployment rate (Unrate), Ln(labor force), and Ln(unemployed) - regression analysis

\begin{tabular}{lccc}
\hline & Unrate & Ln(labor force) & Ln(unemp) \\
\cline { 2 - 4 } & $\mathbf{( 1 )}$ & $\mathbf{( 2 )}$ & $\mathbf{( 3 )}$ \\
\hline Panel A: start of sales & & & \\
\hline Recreational sale & -0.230 & 0.003 & $-0.038^{\star}$ \\
& $(0.1384)$ & $(0.0066)$ & $(0.0174)$ \\
Ln(number of medical patients) & $-0.550^{\star \star}$ & 0.005 & $-0.063^{\star}$ \\
& $(0.2050)$ & $(0.0071)$ & $(0.0300)$ \\
\hline$R^{2}$ & 0.923 & 0.999 & 0.996 \\
Observations & 6,144 & 6,144 & 6,144 \\
\hline Panel B: amount of sales & & & \\
\hline \$0 sales $\leq \$ 500,000$ & -0.207 & 0.002 & -0.026 \\
& $(0.1517)$ & $(0.0069)$ & $(0.0203)$ \\
Sales > \$500,000 & $0.301^{\star \star}$ & 0.007 & $-0.077^{\star \star}$ \\
& $(0.1427)$ & $(0.0077)$ & $(0.0223)$ \\
Ln(number of medical patients) & $-0.555^{\star \star}$ & 0.005 & $-0.066^{\star \star}$ \\
& $(0.2072)$ & $(0.0073)$ & $(0.0309)$ \\
\hline$R^{2}$ & 0.923 & 0.999 & 0.996 \\
Observations & 6,144 & 6,144 & 6,144 \\
\hline
\end{tabular}

Notes: Panel A uses a $\{0,1\}$ any sales as the treatment variable, while Panel B compares counties with sales between $\$ 0$ and $\$ 500,000$ or sales $>\$ 500,000$ with counties with zero sales. Each column represents a separate regression. All regressions include month, year, county, fixed effects and a county-level time trend. Standard errors are clustered at the county level and reported in parentheses.

${ }^{+} p<0.1,{ }^{\star} p<0.05,{ }^{\star \star} p<0.01$. 
Table A13 The effect of recreational dispensary entry and sales on employment regression analysis

\begin{tabular}{lccccc}
\hline & All & Cons & Manu & NR & Service \\
\cline { 2 - 6 } & $\mathbf{( 1 )}$ & $\mathbf{( 2 )}$ & $\mathbf{( 3 )}$ & $\mathbf{( 4 )}$ & $\mathbf{( 5 )}$ \\
\hline Panel A: start of sales & & & & & \\
\hline Recreational sale & -0.001 & 0.022 & 0.040 & 0.031 & 0.001 \\
& $(0.0097)$ & $(0.0332)$ & $(0.0545)$ & $(0.0441)$ & $(0.0097)$ \\
Ln(number of medical patients) & $0.024^{\star}$ & -0.011 & -0.028 & 0.085 & $0.035^{\star \star}$ \\
& $(0.0095)$ & $(0.0520)$ & $(0.0504)$ & $(0.0955)$ & $(0.0102)$ \\
\hline$R^{2}$ & 0.999 & 0.993 & 0.997 & 0.981 & 0.998 \\
Observations & 6,144 & 4,608 & 3,936 & 4,608 & 6,144 \\
\hline Panel B: amount of sales & & & & & \\
\hline \$0< sales $\leq \$ 500,000$ & -0.007 & 0.019 & 0.040 & 0.037 & 0.006 \\
& $(0.0106)$ & $(0.0341)$ & $(0.0590)$ & $(0.0453)$ & $(0.0113)$ \\
Sales $>$ \$500,000 & $0.017^{+}$ & 0.032 & 0.043 & -0.016 & $-0.025^{\star \star}$ \\
& $(0.0099)$ & $(0.0348)$ & $(0.0453)$ & $(0.0560)$ & $(0.0120)$ \\
Ln(number of medical patients) & $0.026^{\star \star}$ & -0.010 & 0.028 & 0.086 & $0.037^{\star \star}$ \\
& $(0.0101)$ & $(0.0521)$ & $(0.0494)$ & $(0.0955)$ & $(0.0106)$ \\
\hline$R^{2}$ & 0.999 & 0.993 & 0.997 & 0.981 & 0.998 \\
Observations & 6,144 & 4,608 & 3,936 & 4,608 & 6,144 \\
\hline
\end{tabular}

Notes: Panel A uses a $\{0,1\}$ any sales as the treatment variable, while Panel B compares counties with sales between $\$ 0$ and $\$ 500,000$ or sales $>\$ 500,000$ with counties with zero sales. Each column represents a separate regression. The industry subsectors are Construction (Cons), Manufacturing (Manu), Natural Resources and Mining (NR), and Service. All regressions include month, year, county, fixed effects and a county-level time trend. Standard errors are clustered at the county level and reported in parentheses.

${ }^{+} p<0.1,{ }^{\star} p<0.05,{ }^{\star \star} p<0.01$. 
Table A14 The effect of recreational dispensary entry and sales on wages - regression analysis

\begin{tabular}{|c|c|c|c|c|c|}
\hline & All & Cons & Manu & NR & Service \\
\hline & (1) & (2) & (3) & (4) & (5) \\
\hline \multicolumn{6}{|l|}{ Panel A: start of sales } \\
\hline Recreational sale & $\begin{array}{c}-0.005 \\
(0.0094)\end{array}$ & $\begin{array}{l}-0.018 \\
(0.0161)\end{array}$ & $\begin{array}{c}-0.006 \\
(0.0189)\end{array}$ & $\begin{array}{l}0.003 \\
(0.0241)\end{array}$ & $\begin{array}{c}0.017^{\star} \\
(0.0076)\end{array}$ \\
\hline Ln(number of medical patients) & $\begin{array}{l}-0.002 \\
(0.0098)\end{array}$ & $\begin{array}{l}0.010 \\
(0.0284)\end{array}$ & $\begin{array}{c}-0.061^{+} \\
(0.0329)\end{array}$ & $\begin{array}{l}0.010 \\
(0.0511)\end{array}$ & $\begin{array}{l}-0.007 \\
(0.0153)\end{array}$ \\
\hline$\overline{R^{2}}$ & 0.946 & 0.844 & 0.950 & 0.926 & 0.936 \\
\hline Observations & 2,048 & 1,536 & 1,312 & 1,536 & 2,048 \\
\hline \multicolumn{6}{|l|}{ Panel B: amount of sales } \\
\hline$\$ 0<$ sales $\leq \$ 500,000$ & $\begin{array}{c}-0.002 \\
(0.0096)\end{array}$ & $\begin{array}{l}-0.013 \\
(0.0179)\end{array}$ & $\begin{array}{l}-0.003 \\
(0.0192)\end{array}$ & $\begin{array}{c}0.007 \\
(0.0236)\end{array}$ & $\begin{array}{c}0.019^{\star \star} \\
(0.0081)\end{array}$ \\
\hline Sales $>\$ 500,000$ & $\begin{array}{l}-0.013 \\
(0.0111)\end{array}$ & $\begin{array}{c}-0.033^{+} \\
(0.0179)\end{array}$ & $\begin{array}{l}-0.015 \\
(0.0219)\end{array}$ & $\begin{array}{l}-0.015 \\
(0.0337)\end{array}$ & $\begin{array}{l}0.011 \\
(0.0075)\end{array}$ \\
\hline Ln(number of medical patients) & $\begin{array}{l}-0.002 \\
(0.0097)\end{array}$ & $\begin{array}{l}0.008 \\
(0.0288)\end{array}$ & $\begin{array}{c}-0.062^{+} \\
(0.0329)\end{array}$ & $\begin{array}{l}0.009 \\
(0.0504)\end{array}$ & $\begin{array}{l}-0.008 \\
(0.0153)\end{array}$ \\
\hline$\overline{R^{2}}$ & 0.946 & 0.844 & 0.950 & 0.926 & 0.936 \\
\hline Observations & 2,048 & 1,536 & 1,312 & 1,536 & 2,048 \\
\hline
\end{tabular}

Notes: Panel A uses a $\{0,1\}$ any sales as the treatment variable, while Panel B compares counties with sales between $\$ 0$ and $\$ 500,000$ or sales $>\$ 500,000$ with counties with zero sales. Each column represents a separate regression. The industry subsectors are Construction (Cons), Manufacturing (Manu), Natural Resources and Mining (NR), and Service. All regressions include quarter, year, county, fixed effects and a county-level time trend. Standard errors are clustered at the county level and reported in parentheses.

${ }^{+} p<0.1,{ }^{\star} p<0.05,{ }^{\star \star} p<0.01$. 


\section{Robustness without Denver County}

Table A15 The effect of recreational dispensary entry on the unemployment rate (Unrate), Ln(labor force), and Ln(unemployed) - regression analysis

\begin{tabular}{lccc}
\hline & Unrate & Ln(labor force) & Ln(unemp) \\
\cline { 2 - 4 } & $\mathbf{( 1 )}$ & $\mathbf{( 2 )}$ & $\mathbf{( 3 )}$ \\
\hline Panel A: start of sales & & & \\
\hline Recreational sale & $-0.688^{\star \star}$ & 0.000 & $-0.069^{\star \star}$ \\
& $(0.2548)$ & $(0.0116)$ & $(0.0197)$ \\
Ln(number of medical patients) & $-0.618^{\star}$ & -0.006 & -0.025 \\
& $(0.2703)$ & $(0.0127)$ & $(0.0250)$ \\
\hline$R^{2}$ & 0.881 & 0.999 & 0.995 \\
Observations & 6,048 & 6,048 & 6,048 \\
\hline Panel B: amount of sales & & & \\
\hline \$0 sales $\leq \$ 500,000$ & $-0.729^{\star \star}$ & 0.003 & $-0.058^{\star \star}$ \\
& $(0.2809)$ & $(0.0109)$ & $(0.0223)$ \\
Sales $>$ \$500,000 & $-0.634^{\star \star}$ & -0.003 & $-0.083^{\star \star}$ \\
& $(0.2693)$ & $(0.0146)$ & $(0.0253)$ \\
Ln(number of medical patients) & $-0.610^{\star \star}$ & -0.006 & -0.027 \\
& $(0.2736)$ & $(0.0128)$ & $(0.0263)$ \\
\hline$R^{2}$ & 0.881 & 0.999 & 0.995 \\
Observations & 6,048 & 6,048 & 6,048 \\
\hline
\end{tabular}

Notes: Panel A uses a $\{0,1\}$ any sales as the treatment variable, while Panel B compares counties with sales between $\$ 0$ and $\$ 500,000$ or sales $>\$ 500,000$ with counties with zero sales. Each column represents a separate regression omitting Denver. All regressions include month, year, and county fixed effects. Standard errors are clustered at the county level and reported in parentheses.

${ }^{+} p<0.1,{ }^{*} p<0.05,{ }^{* *} p<0.01$. 
Table A16 The effect of recreational dispensary entry on employment - regression analysis

\begin{tabular}{lccccc}
\hline & All & Cons & Manu & NR & Service \\
\cline { 2 - 6 } & $\mathbf{( 1 )}$ & $\mathbf{( 2 )}$ & $\mathbf{( 3 )}$ & $\mathbf{( 4 )}$ & $\mathbf{( 5 )}$ \\
\hline Panel A: start of sales & & & & & \\
\hline Recreational sale & $0.043^{\star \star}$ & 0.054 & $0.131^{\star \star}$ & -0.019 & $0.037^{\star}$ \\
& $(0.0152)$ & $(0.0552)$ & $(0.0360)$ & $(0.0674)$ & $(0.0155)$ \\
Ln(number of medical patients) & -0.022 & $-0.175^{+}$ & $-0.190^{\star \star}$ & 0.170 & -0.026 \\
& $(0.0143)$ & $(0.0918)$ & $(0.0606)$ & $(0.1178)$ & $(0.0183)$ \\
\hline$R^{2}$ & 0.998 & 0.988 & 0.995 & 0.965 & 0.998 \\
Observations & 6,048 & 4,512 & 3,840 & 4,512 & 6,048 \\
\hline Panel B: amount of sales & & & & & \\
\hline \$0< sales $\leq \$ 500,000$ & $0.029^{+}$ & 0.053 & $0.148^{\star \star}$ & -0.032 & 0.025 \\
& $(0.0155)$ & $(0.0489)$ & $(0.0381)$ & $(0.0661)$ & $(0.0173)$ \\
Sales > \$500,000 & $0.062^{\star \star}$ & 0.055 & $0.110^{\star \star}$ & -0.003 & $0.054^{\star \star}$ \\
& $(0.0181)$ & $(0.0677)$ & $(0.0387)$ & $(0.0829)$ & $(0.0172)$ \\
Ln(number of medical patients) & -0.019 & $-0.175^{+}$ & $-0.195^{\star \star}$ & 0.173 & -0.024 \\
& $(0.0149)$ & $(0.0921)$ & $(0.0593)$ & $(0.1182)$ & $(0.0181)$ \\
\hline$R^{2}$ & 0.998 & 0.988 & 0.995 & 0.965 & 0.998 \\
Observations & 6,048 & 4,512 & 3,840 & 4,512 & 6,048 \\
\hline
\end{tabular}

Notes: Panel $A$ uses a $\{0,1\}$ any sales as the treatment variable, while Panel B compares counties with sales between $\$ 0$ and $\$ 500,000$ or sales $>\$ 500,000$ with counties with zero sales. Each column represents a separate regression omitting Denver. The industry subsectors are Construction (Cons), Manufacturing (Manu), Natural Resources and Mining (NR), and Service. All regressions include month, year, and county fixed effects. Standard errors are clustered at the county level and reported in parentheses.

${ }^{+} p<0.1,{ }^{\star} p<0.05,{ }^{\star \star} p<0.01$. 
Table A17 The effect of recreational dispensary entry on wages - regression analysis

\begin{tabular}{lccccc}
\hline & All & Cons & Manu & NR & Service \\
\cline { 2 - 6 } & $(\mathbf{1})$ & $\mathbf{( 2 )}$ & $\mathbf{( 3 )}$ & $\mathbf{( 4 )}$ & $\mathbf{( 5 )}$ \\
\hline Panel A: start of sales & & & & & \\
\hline Recreational sale & 0.001 & 0.007 & 0.010 & 0.028 & 0.004 \\
& $(0.0101)$ & $(0.0265)$ & $(0.0197)$ & $(0.0318)$ & $(0.0127)$ \\
Ln(number of medical patients) & 0.004 & $-0.081^{+}$ & -0.036 & $0.061^{+}$ & 0.002 \\
& $(0.0113)$ & $(0.0469)$ & $(0.0271)$ & $(0.0341)$ & $(0.0176)$ \\
\hline$R^{2}$ & 0.932 & 0.768 & 0.932 & 0.900 & 0.919 \\
Observations & 2,016 & 1,504 & 1,280 & 1,504 & 2,016 \\
\hline Panel B: amount of sales & & & & & \\
\hline \$0 sales $\leq$ \$50,000 & 0.006 & 0.008 & 0.025 & 0.029 & 0.009 \\
& $(0.0106)$ & $(0.0254)$ & $(0.0249)$ & $(0.0294)$ & $(0.0139)$ \\
Sales $>$ \$500,000 & -0.007 & 0.006 & -0.012 & 0.026 & -0.004 \\
& $(0.0119)$ & $(0.0338)$ & $(0.0196)$ & $(0.0384)$ & $(0.0134)$ \\
Ln(number of medical patients) & 0.002 & $-0.081^{+}$ & -0.041 & $0.061^{+}$ & 0.001 \\
& $(0.0109)$ & $(0.0469)$ & $(0.0280)$ & $(0.0339)$ & $(0.0173)$ \\
\hline$R^{2}$ & 0.932 & 0.768 & 0.932 & 0.900 & 0.919 \\
Observations & 2,016 & 1,504 & 1,280 & 1,504 & 2,016 \\
\hline
\end{tabular}

Notes: Panel A uses a $\{0,1\}$ any sales as the treatment variable, while Panel B compares counties with sales between $\$ 0$ and $\$ 500,000$ or sales $>\$ 500,000$ with counties with zero sales. Each column represents a separate regression omitting Denver. The industry subsectors are Construction (Cons), Manufacturing (Manu), Natural Resources and Mining (NR), and Service. All regressions include quarter, year, and county fixed effects. Standard errors are clustered at the county level and reported in parentheses.

${ }^{+} p<0.1,{ }^{\star} p<0.05,{ }^{\star *} p<0.01$. 


\section{Robustness without Las Animas (Outlier in Per-Capita Recreational Cannabis Sales)}

Table A18 The effect of recreational dispensary entry and sales on the unemployment rate (Unrate), Ln(labor force), and Ln(unemployed) - regression analysis

\begin{tabular}{lccc}
\hline & Unrate & Ln(labor force) & Ln(unemp) \\
\cline { 2 - 4 } & $\mathbf{( 1 )}$ & $\mathbf{( 2 )}$ & $\mathbf{( 3 )}$ \\
\hline Panel A: start of sales & & & \\
\hline Recreational sale & $-0.648^{\star}$ & 0.005 & $-0.064^{\star \star}$ \\
& $(0.2546)$ & $(0.0110)$ & $(0.0195)$ \\
Ln(number of medical patients) & $-0.543^{\star}$ & 0.002 & -0.018 \\
& $(0.2664)$ & $(0.0100)$ & $(0.0251)$ \\
\hline$R^{2}$ & 0.880 & 0.999 & 0.995 \\
Observations & 6,048 & 6,048 & 6,048 \\
\hline Panel B: amount of sales & & & \\
\hline \$0 sales $\leq \$ 500,000$ & $-0.713^{\star \star}$ & 0.004 & $-0.056^{\star \star}$ \\
& $(0.2831)$ & $(0.0108)$ & $(0.0225)$ \\
Sales $>$ \$500,000 & $-0.561^{\star \star}$ & 0.006 & $-0.076^{\star \star}$ \\
& $(0.2626)$ & $(0.0130)$ & $(0.0251)$ \\
Ln(number of medical patients) & $-0.526^{+}$ & 0.002 & -0.020 \\
& $(0.2690)$ & $(0.0101)$ & $(0.0267)$ \\
\hline$R^{2}$ & 0.880 & 0.999 & 0.995 \\
Observations & 6,048 & 6,048 & 6,048 \\
\hline
\end{tabular}

Notes: Panel A uses a $\{0,1\}$ any sales as the treatment variable, while Panel B compares counties with sales between $\$ 0$ and $\$ 500,000$ or sales $>\$ 500,000$ with counties with zero sales. Each column represents a separate regression omitting Las Animas. All regressions include month, year, and county fixed effects. Standard errors are clustered at the county level and reported in parentheses.

${ }^{+} p<0.1,{ }^{\star} p<0.05,{ }^{\star \star} p<0.01$. 
Table A19 The effect of recreational dispensary entry and sales on employment regression analysis

\begin{tabular}{lccccc}
\hline & All & Cons & Manu & NR & Service \\
\cline { 2 - 6 } & $\mathbf{( 1 )}$ & $\mathbf{( 2 )}$ & $\mathbf{( 3 )}$ & $\mathbf{( 4 )}$ & $\mathbf{( 5 )}$ \\
\hline Panel A: start of sales & & & & & \\
\hline Recreational sale & $0.047^{\star *}$ & 0.077 & $0.147^{\star \star}$ & 0.001 & $0.039^{\star}$ \\
& $(0.0151)$ & $(0.0532)$ & $(0.0319)$ & $(0.0653)$ & $(0.0156)$ \\
Ln(number of medical patients) & -0.016 & -0.120 & $-0.139^{\star \star}$ & $0.213^{+}$ & -0.025 \\
& $(0.0142)$ & $(0.0828)$ & $(0.0446)$ & $(0.1140)$ & $(0.0190)$ \\
\hline$R^{2}$ & 0.998 & 0.989 & 0.996 & 0.970 & 0.998 \\
Observations & 6,048 & 4,512 & 3,840 & 4,512 & 6,048 \\
\hline Panel B: amount of sales & & & & & \\
\hline \$0< sales $\leq \$ 500,000$ & $0.030^{+}$ & 0.063 & $0.158^{\star \star}$ & -0.026 & 0.025 \\
& $(0.0156)$ & $(0.0485)$ & $(0.0361)$ & $(0.0655)$ & $(0.0175)$ \\
Sales > \$500,000 & $0.070^{\star *}$ & 0.091 & $0.133^{\star *}$ & 0.032 & $0.058^{\star \star}$ \\
& $(0.0172)$ & $(0.0629)$ & $(0.0322)$ & $(0.0777)$ & $(0.0173)$ \\
Ln(number of medical patients) & -0.012 & -0.117 & $-0.144^{\star *}$ & $0.222^{+}$ & -0.021 \\
& $(0.0142)$ & $(0.0828)$ & $(0.0437)$ & $(0.1129)$ & $(0.0186)$ \\
\hline$R^{2}$ & 0.998 & 0.989 & 0.996 & 0.970 & 0.998 \\
Observations & 6,048 & 4,512 & 3,840 & 4,512 & 6,048 \\
\hline
\end{tabular}

Notes: Panel A uses a $\{0,1\}$ any sales as the treatment variable, while Panel B compares counties with sales between $\$ 0$ and $\$ 500,000$ or sales $>\$ 500,000$ with counties with zero sales. Each column represents a separate regression omitting Las Animas. The industry subsectors are Construction (Cons), Manufacturing (Manu), Natural Resources and Mining (NR), and Service. All regressions include month, year, and county fixed effects. Standard errors are clustered at the county level and reported in parentheses.

${ }^{+} p<0.1,{ }^{\star} p<0.05,{ }^{\star \star} p<0.01$. 
Table A20 The effect of recreational dispensary entry and sales on wages - regression analysis

\begin{tabular}{lccccc}
\hline & All & Cons & Manu & NR & Service \\
\cline { 2 - 6 } & $\mathbf{( 1 )}$ & $\mathbf{( 2 )}$ & $\mathbf{( 3 )}$ & $\mathbf{( 4 )}$ & $\mathbf{( 5 )}$ \\
\hline Panel A: start of sales & & & & & \\
\hline Recreational sale & 0.003 & 0.009 & 0.014 & 0.031 & 0.005 \\
& $(0.0100)$ & $(0.0261)$ & $(0.0193)$ & $(0.0315)$ & $(0.0128)$ \\
Ln(number of medical patients) & 0.007 & -0.078 & -0.035 & $0.077^{*}$ & 0.004 \\
& $(0.0110)$ & $(0.0504)$ & $(0.0285)$ & $(0.0334)$ & $(0.0181)$ \\
\hline$R^{2}$ & 0.938 & 0.777 & 0.935 & 0.911 & 0.925 \\
Observations & 2,016 & 1,504 & 1,280 & 1,504 & 2,016 \\
\hline Panel B: amount of sales & & & & & \\
\hline \$0< sales $\leq \$ 500,000$ & 0.007 & 0.010 & 0.030 & 0.031 & 0.010 \\
& $(0.0107)$ & $(0.0253)$ & $(0.0247)$ & $(0.0295)$ & $(0.0140)$ \\
Sales $>$ \$500,000 & -0.003 & 0.009 & -0.008 & 0.031 & -0.002 \\
& $(0.0116)$ & $(0.0334)$ & $(0.0197)$ & $(0.0376)$ & $(0.0136)$ \\
Ln(number of medical patients) & 0.006 & -0.078 & -0.042 & $0.077^{\star *}$ & 0.002 \\
& $(0.0108)$ & $(0.0507)$ & $(0.0299)$ & $(0.0329)$ & $(0.0180)$ \\
\hline$R^{2}$ & 0.938 & 0.777 & 0.935 & 0.911 & 0.925 \\
Observations & 2,016 & 1,504 & 1,280 & 1,504 & 2,016 \\
\hline
\end{tabular}

Notes: Panel A uses a $\{0,1\}$ any sales as the treatment variable, while Panel B compares counties with sales between $\$ 0$ and $\$ 500,000$ or sales $>\$ 500,000$ with counties with zero sales. Each column represents a separate regression omitting Las Animas. The industry subsectors are Construction (Cons), Manufacturing (Manu), Natural Resources and Mining (NR), and Service. All regressions include quarter, year, and county fixed effects. Standard errors are clustered at the county level and reported in parentheses.

${ }^{+} p<0.1,{ }^{\star} p<0.05,{ }^{\star \star} p<0.01$. 


\section{Robustness with Different Bins}

Table A21 The effect of recreational dispensary entry and sales on the unemployment rate (Unrate), $\operatorname{Ln}$ (labor force), and $\operatorname{Ln}($ unemployed) - regression analysis

\begin{tabular}{lccc}
\hline & Unrate & Ln(labor force) & Ln(unemp) \\
\cline { 2 - 4 } & $\mathbf{( 1 )}$ & $\mathbf{( 2 )}$ & $\mathbf{( 3 )}$ \\
\hline Amount of sales & & & \\
\hline$\$ 0<$ sales $\leq \$ 250,000$ & $-0.705^{\star}$ & -0.002 & -0.045 \\
& $(0.2983)$ & $(0.0115)$ & $(0.0291)$ \\
$\$ 250,000<$ sales $\leq \$ 500,000$ & $-0.781^{\star}$ & 0.015 & $-0.089^{\star *}$ \\
Sales $>\$ 500,000$ & $(0.3365)$ & $(0.0132)$ & $(0.0296)$ \\
& $-0.634^{\star}$ & -0.000 & $-0.084^{\star \star}$ \\
Ln(number of medical patients) & $(0.2675)$ & $(0.0145)$ & $(0.0251)$ \\
& $-0.622^{\star}$ & -0.004 & -0.032 \\
$R^{2}$ & $(0.2787)$ & $(0.0130)$ & $(0.0285)$ \\
Observations & 0.882 & 0.999 & 0.995 \\
\hline
\end{tabular}

Notes: Each column represents a separate regression. The omitted sales category is sales $=\$ 0$. Each column represents a separate regression. All regressions include month, year, and county fixed effects. Standard errors are clustered at the county level and reported in parentheses.

${ }^{+} p<0.1,{ }^{\star} p<0.05,{ }^{* \star} p<0.01$.

FE, fixed effect.

Table A22 The effect of recreational dispensary entry and sales on employment regression analysis

\begin{tabular}{lccccc}
\hline & All & Cons & Manu & NR & Service \\
\cline { 2 - 6 } & $\mathbf{( 1 )}$ & $\mathbf{( 2 )}$ & $\mathbf{( 3 )}$ & $\mathbf{( 4 )}$ & $\mathbf{( 5 )}$ \\
\hline Amount of sales & & & & & \\
\hline$\$ 0<$ sales $\leq \$ 250,000$ & 0.018 & 0.048 & $0.141^{\star \star}$ & -0.044 & 0.013 \\
& $(0.0155)$ & $(0.0504)$ & $(0.0383)$ & $(0.0648)$ & $(0.0175)$ \\
$\$ 250,000<$ sales $\leq \$ 500,000$ & $0.055^{\star \star}$ & 0.068 & $0.166^{\star \star}$ & -0.003 & $0.053^{\star}$ \\
& $(0.0199)$ & $(0.0502)$ & $(0.0498)$ & $(0.0920)$ & $(0.0234)$ \\
Sales $>\$ 500,000$ & $0.065^{\star \star}$ & 0.064 & $0.110^{\star \star}$ & 0.005 & $0.058^{\star \star}$ \\
& $(0.0178)$ & $(0.0667)$ & $(0.0377)$ & $(0.0806)$ & $(0.0172)$ \\
Ln(number of medical patients) & -0.015 & $-0.171^{+}$ & $-0.187^{\star \star}$ & 0.180 & -0.019 \\
& $(0.0146)$ & $(0.0918)$ & $(0.0600)$ & $(0.1154)$ & $(0.0171)$ \\
\hline$R^{2}$ & 0.998 & 0.989 & 0.996 & 0.970 & 0.998 \\
Observations & 6,144 & 4,608 & 3,936 & 4,608 & 6,144 \\
\hline
\end{tabular}

Notes: The industry subsectors are Construction (Cons), Manufacturing (Manu), Natural Resources and Mining (NR), and Service. Each column represents a separate regression. The omitted sales category is sales $=\$ 0$. Each column represents a separate regression. All regressions include month, year, and county fixed effects. Standard errors are clustered at the county level and reported in parentheses.

${ }^{+} p<0.1,{ }^{*} p<0.05,{ }^{* *} p<0.01$.

FE, fixed effect. 
Table A23 The effect of recreational dispensary entry and sales on wages - regression analysis

\begin{tabular}{lccccc}
\hline & All & Cons & Manu & NR & Service \\
\cline { 2 - 6 } & $\mathbf{( 1 )}$ & $\mathbf{( 2 )}$ & $\mathbf{( 3 )}$ & $\mathbf{( 4 )}$ & $\mathbf{( 5 )}$ \\
\hline Panel A: amount of sales & & & & & \\
\hline \$0< sales $\leq \$ 250,000$ & 0.006 & 0.002 & 0.015 & 0.029 & 0.008 \\
& $(0.0108)$ & $(0.0253)$ & $(0.0232)$ & $(0.0311)$ & $(0.0140)$ \\
\$250,000 $<$ sales $\leq \$ 500,000$ & 0.005 & 0.021 & 0.050 & 0.028 & 0.012 \\
& $(0.0125)$ & $(0.0301)$ & $(0.0341)$ & $(0.0425)$ & $(0.0158)$ \\
Sales $>\$ 500,000$ & -0.007 & 0.009 & -0.007 & 0.022 & -0.003 \\
& $(0.0116)$ & $(0.0334)$ & $(0.0198)$ & $(0.0379)$ & $(0.0134)$ \\
Ln(number of medical patients) & 0.002 & -0.078 & -0.031 & $0.062^{+}$ & 0.001 \\
& $(0.0107)$ & $(0.0479)$ & $(0.0258)$ & $(0.0324)$ & $(0.0176)$ \\
\hline$R^{2}$ & 0.937 & 0.777 & 0.933 & 0.909 & 0.925 \\
Observations & 2,048 & 1,536 & 1,312 & 1,536 & 2,048 \\
\hline
\end{tabular}

Notes: The industry subsectors are Construction (Cons), Manufacturing (Manu), Natural Resources and Mining (NR), and Service. Each column represents a separate regression. The omitted sales category is sales $=\$ 0$. Each column represents a separate regression. All regressions include quarter, year, and county fixed effects. Standard errors are clustered at the county level and reported in parentheses.

${ }^{+} p<0.1,{ }^{\star} p<0.05,{ }^{\star \star} p<0.01$.

$F E$, fixed effect. 


\section{Robustness with Early-Adopting Counties and Not-Selling Counties}

Table A24 The effect of recreational dispensary entry and sales on the unemployment rate (Unrate), Ln(labor force), and Ln(unemployed) - regression analysis

\begin{tabular}{lccc}
\hline & Unrate & Ln(labor force) & Ln(unemp) \\
\cline { 2 - 4 } & $\mathbf{( 1 )}$ & $\mathbf{( 2 )}$ & $\mathbf{( 3 )}$ \\
\hline Panel A: start of sales & & & \\
\hline Recreational sale & -0.425 & 0.007 & $-0.067^{\star \star}$ \\
& $(0.2868)$ & $(0.0136)$ & $(0.0216)$ \\
Ln(number of medical patients) & $-0.505^{+}$ & 0.001 & -0.026 \\
& $(0.2580)$ & $(0.0107)$ & $(0.0253)$ \\
\hline$R^{2}$ & 0.876 & 0.999 & 0.996 \\
Observations & 4,512 & 4,512 & 4,512 \\
\hline Panel B: amount of sales & & & -0.042 \\
\hline \$0 sales $\leq \$ 500,000$ & -0.230 & 0.008 & $(0.0279)$ \\
& $(0.2756)$ & $(0.0126)$ & $-0.084^{\star \star}$ \\
Sales $>$ \$500,000 & $-0.564^{+}$ & 0.007 & $(0.0252)$ \\
& $(0.3091)$ & $(0.0156)$ & -0.029 \\
Ln(number of medical patients) & $-0.528^{\star \star}$ & 0.001 & $(0.0272)$ \\
\hline$R^{2}$ & $(0.2551)$ & $(0.0107)$ & 0.996 \\
Observations & 0.877 & 0.999 & 4512 \\
\hline
\end{tabular}

Notes: Panel A uses a $\{0,1\}$ any sales as the treatment variable, while Panel B compares counties with sales between $\$ 0$ and $\$ 500,000$ or sales $>\$ 500,000$ with counties with zero sales. Each column represents a separate regression. All regressions include month, year, and county fixed effects. Standard errors are clustered th the county level and reported in parentheses.

${ }^{+} p<0.1,{ }^{\star} p<0.05,{ }^{\star \star} p<0.01$. 
Table A25 The effect of recreational dispensary entry and sales on employment regression analysis

\begin{tabular}{lccccc}
\hline & All & Cons & Manu & NR & Service \\
\cline { 2 - 6 } & $\mathbf{( 1 )}$ & $\mathbf{( 2 )}$ & $\mathbf{( 3 )}$ & $\mathbf{( 4 )}$ & $\mathbf{( 5 )}$ \\
\hline Panel A: start of sales & & & & & \\
\hline Recreational sale & $0.050^{\star}$ & $0.101^{+}$ & $0.180^{\star \star}$ & 0.078 & $0.037^{+}$ \\
& $(0.0222)$ & $(0.0579)$ & $(0.0380)$ & $(0.0876)$ & $(0.0207)$ \\
Ln(number of medical patients) & -0.016 & -0.123 & $-0.121^{\star}$ & $0.299^{\star}$ & -0.027 \\
& $(0.0160)$ & $(0.0969)$ & $(0.0458)$ & $(0.1385)$ & $(0.0206)$ \\
\hline$R^{2}$ & 0.998 & 0.990 & 0.998 & 0.969 & 0.998 \\
Observations & 4,512 & 3,264 & 2,592 & 3,264 & 4,512 \\
\hline Panel B: amount of sales & & & & & \\
\hline \$0< sales $\leq \$ 500,000$ & 0.016 & 0.078 & $0.203^{\star \star}$ & 0.027 & 0.002 \\
& $(0.0252)$ & $(0.0494)$ & $(0.0525)$ & $(0.1017)$ & $(0.0262)$ \\
Sales $>$ \$500,000 & $0.074^{\star \star}$ & $0.114^{+}$ & $0.170^{\star \star}$ & 0.101 & $0.061^{\star \star}$ \\
Ln(number of medical patients) & $(0.0220)$ & $(0.0648)$ & $(0.0362)$ & $(0.0924)$ & $(0.0199)$ \\
& -0.012 & -0.124 & $-0.122^{\star \star}$ & $0.301^{\star *}$ & -0.023 \\
& $(0.0148)$ & $(0.0965)$ & $(0.0441)$ & $(0.1376)$ & $(0.0191)$ \\
\hline$R^{2}$ & 0.998 & 0.990 & 0.998 & 0.969 & 0.998 \\
Observations & 4,512 & 3,264 & 2,592 & 3,264 & 4,512 \\
\hline
\end{tabular}

Notes: Panel $A$ uses a $\{0,1\}$ any sales as the treatment variable, while Panel B compares counties with sales between $\$ 0$ and $\$ 500,000$ or sales $>\$ 500,000$ with counties with zero sales. Each column represents a separate regression The industry subsectors are Construction (Cons), Manufacturing (Manu), Natural Resources and Mining (NR), and Service. Fixed effects (FEs) pertain to both the panels. Standard errors are clustered at the county level and reported in parentheses.

${ }^{+} p<0.1,{ }^{\star} p<0.05,{ }^{\star \star} p<0.01$. 
Table A26 The effect of recreational dispensary entry and sales on wages - regression analysis

\begin{tabular}{lccccc}
\hline & All & Cons & Manu & NR & Service \\
\cline { 2 - 6 } & $\mathbf{( 1 )}$ & $\mathbf{( 2 )}$ & $\mathbf{( 3 )}$ & $\mathbf{( 4 )}$ & $\mathbf{( 5 )}$ \\
\hline Panel A: start of sales & & & & & \\
\hline Recreational sale & 0.004 & -0.009 & -0.009 & 0.042 & 0.021 \\
& $(0.0136)$ & $(0.0301)$ & $(0.0312)$ & $(0.0413)$ & $(0.0158)$ \\
Ln(number of medical patients) & 0.003 & $-0.120^{+}$ & $-0.040^{+}$ & $0.079^{+}$ & 0.006 \\
& $(0.0120)$ & $(0.0658)$ & $(0.0196)$ & $(0.0436)$ & $(0.0213)$ \\
\hline$R^{2}$ & 0.927 & 0.770 & 0.950 & 0.907 & 0.911 \\
Observations & 1,504 & 1,088 & 864 & 1,088 & 1,504 \\
\hline Panel B: amount of sales & & & & & \\
\hline \$0< sales $\leq$ 500,000 & 0.012 & -0.028 & 0.012 & 0.036 & $0.038^{\star \star}$ \\
Sales $>$ \$500,000 & $(0.0153)$ & $(0.0338)$ & $(0.0595)$ & $(0.0412)$ & $(0.0172)$ \\
& -0.001 & 0.002 & -0.019 & 0.045 & 0.009 \\
Ln(number of medical patients) & $(0.0150)$ & $(0.0345)$ & $(0.0234)$ & $(0.0449)$ & $(0.0163)$ \\
& 0.002 & $-0.121^{+}$ & $-0.041^{\star *}$ & $0.079^{+}$ & 0.004 \\
\hline$R^{2}$ & $(0.0119)$ & $(0.0651)$ & $(0.0196)$ & $(0.0434)$ & $(0.0206)$ \\
\hline Observations & 0.927 & 0.771 & 0.951 & 0.907 & 0.911 \\
\hline
\end{tabular}

Notes: Panel A uses a $\{0,1\}$ any sales as the treatment variable, while Panel B compares counties with sales between $\$ 0$ and $\$ 500,000$ or sales $>\$ 500,000$ with counties with zero sales. Each column represents a separate regression The industry subsectors are Construction (Cons), Manufacturing (Manu), Natural Resources and Mining (NR), and Service. All regressions include quarter, year, and county fixed effects. Standard errors are clustered at the county level and reported in parentheses.

${ }^{+} p<0.1,{ }^{\star} p<0.05,{ }^{\star *} p<0.01$. 


\section{Robustness with Late-Adopting Counties and Not-Selling Counties}

Table A27 The effect of recreational dispensary entry and sales on the unemployment rate (Unrate), Ln(labor force), and Ln(unemployed) - regression analysis

\begin{tabular}{lccc}
\hline & Unrate & Ln(labor force) & Ln(unemp) \\
\cline { 2 - 4 } & $\mathbf{( 1 )}$ & $\mathbf{( 2 )}$ & $\mathbf{( 3 )}$ \\
\hline Panel A: start of sales & & & \\
\hline Recreational sale & $-1.129^{\star \star}$ & -0.013 & $-0.079^{\star}$ \\
& $(0.3478)$ & $(0.0159)$ & $(0.0334)$ \\
Ln(number of medical patients) & -0.416 & -0.012 & -0.003 \\
& $(0.3879)$ & $(0.0179)$ & $(0.0397)$ \\
\hline$R^{2}$ & 0.886 & 0.999 & 0.994 \\
Observations & 4,224 & 4,224 & 4,224 \\
\hline Panel B: amount of sales & & & $-0.077^{\star \star}$ \\
\hline \$0 sales $\leq \$ 500,000$ & $-1.245^{\star \star}$ & -0.006 & $(0.0344)$ \\
& $(0.3743)$ & $(0.0150)$ & -0.081 \\
Sales > \$500,000 & $-0.895^{\star \star}$ & -0.028 & $(0.0498)$ \\
& $(0.3789)$ & $(0.0225)$ & -0.003 \\
Ln(number of medical patients) & -0.419 & -0.011 & $(0.0396)$ \\
\hline$R^{2}$ & $(0.3888)$ & $(0.0175)$ & 0.994 \\
Observations & 0.886 & 0.999 & 4,224 \\
\hline
\end{tabular}

Notes: Panel A uses a $\{0,1\}$ any sales as the treatment variable, while Panel B compares counties with sales between $\$ 0$ and $\$ 500,000$ or sales $>\$ 500,000$ with counties with zero sales. Each column represents a separate regression. All regressions include month, year, and county fixed effects. Standard errors are clustered th the county level and reported in parentheses.

${ }^{+} p<0.1,{ }^{*} p<0.05,{ }^{\star \star} p<0.01$. 
Table A28 The effect of recreational dispensary entry and sales on employment regression analysis

\begin{tabular}{lccccc}
\hline & All & Cons & Manu & NR & Service \\
\cline { 2 - 6 } & $\mathbf{( 1 )}$ & $\mathbf{( 2 )}$ & $\mathbf{( 3 )}$ & $\mathbf{( 4 )}$ & $\mathbf{( 5 )}$ \\
\hline Panel A: start of sales & & & & & \\
\hline Recreational sale & $0.042^{\star}$ & 0.031 & $0.113^{\star}$ & -0.079 & $0.041^{\star}$ \\
& $(0.0173)$ & $(0.0831)$ & $(0.0520)$ & $(0.0803)$ & $(0.0188)$ \\
Ln(number of medical patients) & -0.026 & $-0.282^{\star}$ & -0.144 & 0.124 & -0.025 \\
& $(0.0161)$ & $(0.1329)$ & $(0.1006)$ & $(0.1086)$ & $(0.0223)$ \\
\hline$R^{2}$ & 0.998 & 0.979 & 0.992 & 0.953 & 0.997 \\
Observations & 4,224 & 2,784 & 2,496 & 3,168 & 4,224 \\
\hline Panel B: amount of sales & & & & & \\
\hline \$0< sales $\leq \$ 500,000$ & $0.042^{\star \star}$ & 0.056 & $0.141^{\star \star}$ & -0.055 & $0.044^{\star \star}$ \\
Sales $>$ \$500,000 & $(0.0163)$ & $(0.0734)$ & $(0.0462)$ & $(0.0787)$ & $(0.0201)$ \\
& $0.043^{+}$ & -0.005 & 0.053 & -0.126 & $0.037^{+}$ \\
Ln(number of medical patients) & $(0.0244)$ & $(0.1138)$ & $(0.0626)$ & $(0.1007)$ & $(0.0209)$ \\
& -0.026 & $-0.283^{\star *}$ & -0.146 & 0.124 & -0.025 \\
& $(0.0161)$ & $(0.1280)$ & $(0.0919)$ & $(0.1059)$ & $(0.0224)$ \\
\hline$R^{2}$ & 0.998 & 0.979 & 0.993 & 0.953 & 0.997 \\
Observations & 4,224 & 2,784 & 2,496 & 3,168 & 4,224 \\
\hline
\end{tabular}

Notes: Panel A uses a $\{0,1\}$ any sales as the treatment variable, while Panel B compares counties with sales between $\$ 0$ and $\$ 500,000$ or sales $>\$ 500,000$ with counties with zero sales. Each column represents a separate regression. The industry subsectors are Construction (Cons), Manufacturing (Manu), Natural Resources and Mining (NR), and Service. All regressions include month, year, and county fixed effects. Standard errors are clustered at the county level and reported in parentheses.

${ }^{+} p<0.1,{ }^{\star} p<0.05,{ }^{\star \star} p<0.01$. 
Table A29 The effect of recreational dispensary entry and sales on wages - regression analysis

\begin{tabular}{lccccc}
\hline & All & Cons & Manu & NR & Service \\
\cline { 2 - 6 } & $\mathbf{( 1 )}$ & $\mathbf{( 2 )}$ & $\mathbf{( 3 )}$ & $\mathbf{( 4 )}$ & $\mathbf{( 5 )}$ \\
\hline Panel A: start of sales & & & & & \\
\hline Recreational sale & -0.004 & 0.022 & 0.032 & 0.018 & -0.014 \\
& $(0.0121)$ & $(0.0352)$ & $(0.0231)$ & $(0.0348)$ & $(0.0154)$ \\
Ln(number of medical patients) & -0.001 & $-0.124^{+}$ & -0.052 & $0.077^{+}$ & 0.003 \\
& $(0.0133)$ & $(0.0708)$ & $(0.0494)$ & $(0.0393)$ & $(0.0275)$ \\
\hline$R^{2}$ & 0.919 & 0.724 & 0.906 & 0.902 & 0.904 \\
Observations & 1,408 & 928 & 832 & 1,056 & 1,408 \\
\hline Panel B: amount of sales & & & & & \\
\hline \$0< sales $\leq$ 500,000 & 0.001 & 0.034 & 0.039 & 0.031 & -0.011 \\
& $(0.0127)$ & $(0.0282)$ & $(0.0245)$ & $(0.0327)$ & $(0.0166)$ \\
Sales $>$ \$500,000 & -0.017 & 0.002 & 0.015 & -0.012 & -0.021 \\
& $(0.0129)$ & $(0.0569)$ & $(0.0292)$ & $(0.0436)$ & $(0.0154)$ \\
Ln(number of medical patients) & -0.001 & $-0.124^{+}$ & -0.052 & $0.078^{\star *}$ & 0.003 \\
& $(0.0129)$ & $(0.0706)$ & $(0.0491)$ & $(0.0375)$ & $(0.0274)$ \\
\hline$R^{2}$ & 0.920 & 0.724 & 0.906 & 0.902 & 0.904 \\
Observations & 1,408 & 928 & 832 & 1,056 & 1,408 \\
\hline
\end{tabular}

Notes: Panel A uses a $\{0,1\}$ any sales as the treatment variable, while Panel B compares counties with sales between $\$ 0$ and $\$ 500,000$ or sales $>\$ 500,000$ with counties with zero sales. Each column represents a separate regression The industry subsectors are Construction (Cons), Manufacturing (Manu), Natural Resources and Mining (NR), and Service. All regressions include quarter, year, and county fixed effects. Standard errors are clustered at the county level and reported in parentheses.

${ }^{+} p<0.1,{ }^{\star} p<0.05,{ }^{\star *} p<0.01$. 


\section{Robustness with Spillover Counties}

$60 \mathrm{~km}$

Table A30 The effect of recreational dispensary entry and sales on the unemployment rate (Unrate), Ln(labor force), and Ln(unemployed) - regression analysis

\begin{tabular}{lccc}
\hline & Unrate & Ln(labor force) & Ln(unemp) \\
\cline { 2 - 4 } & $\mathbf{( 1 )}$ & $\mathbf{( 2 )}$ & $\mathbf{( 3 )}$ \\
\hline Panel A: Amount of sales & & & \\
\hline Recreational sale & -0.428 & -0.005 & $-0.079^{\star \star}$ \\
& $(0.2914)$ & $(0.0158)$ & $(0.0252)$ \\
Recreational sale=1 $<<0 \mathrm{~km}$ not-sellingmy $=1$ & -0.403 & 0.009 & 0.017 \\
& $(0.2790)$ & $(0.0147)$ & $(0.0283)$ \\
Ln(number of medical patients) & $-0.602^{\star}$ & -0.006 & -0.026 \\
& $(0.2738)$ & $(0.0126)$ & $(0.0255)$ \\
\hline$R^{2}$ & 0.882 & 0.999 & 0.995 \\
Observations & 6,144 & 6,144 & 6,144 \\
\hline
\end{tabular}

Notes: Each column represents a separate regression. All regressions include month, year, and county fixed effects. Standard errors are clustered at the county level and reported in parentheses.

${ }^{+} p<0.1,{ }^{\star} p<0.05,{ }^{\star *} p<0.01$.

FE, fixed effect.

Table A31 The effect of recreational dispensary entry and sales on employment regression analysis

\begin{tabular}{lccccc}
\hline & All & Cons & Manu & NR & Service \\
\cline { 2 - 6 } & $\mathbf{( 1 )}$ & $\mathbf{( 2 )}$ & $\mathbf{( 3 )}$ & $\mathbf{( 4 )}$ & $\mathbf{( 5 )}$ \\
\hline Panel A: amount of sales & & & & & \\
\hline Recreational sale & $0.056^{\star *}$ & 0.054 & $0.091^{+}$ & 0.013 & $0.040^{\star}$ \\
& $(0.0204)$ & $(0.0719)$ & $(0.0486)$ & $(0.0897)$ & $(0.0184)$ \\
Recreational sale=1 $\times<0 \mathrm{~km}$ & -0.019 & 0.007 & 0.064 & -0.047 & -0.002 \\
not-sellingmy=1 & & & & & \\
& $(0.0204)$ & $(0.0635)$ & $(0.0543)$ & $(0.0915)$ & $(0.0189)$ \\
Ln(number of medical patients) & -0.021 & $-0.175^{+}$ & $-0.191^{\star \star}$ & 0.174 & -0.026 \\
& $(0.0148)$ & $(0.0910)$ & $(0.0581)$ & $(0.1161)$ & $(0.0183)$ \\
\hline$R^{2}$ & 0.998 & 0.989 & 0.996 & 0.970 & 0.998 \\
Observations & 6,144 & 4,608 & 3,936 & 4,608 & 6,144 \\
\hline
\end{tabular}

Notes: Each column represents a separate regression. All regressions include month, year, and county fixed effects. Standard errors are clustered at the county level and reported in parentheses. The industry subsectors are Construction (Cons), Manufacturing (Manu), Natural Resources and Mining (NR), and Service.

${ }^{+} p<0.1,{ }^{*} p<0.05,{ }^{* *} p<0.01$.

FE, fixed effect. 
Table A32 The effect of recreational dispensary entry and sales on wages - regression analysis

\begin{tabular}{lccccc}
\hline & All & Cons & Manu & NR & Service \\
\cline { 2 - 6 } & $\mathbf{( 1 )}$ & $\mathbf{( 2 )}$ & $\mathbf{( 3 )}$ & $\mathbf{( 4 )}$ & $\mathbf{( 5 )}$ \\
\hline Panel A: amount of sales & & & & & \\
\hline Recreational sale & 0.010 & 0.037 & 0.000 & 0.049 & 0.009 \\
& $(0.0129)$ & $(0.0285)$ & $(0.0208)$ & $(0.0351)$ & $(0.0125)$ \\
Recreational sale=1 $\times<0 \mathrm{~km}$ & -0.015 & $-0.049^{+}$ & 0.017 & $-0.041^{+}$ & -0.008 \\
not-sellingmy=1 & & & & & \\
& $(0.0115)$ & $(0.0245)$ & $(0.0344)$ & $(0.0231)$ & $(0.0114)$ \\
Ln(number of medical patients) & 0.004 & $-0.082^{+}$ & -0.036 & $0.065^{+}$ & 0.002 \\
& $(0.0117)$ & $(0.0471)$ & $(0.0287)$ & $(0.0345)$ & $(0.0177)$ \\
\hline$R^{2}$ & 0.937 & 0.779 & 0.932 & 0.909 & 0.925 \\
Observations & 2,048 & 1,536 & 1,312 & 1,536 & 2,048 \\
\hline
\end{tabular}

Notes: Each column represents a separate regression. All regressions include quarter, year, and county fixed effects. Standard errors are clustered at the county level and reported in parentheses. The industry subsectors are Construction (Cons), Manufacturing (Manu), Natural Resources and Mining (NR), and Service.

${ }^{+} p<0.1,{ }^{\star} p<0.05,{ }^{\star \star} p<0.01$.

FE, fixed effect.

\section{0 km}

Table A33 The effect of recreational dispensary entry and sales on the unemployment rate (Unrate), Ln(labor force), and Ln(unemployed) - regression analysis

\begin{tabular}{lccc}
\hline & Unrate & Ln(labor force) & Ln(unemp) \\
\cline { 2 - 4 } & $\mathbf{( 1 )}$ & $\mathbf{( 2 )}$ & $\mathbf{( 3 )}$ \\
\hline Panel A: amount of sales & & & \\
\hline Recreational sale & -0.365 & -0.004 & $-0.089^{\star \star}$ \\
Recreational sale=1 $<$ 70km not-sellingmy $=1$ & $(0.3154)$ & $(0.0195)$ & $(0.0299)$ \\
& -0.430 & 0.006 & 0.028 \\
Ln(number of medical patients) & $(0.2864)$ & $(0.0183)$ & $(0.0311)$ \\
& $-0.580^{\star}$ & -0.006 & -0.028 \\
$R^{2}$ & $(0.2774)$ & $(0.0132)$ & $(0.0258)$ \\
\hline Observations & 0.882 & 0.999 & 0.995 \\
\hline
\end{tabular}

Notes: Each column represents a separate regression. All regressions include month, year, and county fixed effects. Standard errors are clustered at the county level and reported in parentheses.

${ }^{+} p<0.1,{ }^{\star} p<0.05,{ }^{\star \star} p<0.01$.

FE, fixed effect. 
Table A34 The effect of recreational dispensary entry and sales on employment regression analysis

\begin{tabular}{lccccc}
\hline & All & Cons & Manu & NR & Service \\
\cline { 2 - 6 } & $\mathbf{( 1 )}$ & $\mathbf{( 2 )}$ & $\mathbf{( 3 )}$ & $\mathbf{( 4 )}$ & $\mathbf{( 5 )}$ \\
\hline Panel A: amount of sales & & & & & \\
\hline Recreational sale & $0.054^{\star}$ & 0.065 & 0.094 & -0.007 & $0.035^{+}$ \\
& $(0.0223)$ & $(0.0754)$ & $(0.0700)$ & $(0.1125)$ & $(0.0205)$ \\
Recreational sale=1 $<70 \mathrm{~km}$ & -0.014 & -0.010 & 0.048 & -0.011 & 0.005 \\
not-sellingmy=1 & & & & & \\
& $(0.0221)$ & $(0.0682)$ & $(0.0726)$ & $(0.1112)$ & $(0.0198)$ \\
Ln(number of medical patients) & -0.021 & $-0.173^{+}$ & $-0.195^{\star \star}$ & 0.173 & -0.027 \\
& $(0.0153)$ & $(0.0946)$ & $(0.0648)$ & $(0.1135)$ & $(0.0184)$ \\
\hline$R^{2}$ & 0.998 & 0.989 & 0.996 & 0.970 & 0.998 \\
Observations & 6,144 & 4,608 & 3,936 & 4,608 & 6,144 \\
\hline
\end{tabular}

Notes: Each column represents a separate regression. All regressions include month, year, and county fixed effects. Standard errors are clustered at the county level and reported in parentheses. The industry subsectors are Construction (Cons), Manufacturing (Manu), Natural Resources and Mining (NR), and Service.

${ }^{+} p<0.1,{ }^{\star} p<0.05,{ }^{\star \star} p<0.01$.

FE, fixed effect.

Table A35 The effect of recreational dispensary entry and sales on wages - regression analysis

\begin{tabular}{lccccc}
\hline & All & Cons & Manu & NR & Service \\
\cline { 2 - 6 } & $\mathbf{( 1 )}$ & $\mathbf{( 2 )}$ & $\mathbf{( 3 )}$ & $\mathbf{( 4 )}$ & $\mathbf{( 5 )}$ \\
\hline Panel A: amount of sales & & & & & \\
\hline Recreational sale & 0.003 & 0.036 & 0.007 & 0.043 & 0.006 \\
& $(0.0148)$ & $(0.0288)$ & $(0.0214)$ & $(0.0368)$ & $(0.0135)$ \\
Recreational sale=1 $<$ < $70 \mathrm{~km}$ & -0.004 & -0.039 & 0.004 & -0.024 & -0.003 \\
not-sellingmy=1 & & & & & \\
& $(0.0135)$ & $(0.0250)$ & $(0.0341)$ & $(0.0258)$ & $(0.0112)$ \\
Ln(number of medical patients) & 0.004 & -0.077 & -0.036 & $0.067^{+}$ & 0.002 \\
& $(0.0113)$ & $(0.0476)$ & $(0.0306)$ & $(0.0345)$ & $(0.0178)$ \\
\hline$R^{2}$ & 0.937 & 0.778 & 0.932 & 0.909 & 0.925 \\
Observations & 2,048 & 1,536 & 1,312 & 1,536 & 2,048 \\
\hline
\end{tabular}

Notes: Each column represents a separate regression. All regressions include quarter, year, and county fixed effects. Standard errors are clustered at the county level and reported in parentheses. The industry subsectors are Construction (Cons), Manufacturing (Manu), Natural Resources and Mining (NR), and Service.

${ }^{+} p<0.1,{ }^{*} p<0.05,{ }^{\star *} p<0.01$.

$\mathrm{FE}$, fixed effect. 


\section{The Multiple-Inference Problem}

Table A36 Multiple inference - adjusted $p$-value

\begin{tabular}{lll}
\hline Dependent variable & p-value & Sharpened q-values \\
\hline Panel A: monthly & & \\
\hline Unemployment rate & $0.009^{\star \star}$ & $0.024^{\star}$ \\
Ln(labor force) & 0.915 & 1 \\
Ln(unemployed) & $0.001^{\star \star}$ & $0.007^{\star \star}$ \\
Ln(all industry employees) & $0.005^{\star \star}$ & $0.019^{\star}$ \\
Ln(construction employees) & 0.292 & 0.638 \\
Ln(manufacturing sector employees) & $0.001^{\star \star}$ & $0.007^{\star \star}$ \\
Ln(natural resource and mining employees) & 0.823 & 1 \\
Ln(service-providing employees) & $0.015^{\star}$ & $0.031^{\star}$ \\
\hline Panel B: quarterly & & 1 \\
\hline Ln(All industry wages) & 0.952 & 1 \\
Ln(Construction wages) & 0.761 & 1 \\
Ln(Manufacturing wages) & 0.594 & 0.941 \\
Ln(Natural resource and mining wages) & 0.424 & 1 \\
Ln(Service-providing wages) & 0.74 & \\
\hline
\end{tabular}

Panel A: $p$-values are from Tables 3-4.

Panel B: $p$-values are from Table 5.

${ }^{+} p<0.1,{ }^{\star} p<0.05,{ }^{\star \star} p<0.01$.

\section{Generalized Synthetic Control Model}

Table A37 The effect of recreational dispensary entry - ATT from GSCM

\begin{tabular}{lccc}
\hline & Unrate & Ln(labor force) & Ln(unemp) \\
\cline { 2 - 4 } & $\mathbf{( 1 )}$ & $(\mathbf{2})$ & $(\mathbf{3})$ \\
\hline Start of sales & & & \\
\hline Recreational sale & $-0.566^{\star}$ & 0.024 & -0.006 \\
& $(0.4191)$ & $(0.0334)$ & $(0.0332)$ \\
Ln(number of medical patients) & 0.018 & $-0.010^{\star}$ & 0.043 \\
& $(0.2547)$ & $(0.0084)$ & $(0.0713)$ \\
\hline Observations & 6,144 & 6,144 & 6,144 \\
\hline
\end{tabular}

Notes: Each column represents a separate regression with the synthetic control method. The standard errors are bootstrapped, and in the mean squared prediction error (MSPE), there is an optimal number of unobserved factors $\left(r^{\star}\right)$ selected from the model.

${ }^{+} p<0.1,{ }^{\star} p<0.05,{ }^{\star \star} p<0.01$.

ATT, average treatment effect on the treated; GSCM, generalized synthetic control method; Unrate, unemployment rate. 
Table A38 The effect of recreational dispensary entry on employment - ATT from GSCM

\begin{tabular}{|c|c|c|c|c|c|}
\hline & $\operatorname{Ln}(A l l)$ & Ln(Cons) & Ln(Manu) & $\operatorname{Ln}(\mathrm{NR})$ & Ln(Service) \\
\hline & (1) & (2) & (3) & (4) & (5) \\
\hline \multicolumn{6}{|l|}{ Start of sales } \\
\hline Recreational sale & $\begin{array}{l}-0.035 \\
(0.0203)\end{array}$ & $\begin{array}{l}-0.120 \\
(0.0804)\end{array}$ & $\begin{array}{c}0.137^{\star \star} \\
(0.0562)\end{array}$ & $\begin{array}{l}-0.298 \\
(0.1314)\end{array}$ & $\begin{array}{c}0.042 \\
(0.0587)\end{array}$ \\
\hline Ln(number of medical patients) & $\begin{array}{c}0.001 \\
(0.0148)\end{array}$ & $\begin{array}{l}-0.502 \\
(0.2495)\end{array}$ & $\begin{array}{c}0.097 \\
(0.1150)\end{array}$ & $\begin{array}{l}-0.010 \\
(0.0894)\end{array}$ & $\begin{array}{c}0.007 \\
(0.0229)\end{array}$ \\
\hline Observations & 6,144 & 4,608 & 3,936 & 4,608 & 6,144 \\
\hline
\end{tabular}

Notes: Each column represents a separate regression with the synthetic control method. The industry subsectors are Construction (Cons), Manufacturing (Manu), Natural Resource and Mining (NR), and Service. The standard errors are bootstrapped, and in the mean squared prediction error (MSPE), there is an optimal number of unobserved factors $\left(r^{\star}\right)$ selected from the model.

${ }^{+} p<0.1,{ }^{\star} p<0.05,{ }^{\star \star} p<0.01$.

ATT, average treatment effect on the treated; GSCM, generalized synthetic control method.

Table A39 The effect of recreational dispensary entry on wage - ATT from GSCM

\begin{tabular}{|c|c|c|c|c|c|}
\hline & $\operatorname{Ln}(A l l)$ & Ln(Cons) & Ln(Manu) & $\operatorname{Ln}(N R)$ & Ln(Service) \\
\hline & (1) & (2) & (3) & (4) & (5) \\
\hline \multicolumn{6}{|l|}{ Start of sales } \\
\hline \multirow[t]{2}{*}{ Recreational sale } & -0.003 & 0.007 & 0.011 & 0.036 & -0.004 \\
\hline & $(0.0178)$ & $(0.0531)$ & $(0.0321)$ & $(0.0424)$ & $(0.0152)$ \\
\hline \multirow[t]{2}{*}{ Ln(number of medical patients) } & -0.017 & 0.006 & -0.027 & $0.114^{\star \star}$ & -0.010 \\
\hline & $(0.0161)$ & $(0.1258)$ & $(0.0474)$ & $(0.0698)$ & $(0.0438)$ \\
\hline Observations & 6144 & 4608 & 3936 & 4608 & 6144 \\
\hline
\end{tabular}

Notes: Each column represents a separate regression with the synthetic control method. The industry subsectors are Construction (Cons), Manufacturing (Manu), Natural Resource and Mining (NR), and Service. The standard errors are bootstrapped, and in the mean squared prediction error (MSPE), there is an optimal number of unobserved factors $\left(r^{\star}\right)$ selected from the model.

${ }^{+} p<0.1,{ }^{\star} p<0.05,{ }^{\star \star} p<0.01$.

ATT, average treatment effect on the treated; GSCM, generalized synthetic control method. 


\section{Robustness with Spillover Counties}

Table A40 Event study estimates post-dispensary entry periods

\begin{tabular}{|c|c|c|c|}
\hline & Unrate & Ln(labor force) & Ln(unemp) \\
\hline & (1) & (2) & (3) \\
\hline event0:treat & $0.382^{*}$ & $0.041^{*}$ & $0.113^{\star \star}$ \\
\hline event1:treat & $0.320^{+}$ & $0.043^{*}$ & $0.093^{\star \star}$ \\
\hline event2:treat & 0.440 & $0.041^{*}$ & $0.112^{\star}$ \\
\hline event3:treat & 0.179 & $0.031^{+}$ & $0.064^{+}$ \\
\hline event4:treat & 0.192 & -0.007 & 0.025 \\
\hline event5:treat & -0.224 & -0.003 & $-0.062^{\star \star}$ \\
\hline event6:treat & $-0.283^{+}$ & 0.001 & $-0.060^{\star \star}$ \\
\hline event7:treat & -0.300 & 0.009 & $-0.066^{\star}$ \\
\hline event8:treat & -0.373 & 0.013 & $-0.087^{\star \star}$ \\
\hline event9:treat & $-0.486^{\star}$ & 0.015 & $-0.103^{\star \star}$ \\
\hline event10:treat & -0.393 & 0.016 & $-0.085^{\star}$ \\
\hline event11:treat & $-0.564^{\star}$ & $0.036^{\star}$ & $-0.105^{\star \star}$ \\
\hline event12:treat & -0.026 & $0.040^{+}$ & 0.042 \\
\hline event13:treat & -0.119 & $0.038^{+}$ & 0.012 \\
\hline event14:treat & 0.133 & 0.030 & 0.039 \\
\hline event15:treat & 0.058 & 0.023 & 0.014 \\
\hline event16:treat & 0.227 & -0.014 & 0.010 \\
\hline event17:treat & -0.092 & -0.014 & $-0.081^{\star}$ \\
\hline event18:treat & -0.126 & -0.011 & $-0.099^{\star \star}$ \\
\hline event19:treat & -0.246 & -0.004 & $-0.137^{\star \star}$ \\
\hline event20:treat & -0.163 & -0.004 & $-0.117^{\star \star}$ \\
\hline event21:treat & -0.302 & -0.003 & $-0.132^{\star \star}$ \\
\hline event22:treat & -0.266 & -0.002 & $-0.119^{\star \star}$ \\
\hline event23:treat & -0.411 & 0.024 & $-0.140^{\star \star}$ \\
\hline event24:treat & -0.263 & 0.021 & -0.030 \\
\hline event25:treat & -0.249 & 0.023 & -0.028 \\
\hline event26:treat & 0.098 & 0.019 & 0.036 \\
\hline event27:treat & 0.143 & 0.008 & 0.029 \\
\hline event28:treat & 0.195 & -0.026 & -0.000 \\
\hline event29:treat & 0.051 & -0.017 & -0.035 \\
\hline event30:treat & 0.040 & -0.010 & -0.046 \\
\hline event31:treat & -0.024 & -0.002 & $-0.069^{+}$ \\
\hline event32:treat & 0.050 & -0.003 & -0.058 \\
\hline event33:treat & -0.191 & -0.003 & $-0.109^{\star \star}$ \\
\hline event34:treat & -0.341 & -0.003 & $-0.157^{\star \star}$ \\
\hline event35:treat & $-0.524^{+}$ & 0.021 & $-0.200^{\star \star}$ \\
\hline event36:treat & -0.412 & 0.015 & -0.048 \\
\hline event37:treat & $-0.499^{+}$ & 0.019 & $-0.079^{\star \star}$ \\
\hline event38:treat & -0.309 & 0.015 & -0.091 \\
\hline event39:treat & -0.266 & 0.011 & $-0.096^{\star}$ \\
\hline event40:treat & -0.023 & -0.024 & -0.052 \\
\hline event>40:treat & 0.037 & -0.002 & -0.020 \\
\hline
\end{tabular}


Table A40 Continued

\begin{tabular}{lccc}
\hline & Unrate & Ln(labor force) & Ln(unemp) \\
\cline { 2 - 4 } & $\mathbf{( 1 )}$ & $\mathbf{( 2 )}$ & $\mathbf{( 3 )}$ \\
\hline Linear combination & & & \\
$\quad$ Combo coefficient & -0.117 & 0.010 & $-0.046^{*}$ \\
$\quad$ Combo SE & 0.2257 & 0.0139 & 0.0212 \\
Weighted linear combination & & & \\
$\quad$ Combo coefficient & -0.073 & 0.006 & $-0.038^{+}$ \\
$\quad$ Combo SE & 0.2433 & 0.0148 & 0.0218 \\
\hline$R^{2}$ & 0.880 & 0.999 & 0.996 \\
Observations & 4,512 & 4,512 & 4,512 \\
\hline
\end{tabular}

Notes: Table reports the $\tau_{k}$ coefficients for $k \geq 0$ from the event study regressions. Each column represents a separate regression. Below the table, we report the average and weighted average of the $\tau_{k}$ coefficients from the event study, including only the $\tau_{k}$ coefficients for periods post-dispensary entry. All regressions include month, year, and county fixed effects. Standard errors are clustered at the county level and reported in parentheses.

${ }^{+} p<0.1,{ }^{\star} p<0.05,{ }^{\star \star} p<0.01$.

FE, fixed effect; SE, standard error; Unrate, unemployment rate. 